\title{
استخدام البروفيل النمائي للبورتيج في التشخيص الفارق لبعض الاضطرابات النمائية
}

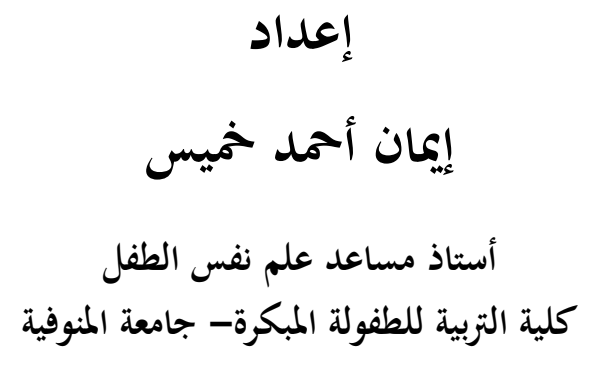

\section{الإستشهاد المرجعى:}

خميس، إيمان أحمد.(• • •).استخدام البروفيل النمائي للبورتيج في التشخيص الفارق لبعض الاضطرابات النمائية. مجلة بكوث ودراسات الطفولة.كلية التربية للطفولة المبكرة، جامعة بني سويف،

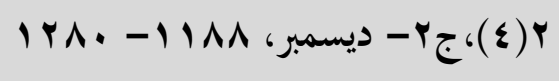


كلية التربية للطفولة المبكرة- جامعة بني سويف

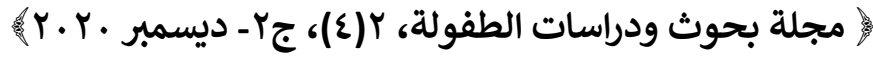




\section{كلية التربية للطفولة المبكرة- جامعة بني سويف}

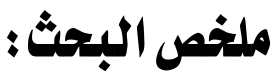

هدفت الدراسة إلى التحقق من فاعلية استخدام البروفيل النمائى للبورتيج فى التثخيص الفارق لبعض الاضطرابات النمائية لعينة مكونة من (·r) طفل وطفلة من الأطفال المصابين بطيف التوحد(منخفضى ومرتفعى الأداء الوظيفى) حيث تم تقسيمهم على مجموعتين بناءاً على شدة الاضطراب من خلال تطبيق مقياس جيليام لتقدير الذاتوية ترجمة وتعريب:عادل

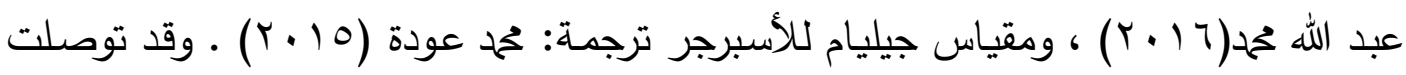
الدراسة إلى فاعلية البروفيل النمائى فى التثخيص الفارق بين منخفضى ومرتفعى الأداء

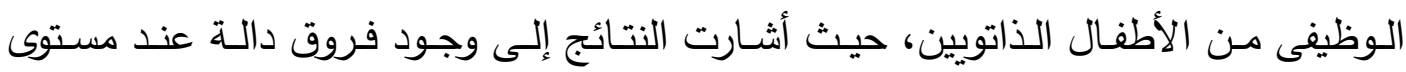
(1 (.) بـين الأطفـال الـذاتويين منخفضسى ومرتفعى الأداء الـوظيفى فـى أبعـاد المجـال

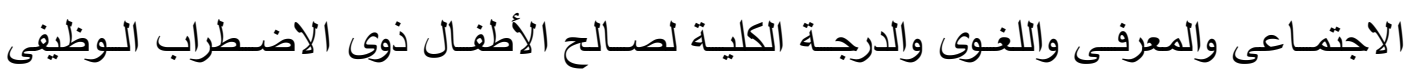

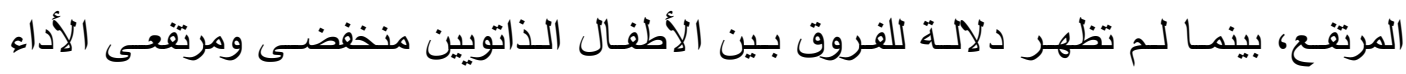
الوظيفى فى أبعاد المجال الحركى والرعاية الذاتية ـ كما أشارت النتائج إلى قدرة البروفيل

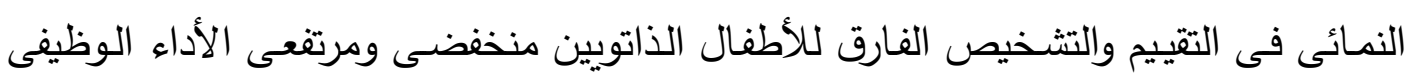
بالإضـافة إلى إمكانيـة تحديد مكامن القوة التعليميـة الخاصـة والمهارات القابلـة للتعلم عند الأطفال. كما ظهر من خلال الصفحة النفسية لكل من الأطفال منخفضى ومرتفعى الأداء الوظيفى أن هنالك قصوراً فى مهارات التواصل والقراءة والكتابة ومهارات التفاعل الاجتماعى والمهارات الحركية لدى الأطفال منخفضي الأداء الوظيفي مقارنة بالأطفال مرتفعى الأداء الوظيفى، كما أشارت الصفحة النفسية إلى تفوق الأطفال منخفضى الأداء الوظيفى فى معدل السلوكيات التكرارية والنمطية وأعتبر ذلك أنه أحد السمات الأساسية والمميزة لهم. الكلمات اللفتتاحية : البروفيل النمائى للبورتيج، الاضطرابات النمائية 


\section{Abstract:}

The study aimed to verify the effectiveness of the use of the developmental profile of Portage in the differential diagnosis of some developmental disorders for a sample of (20) children from the children with autism spectrum (low and high functional performance) as they were divided into two groups based on the severity of the disorder by applying the Gilliam scale to estimate Subjectivity translation and localization: Adel Abdullah Muhammad (2016), and Gilliam Asperger's Scale. Translation: Muhammad Auda (2015).

The study reached the effectiveness of the developmental profile in the diagnosis of the difference between low and high functional performance among autistic children, where the results indicated that there are significant differences at the level $(0.01)$ between low and high autistic children in the dimensions of the social, cognitive, linguistic and overall degree in favor of children with disorder The high functional performance, while there was no significance of the differences between the children with low and high levels of functional performance in the dimensions of the motor field and the self-care. The results also indicated the ability of the developmental profile in the evaluation and differential diagnosis of self-directed children with low and high functional performance, in addition to the ability to determine the special educational strengths and learnable skills in children. It also appeared through the psychological page for both children with low and high functional performance that there are deficiencies in communication, reading and writing skills, social interaction skills and motor skills of children with low functional performance compared to children with high functional performance. The psychological page also indicated the superiority of children with low functional performance in the rate of stereotypical behaviors and I consider this to be one of the basic characteristics of them.

\section{Keywords: Developmental Profile of Portage, Developmental}

Disorders

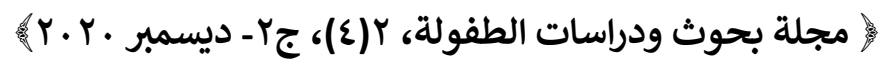




\section{كلية التربية للطفولة المبكرة- جامعة بني سويف}

\section{المقدمة}

تعتبر الاضطرابات النمائية من أكثر الاضطرابات تأثيرًا على القدرات الأدائية والوظيفية لكل المجالات النمائية المختلفة، وعليه فقد ظهرت بعض المقاييس والأدوات والقوائم التي تساهم في تشخيص وتقييم هذه الاضطرابات في محاولة لإرساء اللبنة الأولية لعملية تقديم الخدمات التدريبية والتعليمية والتأهيلية للأطفال من ذوي الاضطرابات النمائية. وتعتبر الذاتوية(Autism) من أكثر أنواع الاضطرابات النمائية شيوعًا وانتشارا باعتبارهم من منخفضي الأداء الوظيفي، والتي حازت على اهتمام العديد من الباحثين؛ حيث قاموا بعمل الأبحاث والدراسات التي تهذف إلى التعرف على التشخيص الدقيق لهؤلاء الأطفال بعيدًا عن الاضطرابات الأخرى، كما استهدفوا وضع البرامج التي من شأنها تنميتهم في شتى المجالات.

أما حالات الذاتوية من مرتفعي الأداء الوظيفي فهي ثاني الاضطرابات النمائية شيوعًا وانتشارًا ولكنها لم تحظى باهتمام الباحثين بالثكل الكافي وذلك لأنها تتسم بوجود صفات وسلوكيات قريبة من أعراض الأسبرجر ، ونظرًا إلى وجود تثابه بين أعراضها مع الكثير من أعراض الذاتوية فغالبًا ما يحدث خلط بينهما. وبالرغم من تحديد محكات دقيقة لتشخيص الذاتوية وتحديد السمات أو العلامات المميزة للنمو المبكر لهؤلاء الأطفال؛ فإن صعوبة الوصول إلى تشخيص دقيق لحالات الذاتوية والإسبرجر ما زال موجود بالفعل نظرًا للتثابه الموجود بين الحالتين. ولقد قام عديد من الباحثين بإجراء الدراسات والبحوث في محاولة للتشخيص الفارق بين حالات الأطفال الذاتوية وحالات الذاتوية مرتفعي الأداء الوظيفي بطرق شتى كاعتمادهم على الملاحظة المقننة من قبل أخصائي مدرب أو من خلال المقابلة المقننة مع ولي الأمر، إلا أن هذه الطرق تعتبر غير موضوعية في التشخيص، وذلك لأنها تعتمد أساسًا على التقدير 


\section{كلية التربية للطفولة المبكرة- جامعة بني سويف}

الذاتي للآباء والمعلمات وعلى تفسير أيهما لما يلاحظه من سلوكيات وعلى مدى دقة ذاكرته في استدعاء ما مر به الطفل من أحداث أو تفسير لسلوكياته، مما يفقدها موضوعيتها، دون وجود أداة تشخيصية وتقييمية تعتمد على أداء الطفل؛ مما يؤدى إلي صعوبة في تحديد مستوى أداء الطفل بدقة هذا بالإضافة إلى المحدودية الثديدة في المقاييس العربية المخصصة لذلك.

ويحتل برنامج البورتيج مكانة هامة في تقييم وتثخيص الاضطرابات النمائية خلا مراحل النمو المبكرة من الميلاد وحتى 7 سنوات، ويستخدم على نطاق واسع في جميع مراكز رعاية ذوي الاحتياجات الخاصة في معظم دول العالم لتقييم وتقدير الاضطرابات النمائية لاى الأطفال من ذوي الاحتياجات الخاصة، نظرا لما يتميز به من سهولة وبساطة في الاستخدام ولقدرته على تقييم مجالات النمو المختلفة والتي من بينها: مجال الرعاية الذاتية

$$
\text { المجال الإدراكي المجال الاجتماعي المجال المركي }
$$

ومن هنا جاءت هذه الدراسة في محاولة استخدام برنامج البورتيج للتشخيص الفارق لبعض الاضطرابات النمائية للأطفال من حالات الذاتوية منخفي الأداء الوظيفي ومرتفعي

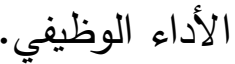




\section{مشكلة الدراسة}

في إطار السعي نحو تقديم خدمات أفضل للأطفال المعاقين من خلال الاهتمام

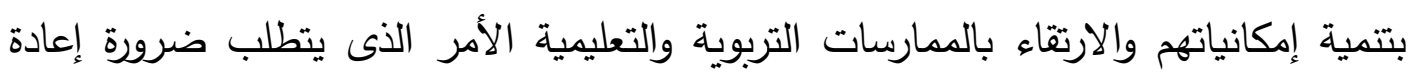

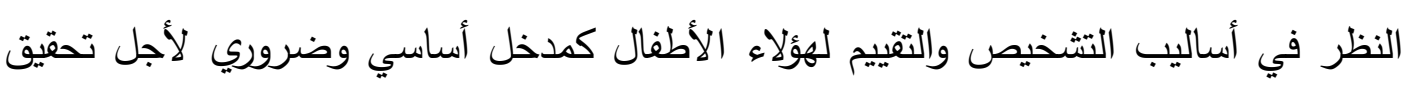
الإصلاح التربوي والتعليمي، فضلا عن القضية الملحة والمعاصرة في مجال التشخيص والتقييم والتي تهدف إلى استخدام أدوات تمكن القائمين على رعاية الأطفال الذاتويين مرتفعي

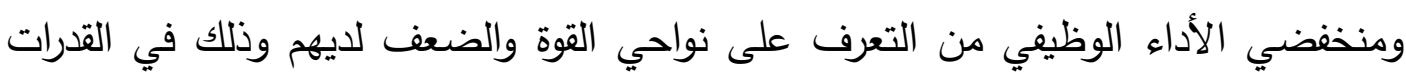
الآدائية والوظيفية، الأمر الذى يدعو إلى التحقق من فعالية أساليب التقييم المستخدمة لتتييم

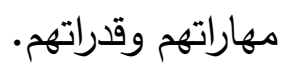
ولقد تعددت الدراسات التي هدفت إلي تثخيص وتتييم اضطراب الذاتوية كما أكدت العديد منها على أهمية استخدام البروفيل النفس تربوي في تثخيص وتقييم الأطفال الذاتويين ومنها: دراسة (Shek,Tsang,Lam,Tang\&Cheung, 2005) والتي هدفت إلى التعرف على الخصائص السيكو مترية للبروفيل النفس تربوي (PEP3)، وتكونت عينة الدراسة من

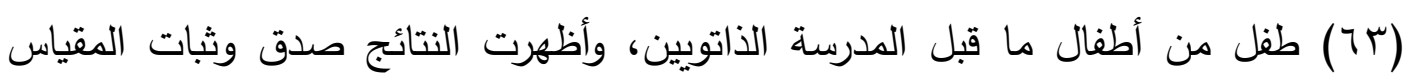

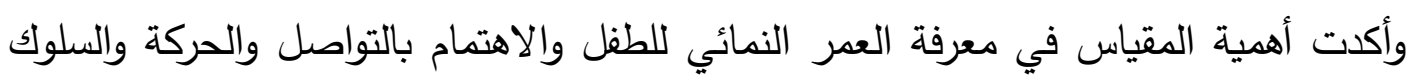
التكيفي والمشكلات السلوكية التي يعانى منها الأطفال مما يجعله أداه مناسبة للتشخيص والتقيين.

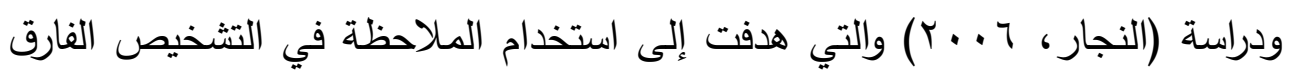

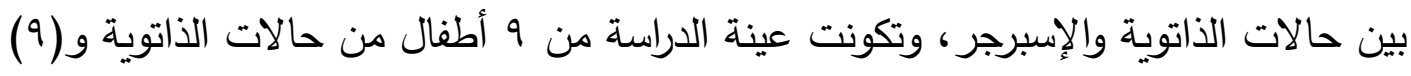

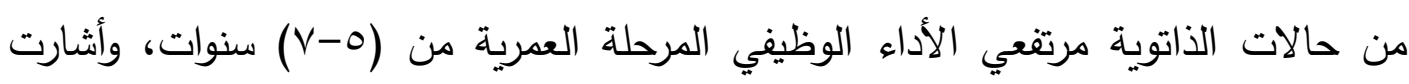

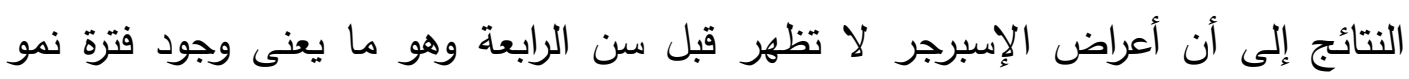


طبيعي تتعكس على كافة مجالات النمو الحسى والحركي واللغوي والاجتماعي والانفعالي

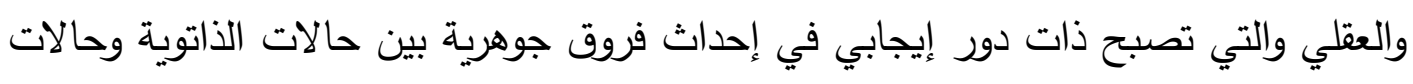

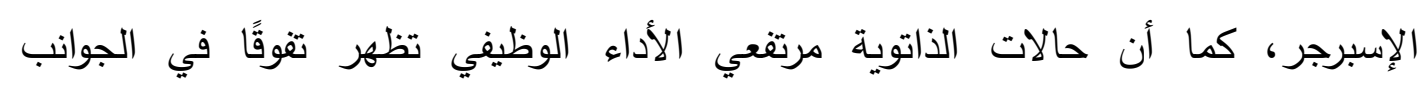

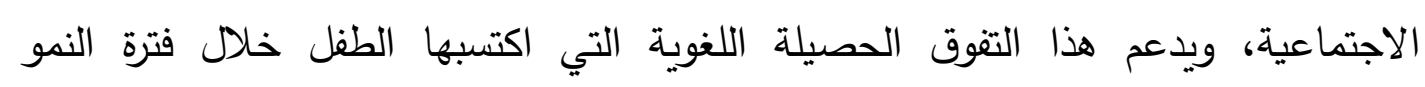
الطبيعي. كما هدفت دراسة (الزريقات والإمام، 1) ب. (1) إلى التعرّف على مستوى الأداء النفسي والتربوي لاى عينة من أطفال التوحد بالأردن. ولتحقيق هدف الدراسة فقد تم تصميم اختبار

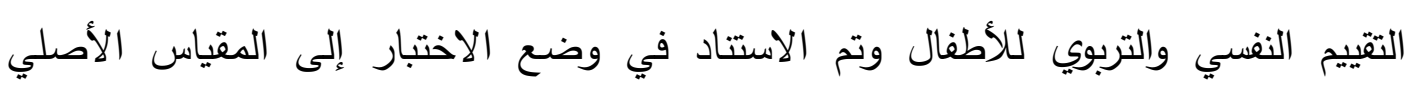

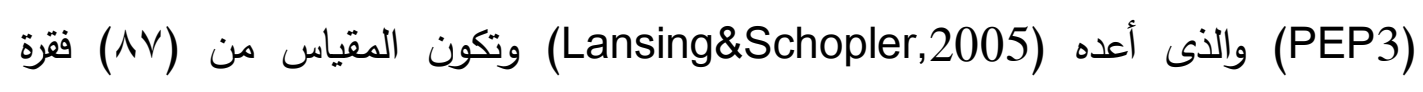
موزعة على سبعة أبعاد رئيسة هي: المعرفي، الاجتماعي الانفعالي، اللغة الاستقبالية، اللغة

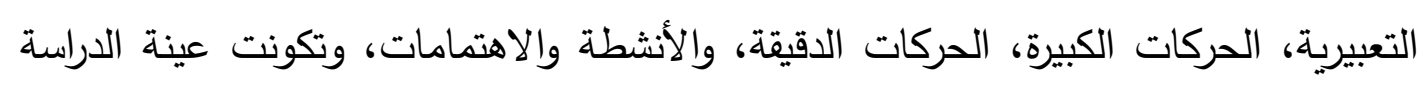

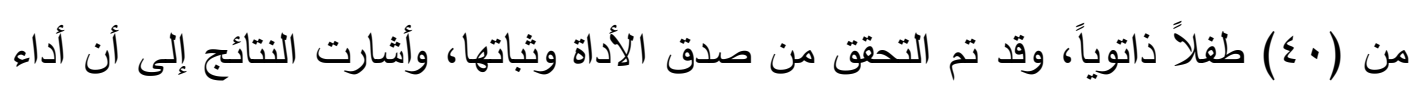

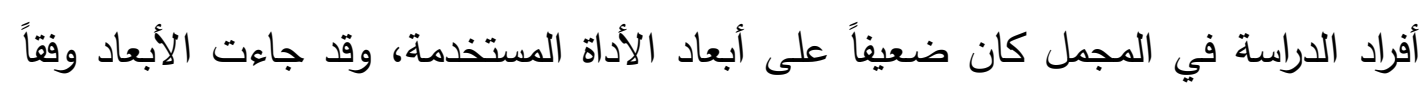

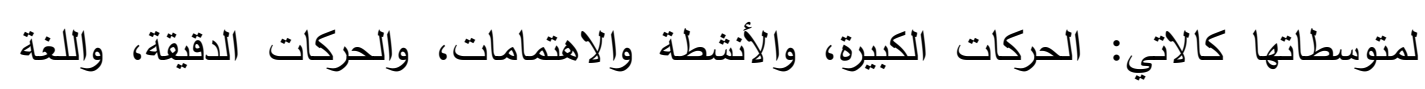

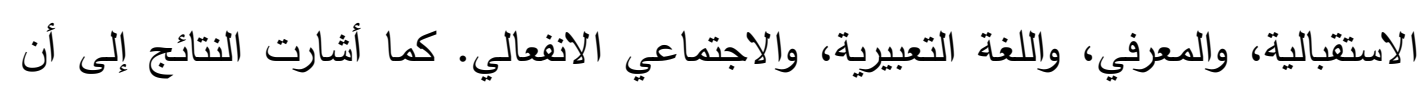

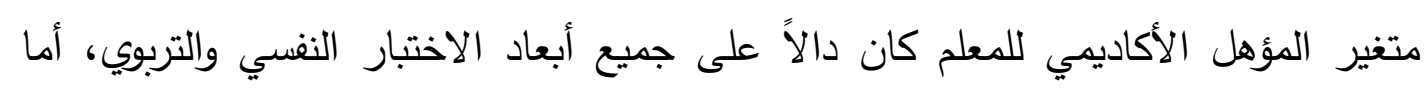

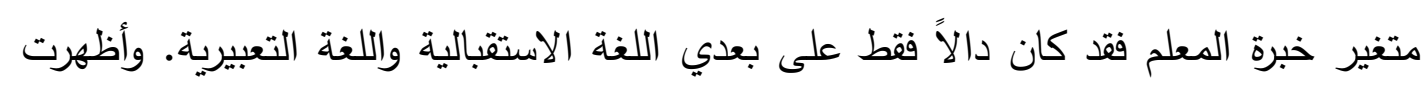

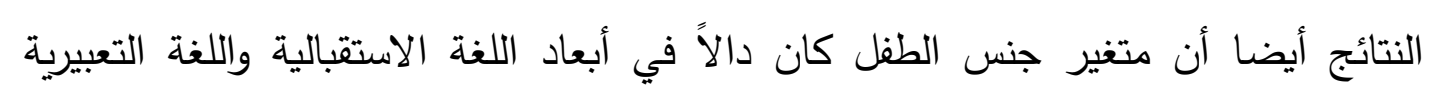
والحركات الدقيقة وذلك لصالح الإناث.

وفى ضوء هذا وما توصلت له العديد من الدراسات والتي أوصت بضرورة تبنى الآنى

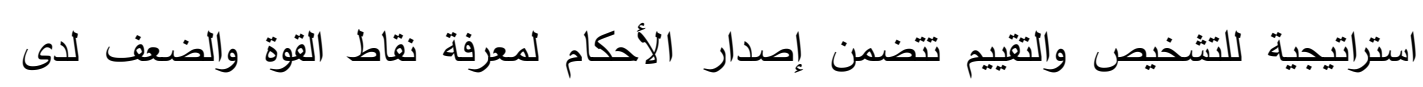

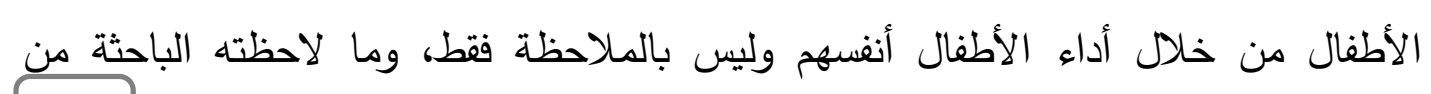
1195

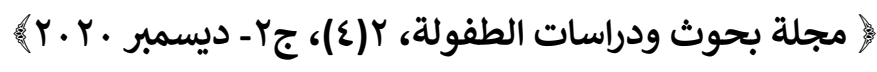




\section{كلية التربية للطفولة المبكرة- جامعة بني سويف}

محاولة الكثير من الباحثين للتشخيص الفارق بين حالات الذاتوية مرتفعي ومنخفضي الأداء الوظيفي باستخدام أدوات واختبارات مختلفة تعتمد على الملاحظة سواء من المعلمة أو الأم أكثر من اعتمادها على الأداء الفعلي للأطفال أنفهح ولا تعمل على تحديد نقاط القوة والضعف لديهم لوضع البرامج الأفضل لهم، كذلك قصور في الدراسات والأبحاث التي تسعى إلى تجديد أدوات التشخيص والتقييم، لذلك تسعى هذه الدراسة إلى التعرف على أهمية استخدام البروفيل النمائي للبورتيج كأداة تشخيصيه وتقييمية تعتمد على أداءات الأطفال الذاتويين أكثر من اعتمادها على الملاحظة وذلك من خلال الإجابة على التساؤلات التالية: () هل تختلف التقييمات النمائية للأطفال ذوي الاضطرابات النمائية (الذاتوية منخفضي الأداء الوظيفي ومرتفعي الأداء الوظيفي) عند استخدام البروفيل النمائي للبورتيج؟ r) هل يختلف شكل البروفيل النفسي للأطفال ذوي الاضطرابات النمائية (الذاتوية منخفضي الأداء الوظيفي ومرتفعي الأداء الوظيفي) عند استخدام مقياس البروفيل النمائي للبورتيج ؟

\section{أهداف اللدراسة}

تهدف الدراسة الحالية إلى:

( ) التحقق من فاعلية استخدام البروفيل النمائي للبورتيج في تشخيص وتقييم حالات الأطفال من ذوي الاضطرابات النمائية. r) مقارنة التشخيص والتتييمات الفارقة باستخدام برنامج البورتيج مع حالات الأطفال ذوي الاضطرابات النمائية. r) تقديم البروفيل النمائي للبورتيج ليحدد جوانب التشابه والاختلاف بينهما ويعكس فاعلية استخدام كل منهما. 


\section{أهية الدراسة}

( ) التحقق من فاعلية استخدام الأدوات التشخيصية والتقييمية المستخدمة في الاضطرابات النمائية والتي تساعد في وضع برامج تعليمية فردية وجماعية للأطفال.

r) بالرغم من وجود العديد من الدراسات التي اهتمت بدراسة التشخيص الفارق بين الأطفال الذاتوين منخفي الأداء الوظيفي ومرتفعي الأداء الوظيفي باعتبارهم ضمن الاضطرابات النمائية إلا إن الجهود المبذولة للتشخيص تقتصر على ملاحظة الأعراض دون النظر إلى القدرات الوظيفية والأدائية لكل طفل على حده ، وهذا يساعد في تقديم البرامج التعليمية لكل طفل بناء على ما يمتلك من قدرات وظيفية. r) استخدام البروفيل النمائي لبرنامج البورتاج في تشخيص وتقييم أداء الأطفال الذاتويين منخفضي الأداء الوظيفي ومرتفعي الأداء الوظيفي باعتبارهم ضمن الاضطرابات النمائية لذا تعتبر هذه الدراسة محاولة للتحقق من فاعلية أدوات التشخيص والتقييم المستخدمة في الاضطرابات النمائية.

\section{مصطاحسات الدراسة}

\section{أ) الاضطرابات النمائية Pervasive Developmental Disorders}

هي حالات اضطراب ذاتي بيولوجي عصبي يتمثل في توقف النمو على المحاور اللغوية والمعرفية والانفعالية والاجتماعية أو فقدانها بعد تكوينها بما يؤثر سلبا مستقبلاً على بناء الثخصية وتطلق بعض الدوائر العلمية على هذه المجموعة اصطلاح طيف Asperger Autistic Spectrum التوحي: الذاتوية Autism، الإسبرجر Disorders Syndrome، الريت Rett Syndrome، اضطرابات الطفولة التحلية Disintegrative Childhood 


\section{Portage Program برنامج البورتيج}

يعرف البرنامج بأنه مجموعة من الأثشطة، الألعاب والممارسات العلمية التي يقوم بها الطفل تحت إشراف وتوجيه من جانب المشرفة التي تعمل علي تزويده بالخبرات، المعلومات، الدفاهيم، الاتجاهات وتدريبه علي أساليب التفكير السليم وحل المشكلات التي

$$
\text { تُرغبه في البحث والاكتثاف (بهادر ، 0. . ب: 0 ؛). }
$$

ويعتبر برنامج بورتيج أحد أهم أدوات التدخل المبكر ؛ حيث إنها يتم تطبيقه على المرحلة

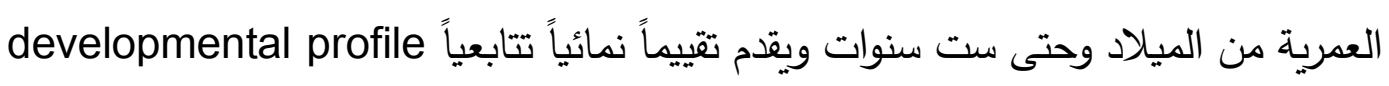
يتكون من: قائمة ملاحظة السلوك checklist: وهو كراسة اختبارات السلوك ويطبق على كل طفل ولكل طفل checklist قائمة خاصة به ويكتب عليه (اسم الطفل- اسم المؤسسةتاريخ ميلاده) ويشتمل على خمس مجالات تقييمية five core areas:

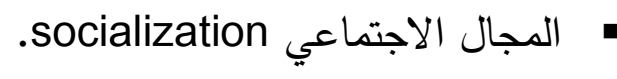

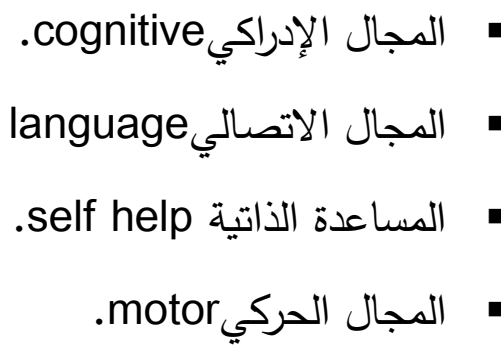
صمم برنامج البورتيج في الولايات المتحدة عام 979 وترجم إلى العديد من اللغات وتم تطبيقه وتتنينه في العديد من دول العالم ومن بينها بعض الدول العربية. حيث يخدم البرنامج

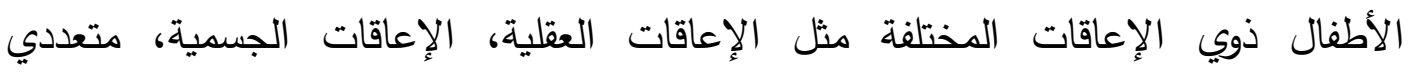
الإعاقات، واضطرابات النطق والكلام. 


\section{حدود اللدراسة}

الحدود المكانية: تتمثل الحدود المكانية للدراسة الحالية في مركز المثالى للصحة النفسية التابع لجمعية المثالى لتتمية المجتمع بحى وسط الإسكندرية .

الحدود البشرية: تتمثل الحدود البشرية في الدراسة الحالية من الأطفال ذوى اضطرابات الذاتوية المترددين على مركز المثالى للصحة النفسية التابع لجمعية المثالى لتنمية

$$
\text { المجتمع بحى وسط الإسكندرية. }
$$

الحدود الزمنية: تحددت الحدود الزمنية للدراسة الحالية في المدى الزمني للعام الدراسي

$$
\cdot(r \cdot r \cdot-r \cdot 19)
$$

الحدود الموضوعية: تحددت الحدود الموضوعية للدراسة الحالية في التشخيص الفارق لبعض الاضطرابات النمائية باستخدام البروفيل النمائي للبورتيج.

\section{الإهطار النيطرى}

\section{أولاً: اضطراب الذاتوية: Autistic Disorder}

الذاتوية نوع من الإعاقات التطورية، وهي من أكثر الإعاقات صعوبة بالنسبة للطفل وأسرته، حيث تعوق عملية الاتصال والتعلم والتفاعل الاجتماعي، وعادة ما تظهر خلال السنوات الثلاث الأولى من عمر الطفل، وهي تتتج عن اضطراب في الجهاز العصبي مما

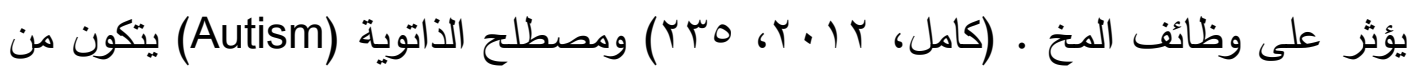
كلمتين يونانيتين الأولى (Aut) وتعني ذاتي أو ما يتعلق بالذات وهي مشتقة من الكلمة اليونانية (Autos) وتعني الذات أو النفس، وأما الجزء الثاني من المصطلح (ism) فيشير إلى التوجه أو الحالة، وهكذا فإن مصطلح (Autism) يعني التوجه الذاتي أو الحالة الذاتية،

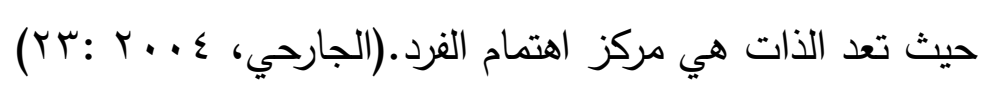


تتتوع تعريفات الذاتوية وفقا لتتوع مجالات الدراسة والبحث والتخصصات المختلفة. فقد

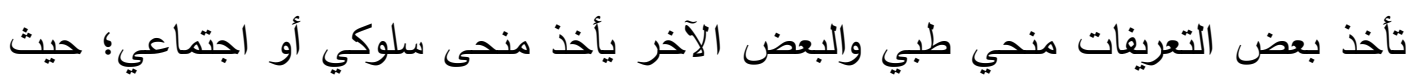

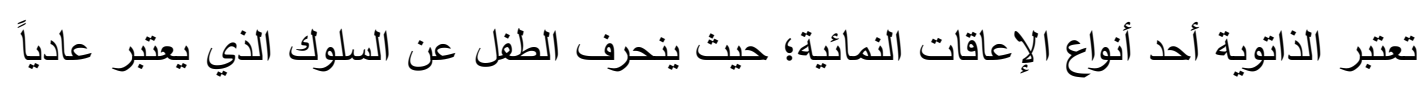

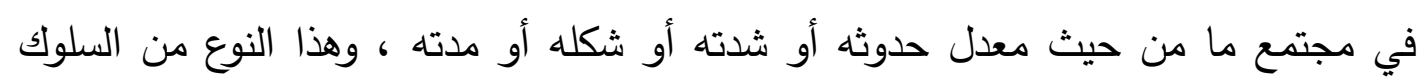
يحدث بثكل متكرر ويتطلب تدخلا علاجيا مكثفاً وطويل المدى، وهو اضطراب سلوكي شديد

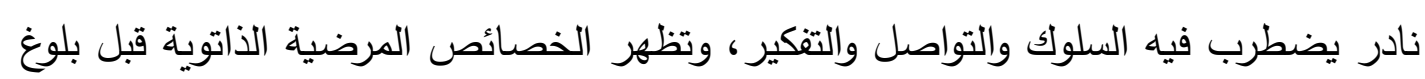

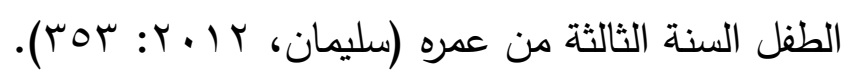

فهي اضطراب نمائى ومعقد، عادة ما يظهر خلال السنوات الثلاثة الأولى من عمر

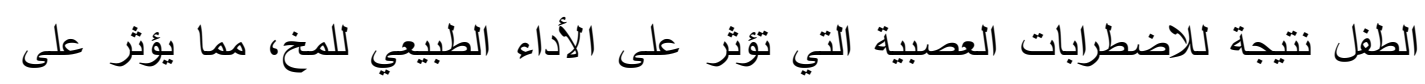

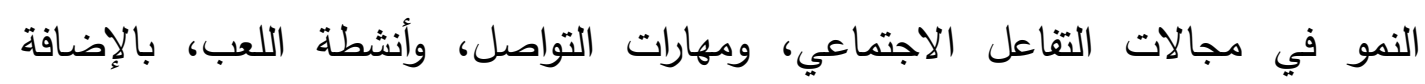

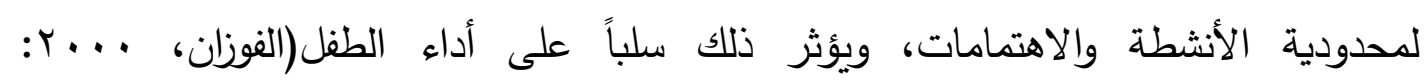

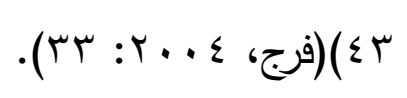

ويعرفها (Cindy,2005) بأنها مجموعة من الاضطرابات العصبية النمائية التي تظهر قبل سن ثلاث سنوات من العمر وتتسم بالإعاقات في المهارات الاجتماعية والاتصالية ووجود السلوكيات والاهتمامات النمطية والتكرارية.

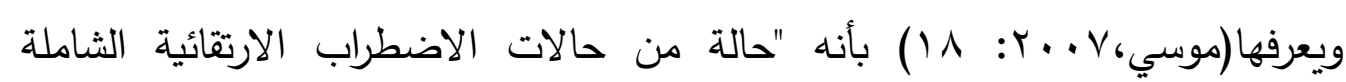

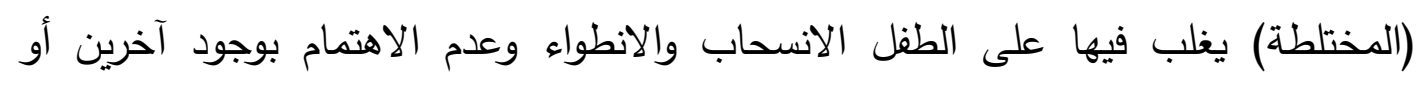

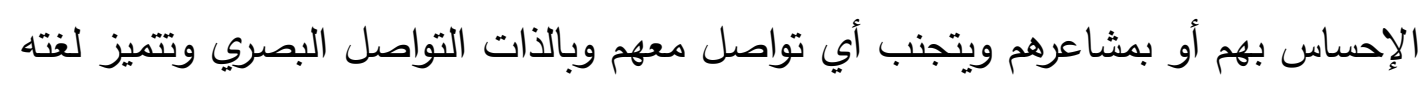

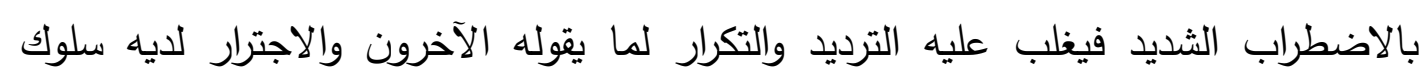

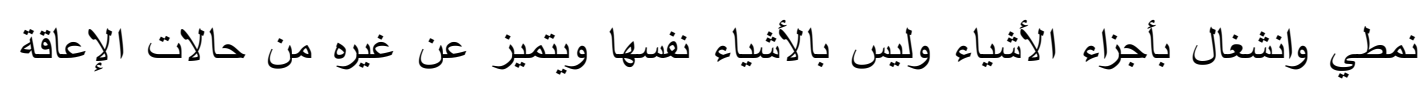
الأخرى بمجموعة من الخصائص المميزة والمتغيرات المعرفية وغير المعرفية". 
ويعتبر (James,Jane,Sadagopa,etal.,2007:1046) أن الذاتوية اضطراب نمائي يتسم بالعزلة الاجتماعية وعيوب التواصل والسلوكيات النمطية أو التكرارية.

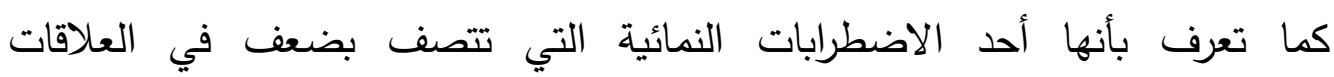

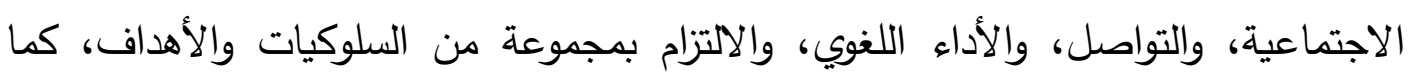
يختلف الأطفال المصابون بالذاتوية من حيث شدة الأعراض، وطرق التعبير في مواقف الحياة اليومية.(Dawson, 2008:137).

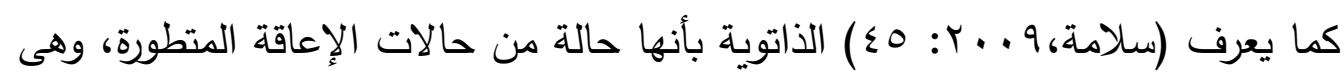

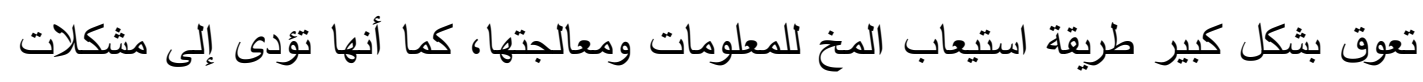
في اتصال الطفل بمن حوله، واضطرابات في اكتساب مهارات التعلم والسلوك الاجتماعي. ويمكن اعتبارها اضطراب عصبي نمائي يدوم مدى الحياة يؤثر على التفاعل الاجتماعي والتواصل والسلوك.(Valkanova, Rhodes, Allan, etal. 2013:13) ويشير(Stephen\&Dominick,2009:157) إلي أن اضطرابات الذاتوية عبارة عن إعاقات كبيرة في التفاعل الاجتماعي والتواصل والإدرالك والوظيفة السلوكية. وتعد اضطرابات الذاتوية وفقا لتعريف Colby,James,Marianne,Deborah,et al.,2010:787) بأنها اضطرابات عصبية نمائية تتسم بالإعاقة في التفاعلات الاجتماعية

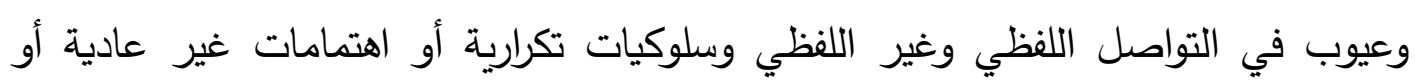

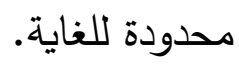
ويشير (Helen 2011:68) إلي أن الذاتوية اضطراب عصبي نمائي يتسم بالإعاقة في التفاعل الاتصالي والاجتماعي والسلوكيات التكرارية.

ويعرفها (الثخص،r T • r: ror) علي أنها اضطراب شديد في عملية التواصل والسلوك يصيب الأطفال في مرحلة الطفولة المبكرة (ما بين • ب- r؟ شهرا من العمر) ويؤثر في 1201

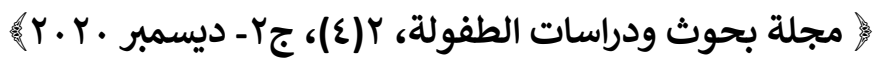




\section{كلية التربية للطفولة المبكرة- جامعة بني سويف}

سلوكهم، حيث نجد أن معظم هؤلاء الأطفال يفتقرون إلى الكلام المفهوم ذو المعني الواضح، كما يتصفون بالانطواء علي أنفهه وعدم الاهتمام بالآخرين، وتبلد المشاعر، وينصرف اهتمامهم أحياناً إلي الحيوانات أو الأشياء غير الإنسانية ويلتصقون بها. ويعرفها (عادل عبدالله، ع ( ب) بأنها اضطراب نمائى وعصبى معقد يتعرض الطفل له قبل الثالثة من عمره، ويلازمه مدى حياته، ويمكن النظر إليه على أنه اضطراب نمائى عام أو منتشر يؤثر سلبا على العديد من جوانب نمو الطفل، ويظهر على هيئة استجابات سلوكية قاصرة وسلبية فى الغالب تدفع بالطفل إلى التقوقع حو ذاته. وتتتخلص الباحثة مما سبق أن اضطراب الذاتوية نوع من الاضطرابات الارتقائية التى تؤثر على جميع جوانب النمو ، وأهم ما يميزها بأنها حالة نمائية عصبية مصحوبة بصعوبات اجتماعية وتواصلية واهتمامات محدودة فى مرحلة الطفولة، وتعيق عملية التواصل الاجتماعي وتتفق هذه التعريفات في أن الذاتوية تتسم بالإعاقة في ثلاثة مجالات رئيسة: التفاعل الاجتماعي، التواصل والحركات النمطية والسلوك التكراري وتظهر قبل العام الثالث من عمر الطفل. كما ترى الباحثة أن بعض التعريفات ركزت علي الأسباب المحتملة للاضطراب والأعراض المصاحبة، والبعض الآخر ركز علي أعراض ومظاهر الاضطراب فقط، كما ترى الباحثة أنه نظراً لأن أسباب الذاتوية ليست مؤكدة حتي الأن حيث يفضل عدم ذكرها في التعريف الإجرائي والاقتصار علي الأعراض والمظاهر فقط، حيث تعرف الذاتوية بأنها اضطراب نمائي معقد يتسم بالإعاقة في ثلاثة مجالات رئيسة: التفاعل الاجتماعي، والتواصل والسلوك، يظهر هذا الاضطراب قبل العام الثالث من عمر الطفل.

تثخيص الأتوية: ينبغي تثخيص الأتوية من قبل فريق متعدد التخصصات

(Valkanova,etal., 2013: 13) الإعاقة في التفاعل الاجتماعي، والتواصل، واللغة، وعدم مرونة السلوك 
(Cheryl,Trepagnier,Sebrechts,Finkelmeyer,etal., 2006)

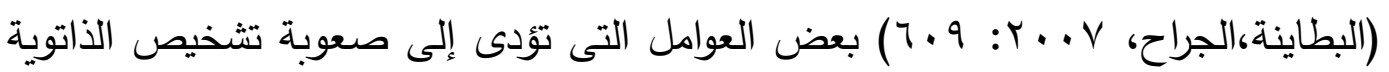
في العمر المبكر من الطفولة وهي: عدم اكتمال الأنماط السلوكية للطفل قبل عامه الثاني. إصابة الطفل بالإعاقة العقلية مما يترتب عليه التركيز على الإعاقة العقلية وإغفال تثخيص الذاتوية وعدم اكتثافها. مشكلات اللغة وتأخر النمو اللغوي التي يعانى منها طفل الذاتوية قد لا تسمح بأجراء

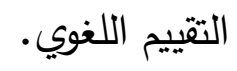
قد تكون مظاهر النمو طبيعية، ثم يحدث فجأة سلوك الذاتوية وفقدان المهارات وخاصة عندما يتجاوز عمر الطفل العامين. قد يكون للوالدين دور في تأخر التثخيص للإصابة بالذاتوية، نتيجة عدم الدراية والخبرة.

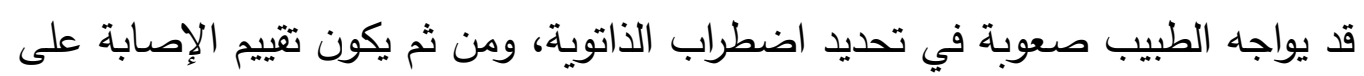
أنها من مشكلات النمو. تعتبر جميع علامات اضطرابات طيف الذاتوية وأعراضها القابلة للتثخيص سلوكية، لذلك تعتمد مجموعة كبيرة من الوسائل التثخيصية على ملاحظة سلوك الفرد سواء بثكل

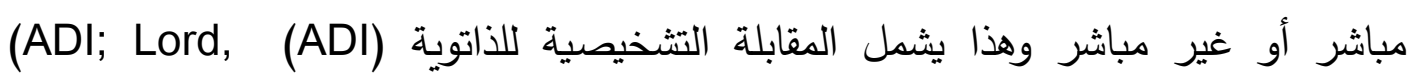
Rutter\&LeCouteur, 1994) 3Di; ) (3Di) والمقابلة التتموية التشخيصية متعددة الأبعاد (ADOS; Lord,etal., 2000) والمقابلة التشخيصية لاضطرابات التواصل الاجتماعي (Skuse, etal., 2004 (DISCO; Leekam, Libby, Wing, Gould \& Taylor, 2002) الاختبارات بصور مختلفة بناءً على عمر الفرد ومستوى اللغة لديه، كما تتتوع الوسائل 


\section{كلية التربية للطفولة المبكرة- جامعة بني سويف}

التشخيصية في طريقة جمعها للبيانات حيث تتضمن أغلب الوسائل مثل المقابلة التشخيصية للذاتوية معرفة تاريخ المرض والذي تكمن أهميته بشكل خاص في تحديد النمو اللغوي المبكر لايه، إلّا أن غيرها من وسائل تعتمد بشكل كبير على مقابلة الشخص ذاته وملاحظة سلوكه بثكل مباشر مثل جدول الملاحظات التشخيصية للذاتوية ومن المعروف أن التشخيص على أساس الملاحظة المباشرة أكثر فعالية لأغراض البحث لأنه لا يعتمد على معلومات من طرف ثالث إلّا أن أغلب التشخيصات الفعالة على الأرجح تتضمن دمجاً بين الأساليب مثل إجراء المقابلة التشخيصية للذاتوية إلى جانب جدول الملاحظات التشخيصية للذاتوية حيث يتم الحكم في الغالب على صحة البحث إكلينيكيا من خلال أسلوب التشخيص ومصدره ويتطلب الحصول على مثل هذه التشخيصات الفعالة على الأقل التدريب من قبل أحد المختصين

$$
\text { وربما التعاون مع شركاء إكلينيكيين (فؤاد، 1 • ؟: هץ). }
$$

شهدت العقود الأخيرة تقدماً كبيراً في درجة تشخيص اضطراب طيف الذاتوية مقارنة بما كانت عليه النتائج العلمية في الحقبة الزمنية الماضية، ولعل ما يميز هذا التقدم كونه تقدماً شاملاً تناول جميع المفاهيم المرتبطة بالذاتوية، كفه طبيعة الأسباب وأليات التشخيص والأعراض وكيفية التعامل معه من خلال البرامج التربوية والتأهيلية والعلاجية، ولعل الأحدث في الميدان ما تم اعتماده في الطبعة الخامسة من الدليل الإحصائي والتشخيصي الأمريكي ما أدى إلى تغيير فئة اضطراب الذاتوية ومعايير تشخيصها، وبناءً (DSM- V, 2013) على ذلك فإن الطبعة الخامسة من الدليل الإحصائي التشخيصي تستخدم الآن مسمى جديد هو اضطراب طيف الذاتوية (ASD)، والذي يجمع ما كان يعرف سابقاً باضطراب الذاتوية (AD)، ومتلازمة إسبرجر (Asperger Syndrome)، واضطراب التفكك الطفولي (CDD)، والاضطراب النمائي الثامل غير المحدد PDD) 
ضمOS) السلوكية (2013) American Academy of Child\&Adolescent Psychiatry) بينما أوردت الطبعة الخامسة من الدليل الإحصائي التشخيصي اضطراب التوحد ضمن

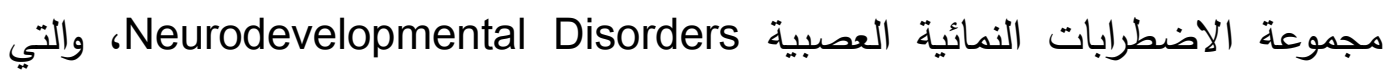

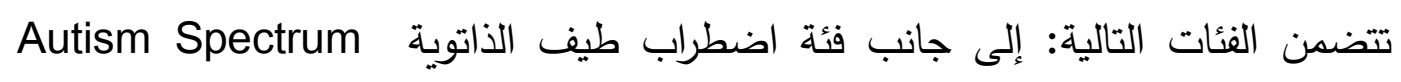
Disorder، الاضطرابات العقلية Intellectual Disabilities، واضطرابات التواصل Communication Disorders

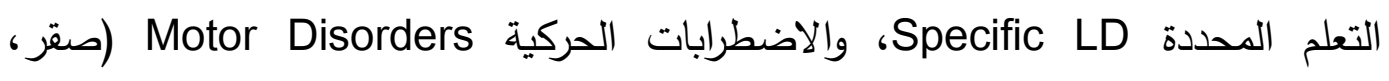
.$(9 \cdot: 4 \cdot 10$

وتري الباحثة أن عملية تثخيص الذاتوية أمراً ضرورياً، بالإضافة إلي صعوبتها البالغة

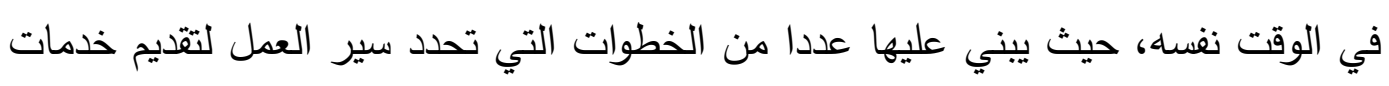

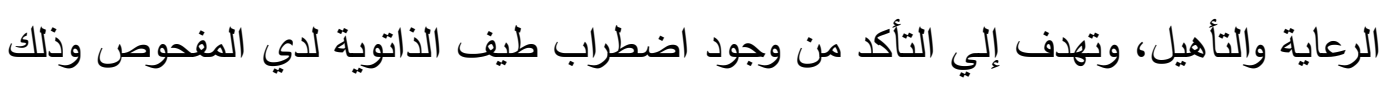
خلال انطباق المعايير التشخيصية من مصادر مختلفة، لذا يجب توفر فريق تشخيص

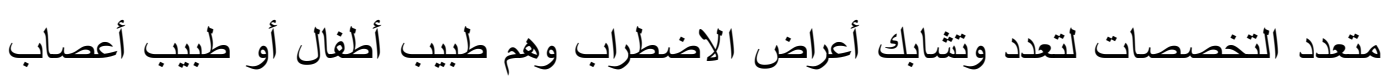
وأخصائي التربية الخاصة وأخصائي التخاطب والأخصائي النفسي بجانب ولي الأمر .

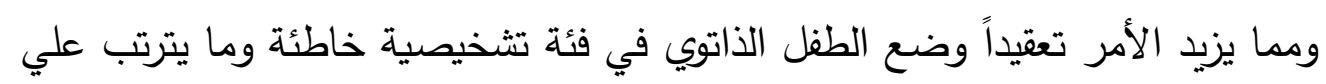
ذلك من حرمانه من خذمات الدعم والتدخل التي يحتاجها ويتم وضعه في برنامج تعليمي غير مناسب، لذا وجب أن تكون قضية التشخيص الدقيق والمبكر أولي وأهم القضايا التي يجب التعاون والعمل علي إنجاحها لما يترتب عليها بعد ذلك من جهد يجب أن يكون في

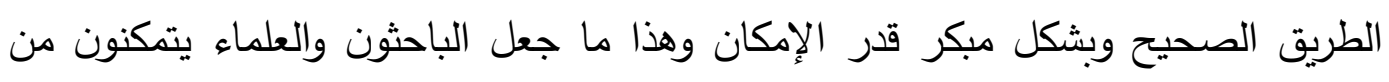
إجراء تغييرات علي تثخيص الذاتوية. 
(د) التغيرات التي طرأت على تثخيص الذاتوية: فيما يلي عرض للتغيرات التي طرأت على

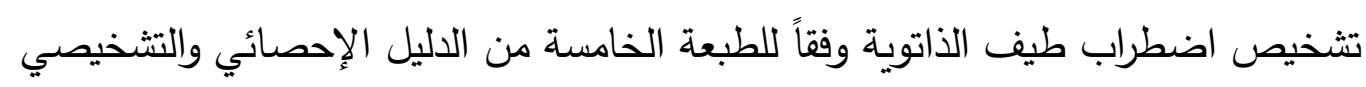

\section{() (ستخدام تسمية تثخيصية موحدة:}

تضمنت المعايير الجديدة استخدام تسمية تشخيصية موحدة (Single Diagnosis)

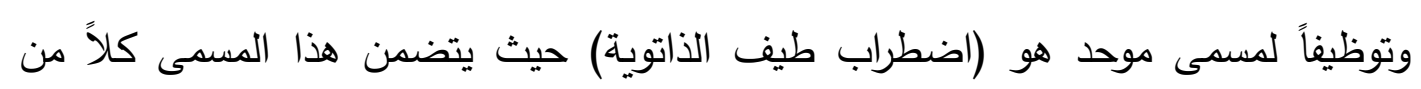

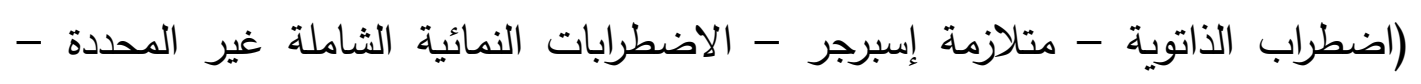

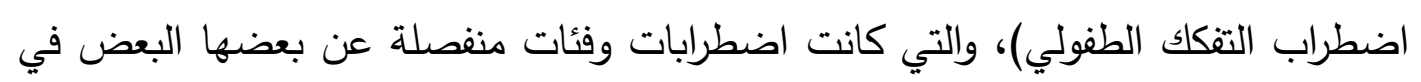
الطبعة الرابعة المعدلة من (DSM) حيث تم تجميعها في فئة واحدة دون الفصل بينهما (American Psychiatric Association, Highlights of Changes from DSM-

$$
\text { .IV - TR to DSM-5 , 2013: 1-2) }
$$

\section{r إسقاط متلازمة ريت من فئة اضطراب طيف التوحد:}

تضمنت المعايير التثخيصية الجديدة إسقاط متلازمة ريت من فئة اضطراب طيف

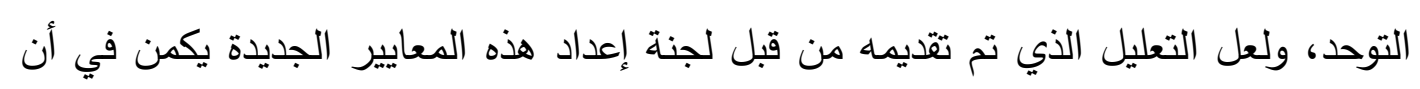

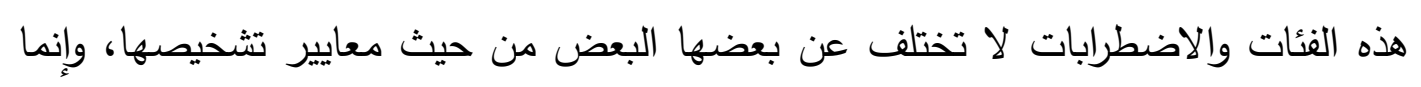
اختلافها يكمن في درجة شدة الأعراض السلوكية ومستوى اللغة ودرجة الذكاء لاى أفرادها، لذا فإن الدليل قد عمد إلى جمعها في فئة واحدة لا تختلف في آلية تشخيصها، كما أن اللجنة

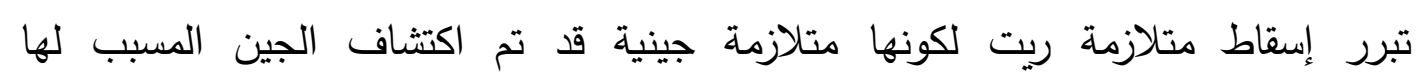
(Susan, 2013:20)

r التشخيص استناداً إلى معيارين اثنين بدلا من ثلاثة معايير:

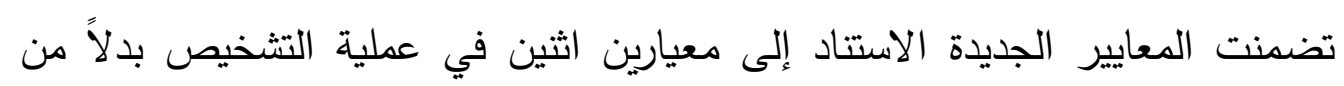
المعايير الثلاثة التثخيصية التي كانت مستخدمة من قبل في الطبعة الرابعة، حيث تضمنت 
المعايير الجديدة التشخيص وفقاً لمعياري فقط هما القصور في المعيار الأول (التواصل الاجتماعي Social Communication)، و(التفاعل الاجتماعي هocial Interaction) المعيار الثاني (الصعوبات في الأنماط السلوكية، والاهتمامات، والأنشطة الدحدودة، (Carpenter, 2013: 6) (التكرارية، والنمطية) ؛) تحديد عدد الأعراض التي يتم التثخيص بناءً عليها: تضمنت المعايير الجديدة سبعة أعراض سلوكية على النحو التالي: ثلاثة أعراض في

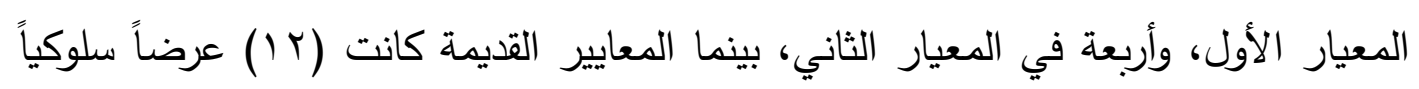

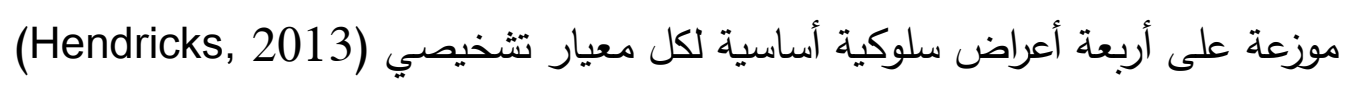
•) تعديد مستوى شدة الأعراض: فرضت المعايير التثخيصية الجديدة على المتخصصين والمشخصين تحديد ما يعرف بمستوى الثدة (Level of Severity)، والتي يتم بناء عليها تحدد مستوى ونوع الدعم

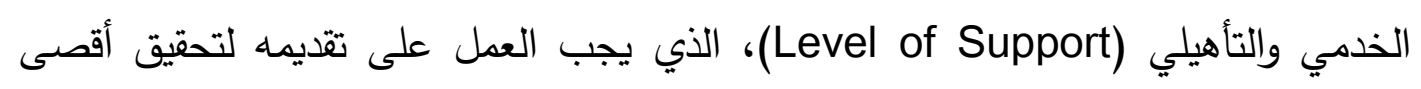

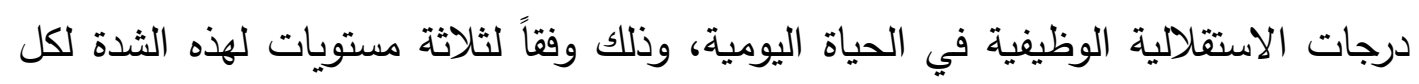
معيار تشخيصي، ولعل السبب من وراء إضافة هذا الشرط يكمن في الدمج الذي تضمنه لئه

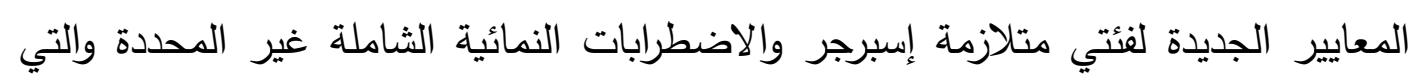
كانت فئتين منفصلتين عن بعضهما وعن التوحد في الطبعة الرابعة(1) (Carpenter,2013) 1 آ) تحديد وتوسيع الددى العمري: تضمنت المعايير الجديدة توسيعاً للمدى العمري الذي تظهر فيه الأعراض لتشمل عمر تهرئ

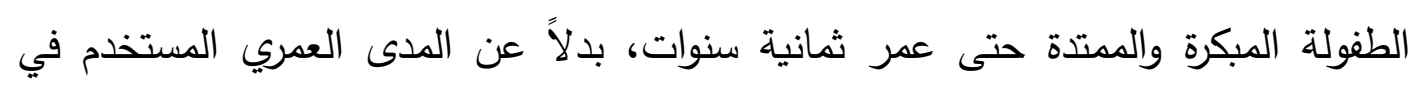

$$
\text { الطبعة الرابعة وهو عمر ثلاثة سنوات (فيريس: r أ. r، م). }
$$




\section{كلية التربية للطفولة المبكرة- جامعة بني سويف}

V) إدراج الاستجابات غير الاعتيادية للمدخلات الحسية ضمن الأعراض التشخيصية: تضمنت المعايير الجديدة في بعدها الثاني (المعيار الثاني) الإشارة إلى الاستجابات غير الاعتيادية للمدخلات الحسية كواحدة من الأعراض السلوكية، التي إن وجدت لاى الطفل تعتبر من الأعراض الأساسية في تشخيصه باضطراب طيف التوحد، على العكس من ذلك فلم تستخدم الطبعة الرابعة مثل هذا العرض كواحد من الأعراض الأساسية وإنما كانت تعتبره من الأعراض المساندة (Susan, 2013: 20).

^) إدراج فئة اضطراب التواصل الاجتماعي كفئة تثخيصية جديدة: ضافت الطبعة الخامسة من الاليل الإحصائي التشخيصي التى تضمنت المعايير الجديدة فئة تشخيصية أخرى تعرف باسم (اضطراب التواصل الاجتماعي) والتي تعتبر التثخيص المناسب للطفل الذي تتطبق عليه الأعراض السلوكية ضمن المعيار الأول لفئة اضطراب طيف الذاتوية ولا تتواجد لديه الأعراض السلوكية في المعيار الثاني، ووفقاً لذلك فإن انطباق الأعراض في كلا المعيارين يسبب التشخيص باضطراب طيف الذاتوية في حين أن انطباق الأعراض في المعيار الأول فقط يسبب التشخيص باضطراب التواصل، ويوضح الجدول التالي أهم الفروق بين الطبعة الرابعة والطبعة الخامسة للدليل الإحصائي والتثخيصي

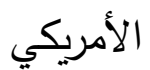


جدول (1)

أهم الفروق بين الطبعة الرابعة والطبعة الخامسة للدليل الإحصائي والتثخيصي

\begin{tabular}{|c|c|c|}
\hline الطبعة الخامسة DSM V 2013 & الطبعة الرابعة DSM IV 2000 & 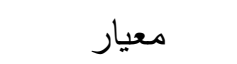 \\
\hline اضطراب طيف الذاتوية (ASD) & الاضطرابات النمائية الثاملة (PDD) & مسمي الفئة \\
\hline متصلة لثلاث فئات ممتدة وفقاً لمستوي & متصلة لخمسة اضطرابات نمائية متقاطعة & 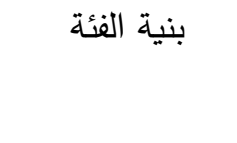 \\
\hline 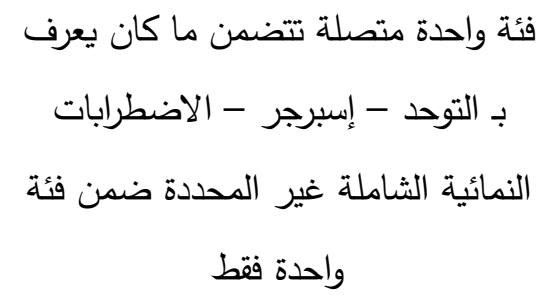 & غير اليت اضطرابات هي (التوحد - إسبرجر - غلاضدرة - اضطرابات النمائية الثاملة & مكونات الفئة \\
\hline محكين: (التفاعل والتواصل الاجتماعي - & ثلاث محكات: التفاعل الاجتماعي - التواصل - السلوكيات النمطية. & التشخيص محكات \\
\hline تحديد مستوي الثدة وفقاً لثلاثة مستويات & خمسة اضطرابات منفصلة تمثل اختلافا & 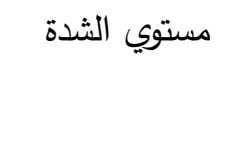 \\
\hline محددة في: الإعاقة العقلية - اضطرابات & غير محددة. & أخراحبة لإعاقة \\
\hline الطفولة المبكرة (^) سنوات & (ץ) سنوات & ل المهور الأعراض \\
\hline
\end{tabular}

ويشير (الزغبي، 0 ـ ب: TY) إلى أنه يفضل مراجعة الأطباء والنفسيين لتحديد نقائص الإصدار الرابع، ثم دمج الكثير من الأعراض التي كانت متثابهة ومتقاربه جداً في أصناف أكثر اتساعاً بالنسبة لاضطراب طيف الذاتوية بسبب الأعراض المشتركة بين العديد من

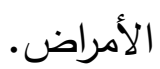


(ه)(مستويات التشخيص وفقاً للطبعة الخامسة من اللاليل الإحصائي التثخيصي الخامس:

وفقًا للطبعة الخامسة من الدليل الإحصائي التثخيصي (DSM- V, 2013) يعتد التثخيص علي عملية متعددة المستويات لتكون عملية دقيقة ومتنوعة من خلال المستويات

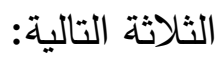

\section{المستوي الأول: المحكات التشخيصية:}

يتضمن المستوي الأول من عملية التثخيص توضيح طبيعة الأعراض ونوع المشكلات

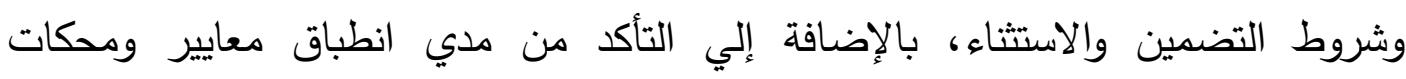

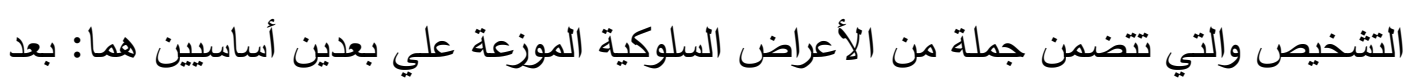

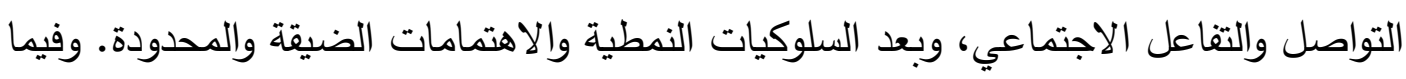
يلي استعراض المحكات التثخيصية الخاصة باضطراب طيف الذاتوية كما وردت في الدليل

$$
\text { الإحصائي التثخيصي الخامس (DSM-V, 2013) }
$$

\section{1) البعد الأول: قصور وعجز دائم في التواصل والتفاعل الاجتماعي:}

ويظهر هذا التصور والعجز في عدد من البيئات التي يتفاعل فيها الطفل، سواء كان هذا

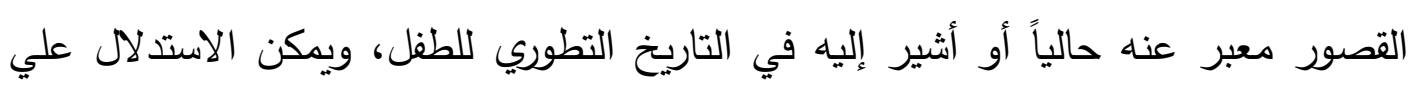
الأعراض التشخيصية في هذا المعيار من خلال: • قصور وعجز في التفاعل الاجتماعي. • قصور وعجز في السلوكيات التواصلية اللفظية وغير اللفظية المستخدمة في التفاعل

$$
\text { الاجتماعي }
$$

• قصور وعجز في القدرة علي تطوير العلاقات الاجتماعية وفهم معانيها والمحافظة علي استمراريتها.

r)(البعد الثاني:السلوكيات والاهتمامات والأنثطة(النمطية والمحدودة والتكرارية والضيقة) 
سواء كان هذا القصور معبر عنه حالياً أو أثير إليه في التاريخ التطوري للطفل، ويكون معبر عنه في أثنين علي الأقل منها، ويمكن الاستدلال علي الأعراض التشخيصية في هذا

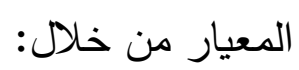

النمطية والتكرارية في الحركات الجسدية (الحركية) وخاصة في استخدام الأشياء

واللغة.

• الإصرار علي الرتابة والتشابه والالتزام الجامد غير المرن بالروتين أو الأنماط الطقوسية في السلوكيات

الاهتمامات المحدودة الثابتة بصورة عالية والتي تبدو غير عادية من حيث مستواها ونوعية تركيزها.

ارتفاع أو انخفاض في الاستجابة للمدخلات الحسية أو اهتمامات غير عادية لجوانب ومظاهر البيئة الحسية.

المستوي الثاني: محكات التحديد: يتطلب تطبيق الطبعة الخامسة من الدليل التشخيصي والإحصائي الأمريكي من المتخصصين والفاحصين والمشخصين، ضرورة تحديد ما إذا كان اضطراب طيف الذاتوية مصحوباً باضطرابات أخري أم لا، دون أن تكون هي المسببة لظهور الأعراض السلوكية التي استخدمت لتشخيص اضطراب طيف الذاتوية. وفيما يلي استعراض محكات التحديد الخاصة باضطراب طيف الذاتوية والتي ينبغي علي المستخدم (المشخص) تحديدها كما وردت في الطبعة الخامسة من الدليل التشخيصي

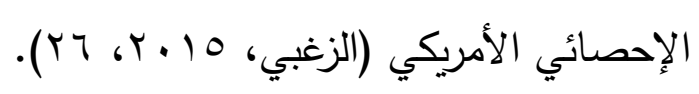

حدد وجود أو عدم وجود اضطرابات واعتلالات عقلية مرافقة لاضطراب طيف الذاتويـة. 


\section{كلية التربية للطفولة المبكرة- جامعة بني سويف}

حدد وجود أو عدم وجود اضطرابات واعتلالات لغوية مرافقة لاضطراب طيف

الذاتوية.

حدد وجود أو عدم وجود ترابط مع حالة طبية أو جينية مرافقة لاضطراب طيف

الذاتوية.

حدد وجود أو عدم وجود ترابط مع عوامل بيئية معروفة مرافقة لاضطراب طيف

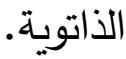

حدد وجود أو عدم وجود مصاحبة لأية اضطرابات عصبية - نمائية - عقلية -

سلوكية مرافقة لاضطراب طيف الذاتوية.

المستوي الثالث: محكات تحديد مستوي الثدة:

تهتم الطبعة الخامسة من الدليل التشخيصي والإحصائي بعملية الربط ما بين التشخيص واتخاذ القرارات التأهيلية والتربوية المتعلقة بتحديد مستوي شدة الدعم المراد تقديمه للطفل المشخص باضطراب طيف الذاتوية وفقاً لمستوي شدة الأعراض السلوكية لديه، وتقسم المعايير التشخصية مستوي الثدة إلي ثلاث مستويات يقل فيها مستوي الدعم المراد تقديمه تدريجياً بانخفاض مستوي شدة الأعراض السلوكية. حيث يدعو الاليل الخامس الأطباء والمتخصصين إلي التثييم الدقيق لخطورة أعراض مرضاهم من أجل تحسين التشخيص، فيجب أن يتضمن التقرير التشخيصي تقييماً دقيقاً لكل عرض علي سلم يبتدئ من المستوي الضعيف إلي المستوي الأقوى، فالكل يوضع علي قائمة متصلة من سلوك نوعي إلي سلوكيات تطابق درجات مختلفة من الاختلال وتحدد الدرجة علي هذا السلم ما إذا كان يجب علاج المرض أم لا، وُيمكن هذا الإجراء من مساعدة الأطباء والمعالجين علي تقييم الأعراض السلوكية لدي المصابين، ومقارنة حاله مع حالات أخري، ويساعد علي كثف حالات تتطلب المساعدة، فخلال الممارسة اليومية يستعمل الأطباء سلالم عديدة وتقييمات مختلفة ، والدليل الخامس يعمل علي قياس وتقنين هذه السلالم 
(التقييمات) بحيث يستخدمها الأطباء والمعالجين جميعاً لتقييم اضطراب الذاتوية، وبالتالي يزيدون من احتمال الوصول إلي نتائج مشابهه حول المرضي للمقارنة، وبذلك تمكن هذه التقييمات من توحيد أفضل للعلاجات، ويمكن الأطباء والمعالجين أيضاً التتبع الجيد لتطور المرض فالانتقال من (خطير) إلي (معتدل) علي سلم الذاتوية قد يكون محفزاً في حد ذاته علي مواصلة التغييرات الإيجابية التي تتحقق (فيري، rا.ب، ؟). ويوضح الجدول التالي محكات تحديد مستوي الثدة الخاصة باضطراب طيف الذاتوية كما وردت في الطبعة الخامسة من الدليل الإحصائي والتشخيصي (DSM - V, 2013).

جدول (r)

محكات تحديد مستوي الثدة الخاصة باضطراب طيف

الذاتوية كما وردت في الطبعة الخامسة من الدليل الإحصائي والتشخيصي

\begin{tabular}{|c|c|c|}
\hline & & \\
\hline 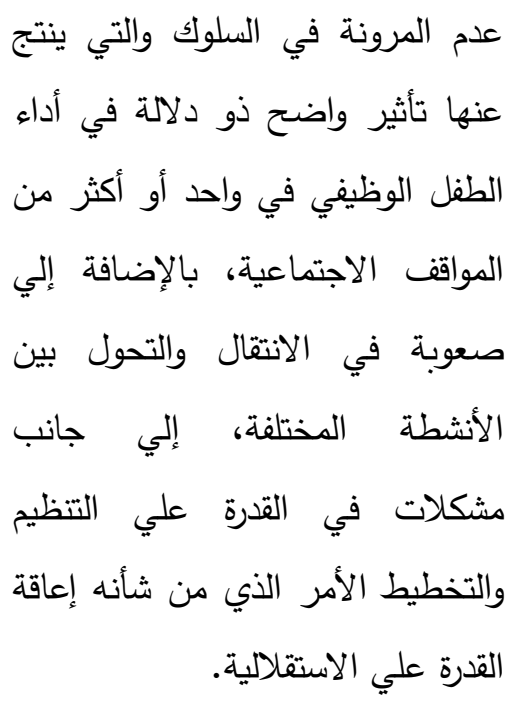 & 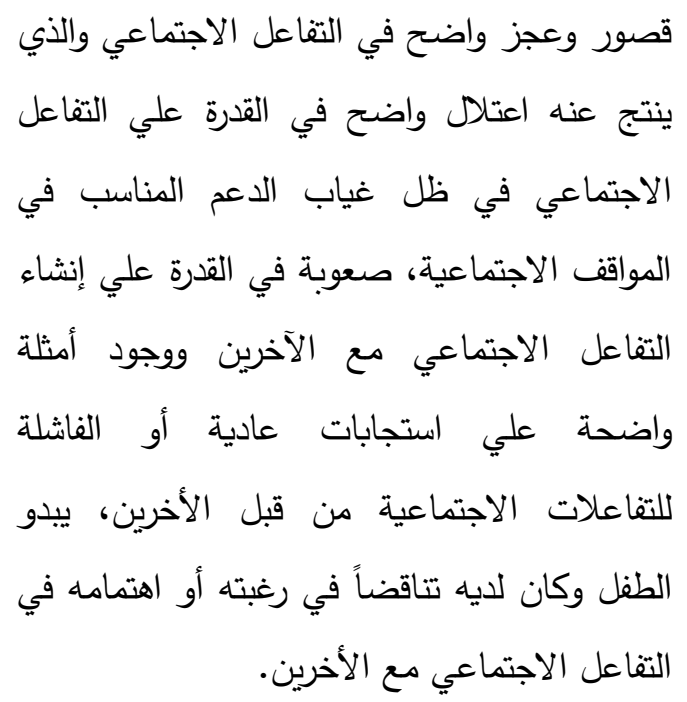 & اليطلب الدستوي رقم (1) \\
\hline علم مدرونة التكيف أو سلوك وصعوبة في القدرة & 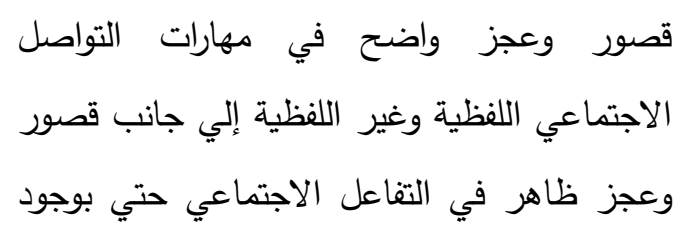 & 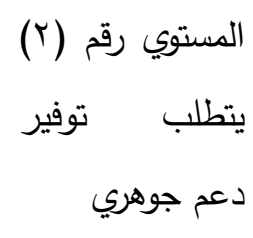 \\
\hline
\end{tabular}




\section{كلية التربية للطفولة المبكرة- جامعة بني سويف}

\begin{tabular}{|c|c|c|}
\hline 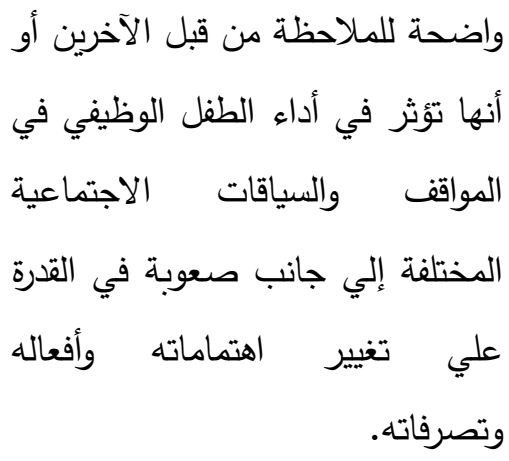 & 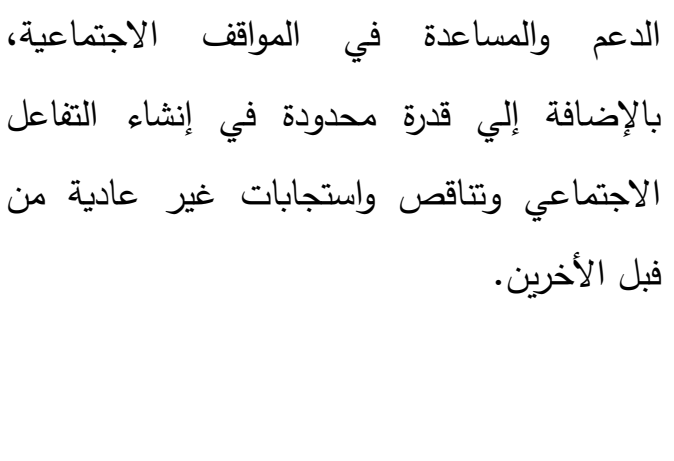 & \\
\hline 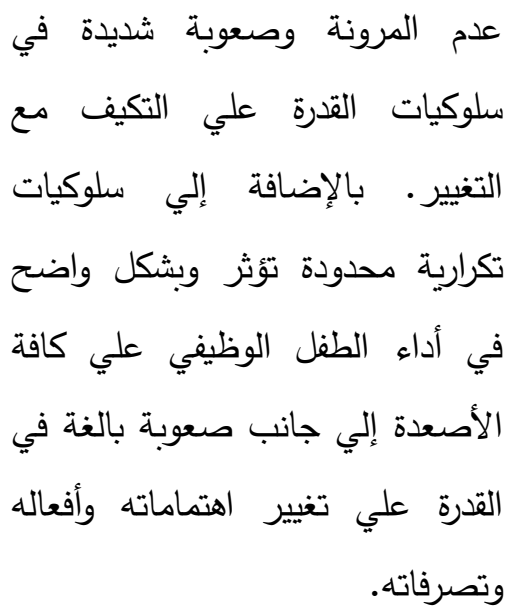 & 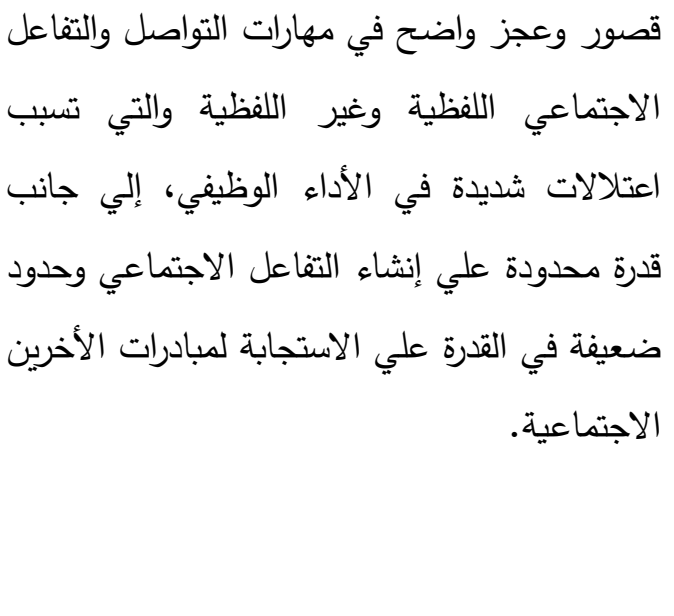 & المستوي رقم (ب) \\
\hline
\end{tabular}

ويتضح من الجدول السابق أن (DSM- V) يعطي المتخصصين استيفاء معلومات

أكثر تقصيلا حول مستوي شدة أعراض الاضطراب، مع إعطاء عدد أكبر من المعطيات وتوصيفها، ومن المفترض أن يعطي المتخصصين تشخيصات أكثر وثوقيه، كما يمكن ذلك المتخصصين والمعالجين من التتبع الجيد من تطور المصابين باضطراب طيف الذاتوية كما

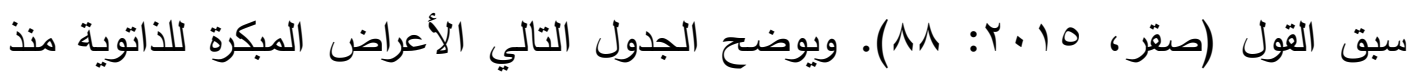
الميلاد وحتى الخمس سنوات الأولى. 
جدول (r)

الأعراض المبكرة للذاتوية منذ الميلاد وحتى الخمس سنوات الأولى

\begin{tabular}{|c|c|c|c|}
\hline المرحلة الرابعة & ال المرحلة الثالثة & المرحلة الثانية & 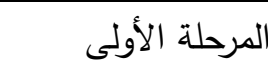 \\
\hline من عمر أربعة سنوات وحتى عمر م & عمر عمر سنتين إلى & من ستة أشهر وحتى العام الأول & منتة أثشهر \\
\hline 1- إذا نمت للديه القدرة على الكلام & 1- اهتمام محدود & 1 - لا يعانق التماساً للدفء وقد & ا- قد يكون الطفل \\
\hline قد تكون في صورة تكرار الكلمات & بما حول الأشخاص & يمشي بصعوبة أو متصلباً حينما & جذاباً أكثر مما \\
\hline التي يقولها الآخرون بشكل روتيني & ل لفترات طويلة. & يتعلق بشيء طلباً للمساعدة على & ل انبغي. \\
\hline في الحال أو بعد ذلك أو بشكل & r - يستخدم الناس & 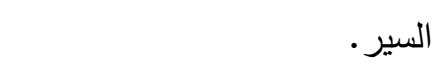 & ب- قد يكون متوتراً \\
\hline مصاداه Echolalia. & الآخرين كأدوات. & r- لا مبالاة نسبية تجاه الوالدين & وسهل الحزن. \\
\hline ץ- نوع الصوت غريب (نغمة عالية & r- ت باصل بالعين & r- لا يلعب ألعاب اجتماعية & ז- لا يحاول التقاط \\
\hline - أو صوت على وتيرة واحدة رتيبة) & محدود ونقص في & بسيطة (كالنظر خلسة أو & الأشياء ولا يبحث \\
\hline r- يصبح حزينا مضطرباً قلقاً & الانتباه البصري. & إصدار صوت " بوو "أو إلقاء & عنها \\
\hline بتغيرات الروتين. & ع - لا يعانق & تحية باي باي) & ع - قد لا يناغي. \\
\hline ع - لا يزال هناك عدم اتصال & (يحضن) وقد يمشي & ع - لا يبدأ في استخدام الكلمات & ه- نقص أو قلة \\
\hline بالأعين وإن حدث فهو محدود ولكنه & متصلباً حتى مع & 0- لا يبدي اهتماما بألعاب & في الابتسامة \\
\hline يظهر بعد التحسن. & المساعدة. & 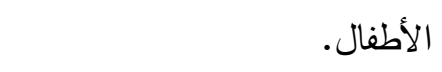 & الاجتماعية. \\
\hline 0- زيادة متدرجة في العاطفة & 0- علاقته بوالديه & ؟- قد يسلب القدرة على حركة & ج- نقص أو قلة \\
\hline والثعور ولكنها ما زالت محدودة. & يشوبها اللامبالاة & يديه (قد يظهر عدم اهتمام & في التواصل بالعين. \\
\hline 7- نوبات غضب وعدوان مستمر & & بيديه. & V- قد يظهر النمو \\
\hline ولكن ربما تتحسن تدريجياً. & & V- نمو حركي متأخر ومتفاوت & الحركي عاديا. \\
\hline ل - - إيذاء الذات. & & بل ومتقطع. & \\
\hline \multirow[t]{2}{*}{ 1- استثارة الذات. } & & ᄉ- قد لا يمضغ أو لا يقبل & \\
\hline & & & \\
\hline
\end{tabular}

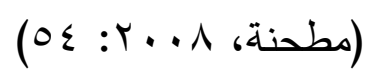




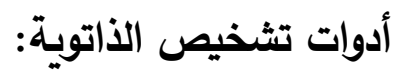

مما لاثكك فيه أن تثخيص وتقييم اضطراب الذاتوية وتحديد من يعانون منه يعتمد على

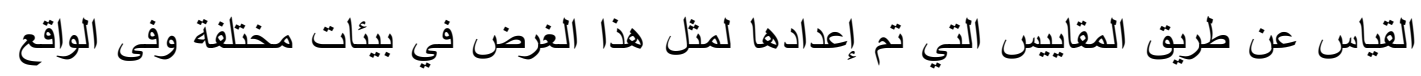

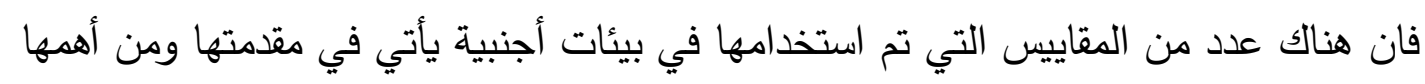

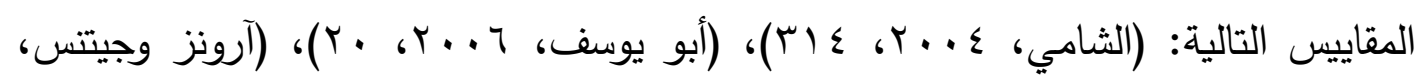

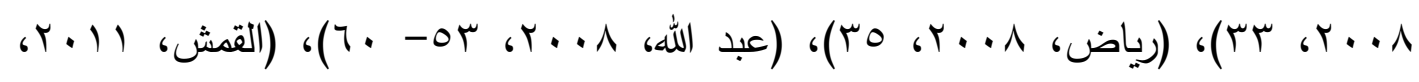

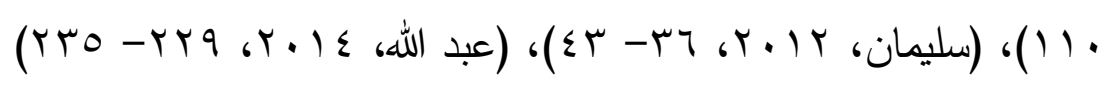

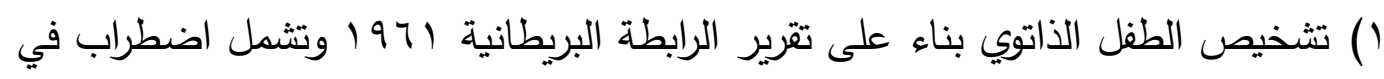

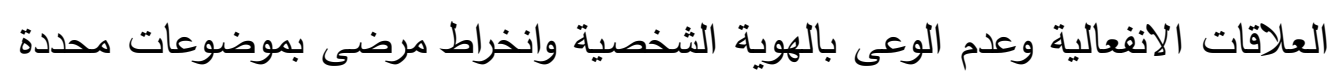

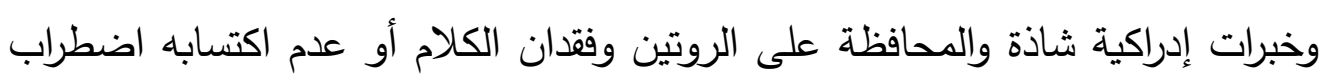

$$
\text { في الأنماط الحركية . }
$$

r) قائمة ملاحظة السلوك الذاتوي التي أعدها كروج (krug,1990) وتعمل على تقيييم الاضطراب عن طريق ثلاث جوانب تتمثل في القصور في القدرة على التعبير اللفظي والانسحاب الاجتماعي وعدم القدرة على التواصل الاجتماعي.

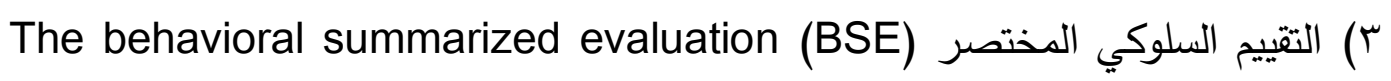
ويحدد ثمانية أبعاد وهى الانسحاب الاجتماعي والقدرة على المحاكاة والتواصل وضعف الانتباه والتعبير اللفظي وغير اللفظي وعلامات الخوف والتوتر والاستجابات الذهنية. ع) مقياس التقدير السلوكي للأطفال ذوى اضطراب الذاتوية (BRIAC): Behavioral Rating Instrument for autistic and typical children (0 وضعت من قبل Rutten ويعمل على تقييم الاضطراب لاى الطفل من خلال ما يتوفر

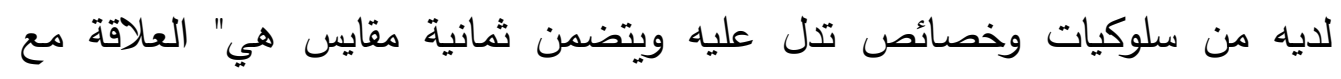


الآخرين والتواصل والنطق والتخاطب والصوت وفهم الحديث الاجتماعي والتجاوب الاجتماعي والقدرة الحركية والنمو النفسي العضوي

آ) قائمة ملاحظة السلوك للأطفال الذاتويين Behavior Observation system (BOS ) اعدها فريمان (Freeman etal,1978) ويتكون من 9 فقرات ملاحظة مدة كل منها r دقائق وتسجل TV سلوكًا مميز لها الاضطراب.

V) مقياس تقدير اضطراب الذاتوية في مرحلة الطفولة (CARS) أعده. Schopler,et.al. القصور فى العلاقات الاجتماعية والتقليد واضطراب الانفعالات والقدرة الحركية السلوكيات النمطية ومقاومة التغيير واستجابات غير عادية وعدم التجاوب مع البيئة المحيطة أو الاندماج معها واستجابات القلق والتواصل اللفظي وغير اللفظي واللعب والمستوى العام للنشاط والانطباعات العامة.

^) مقياس جيليام التقدير لتشخيص اضطراب الذاتوية: (Giliam,1995) تم تصميم هذا المقياس ليعمل على تحقيق أهداف عدة أهمها التوصل إلى تشخيص دقيق لاضطراب الذاتوية بين مختلف الأفراد، ويضم هذا المقياس أربعة مقايس فرعية وهى التواصل والسلوكيات النمطية والتفاعل الاجتماعي والاضطرابات النمائية، وهو من الأدوات المستخدمة في الدراسة الحالية. 9) جدول المراقبة العام لتشخيص الذاتوية (ADOS): هو بروتكولاً موحدًا لمراقبة سلوك التواصل والسلوك الاجتماعي للأطفال من فوق سن • ب شهرا ممن يستطيعون الكلام ويحتمل أصابتهم بالذاتوية. • (1) بطارية التقييم المعرفي والاجتماعي للأطفال الذاتويين (SCEB): والتي قام بإعدادها (Thiébaut,Adrien, Blanc\&Barthelemy, 2010) 


\section{كلية التربية للطفولة المبكرة- جامعة بني سويف}

مقياس منها (التفاعل الاجتماعي واللغة التعبيرية والاهتمام المشترك وتتظيم السلوك والتقليد، والتعبير العاطفي والصورة الذاتية واللعب الرمزي والعلاقات المكانية). (1) البروفيل النفسي التربوي (PEP): أعده (SChopler,1978) ثم قام بتعديله عام • 99 ثم صدرت النسخة الثالثة في عام 0. . ب وقام بتقنينها على البيئة السعودية (حميدان، ^ . . r) ويهدف المقياس إلى تقييم وتشخيص الأطفال الذاتويين من خلال أدائهم على المقياس وسوف نعرض هذا المقياس بالتفصيل في الصفحات القادمة حيث أنه هو موضوع الدراسة الحالية.

مما سبق يتضح لنا تعدد وتتوع أدوات التشخيص والتقييم للأطفال الذاتويين والتي سعت إلى تقديم تشخيص دقيق يهدف إلى تقديم الخدمات التربوية المناسبة ولذا فإن هذه الدراسة تحاول أن تقدم أحد أهم الأدوات المستخدمة في التشخيص والتقييم وهو مقياس الملف النفسي التزبوي والذي يقدم لنا معلومات تفصيلية دقيقة تعتمد علي أداء الطفل نفسه بالإضافة إلى ملاحظة ولي الأمر، مما يجعله من الأدوات الملائمة والمناسبة ولذا سعت هذه الدراسة إلي استخدامه وقياس مدي قدرته في التشخيص الفارق بين الأطفال الذاتوين منخفضى الأداء الوظيفى والأطفال الذاتويين مرتفعي الأداء الوظيفي. (ح) خصائص الأطفال ذوي اضطراب الذاتوية: ( ) | (الخصائص الجسمية:

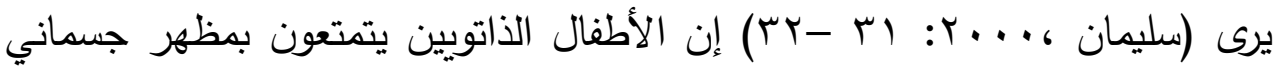
طبيعي، كما إن بعضهم يميلون إلى اكتشاف أجسامهم بصريا، أو عن طريق اتخاذ أوضاع خاصة في الوقوف، أو الجلوس، أو كأن أجسامهم أشياء غير مألوفة لديهج. وهذا يثير إلى أنه لا توجد خصائص جسمية تميز الأطفال الذاتويين عن أقرانهم العاديين فهم يشبهون العاديين إلى حد ما في الطول، والوزن، والصحة العامة. لذلك لا يعتمد على الخصائص 
الجسمية في تثخيص اضطراب الذاتوية، وجدير بالذكر أن بعض الأطفال الذاتويين في

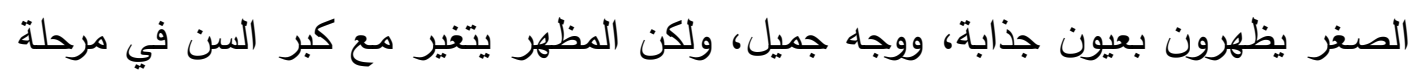
المراهقة والثباب.

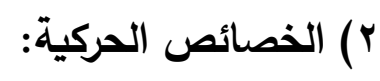

ترى (أديب ، ب991 ا: r 1) أنه قد يظهر لايهم ضعف في التأثر الحركي، وبعض هؤلاء

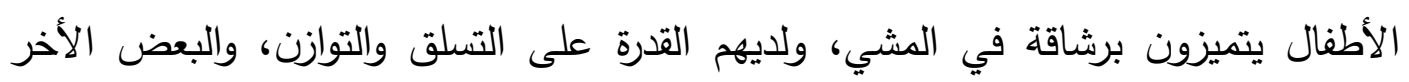

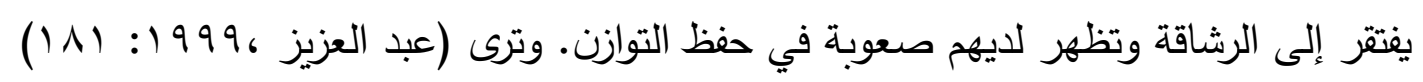

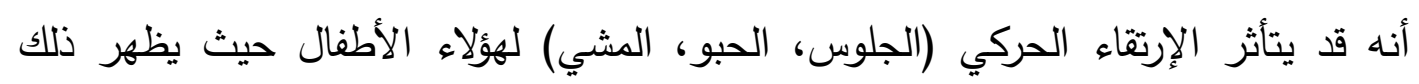

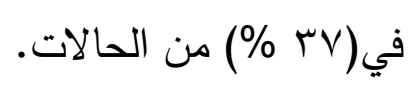

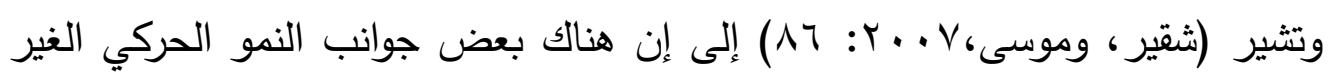

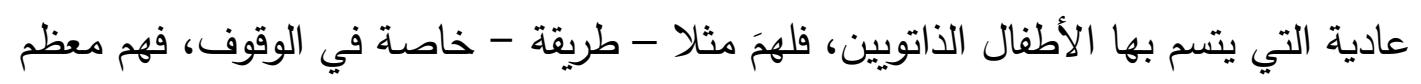
الأحيان يقون ورؤوسهم منحنية كما لو كانوا يحملقون تحت أقدامهم.

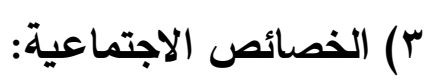
يرى (Klin,1993:612) أن الصفة الإكلينيكية الأساسية لاضطراب الذاتوية هي أنه

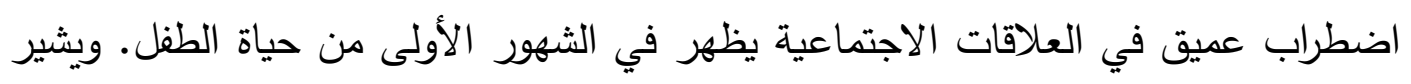

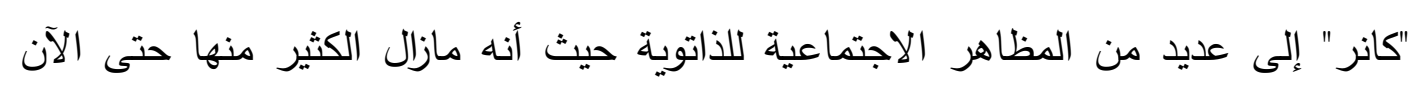

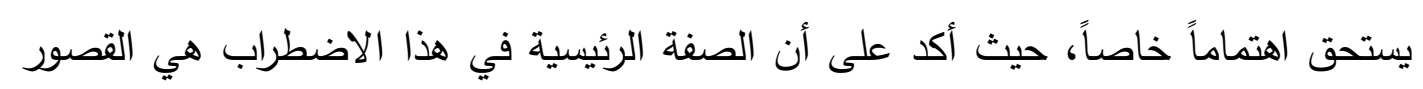
الاجتماعي حيث قارن بين السلوك الاجتماعي للأطفال العاديين والأطفال الذاتويين، فالأطفال

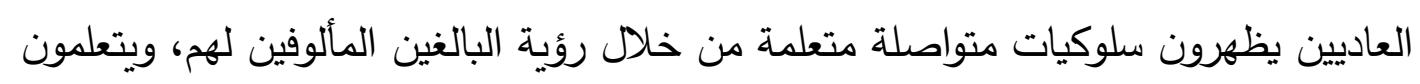

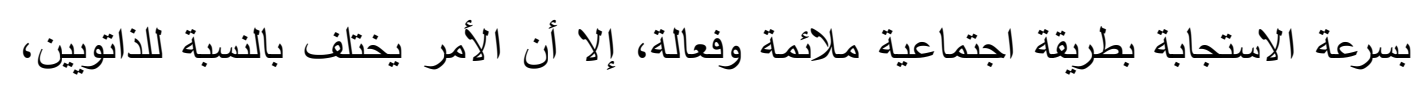




\section{كلية التربية للطفولة المبكرة- جامعة بني سويف}

فهم غالباً ما يفتقرون إلى هذه المقدرة الطبيعية للاستجابة للآخرين بطريقة ملائمة (شقير،

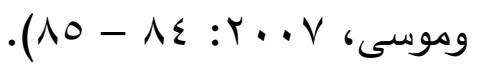

وترى (أمين ، ا . . Y: VV) أن هؤلاء الأطفال يجيدون عزل أنفسهم حتى لو كانوا في حجرة مليئة بأعضاء العائلة، ويقضي الأطفال الذاتوين وقتاً طويلاً بالقرب من أبائهم أو مربيهم. وتشير (أمين ، ؛ . . ب: 01) إلى أن الأطفال الذاتوين يتسمون بنقص (إن لم يكن غياباً كلياً) لسلوك التعلق الطفلي، وفشل مبكر في الارتباط النوعي بشخص ما، ويمكن أن يظهروا عمليا انعداما في قلق الانفصال عند تركهم في بيئة غير مألوفة مع أشخاص غرباء.

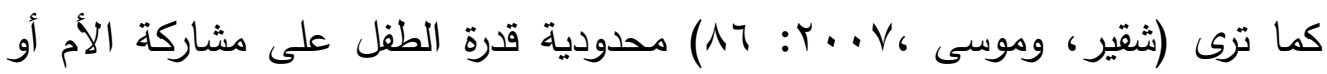
بديلها في الخبرات والاهتمامات بالأشياء والموضوعات والذي يعتبر من أهم مجالات النمو الرمزي. ويعاني طفل الذاتويـة من عجز في سلوك (التقليد) كما تبين أن الذاتوين يعانون من مشكلات في تقليد حركات الجسم البسيطة، وهم نادراً ما يقلدون أفعال والديهم.

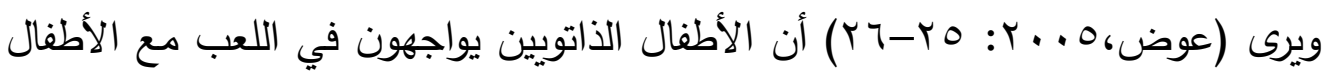
الأخرين نفس الصعوبة التي يواجهونها في اللعب وحدهم بهذه اللعب، فهم لا يعرفون الغرض من أية لعبة، وهم لا يميلون إلى تقليد الأخرين، ولا أخذ زمام المبادرة في إقامة المباريات. وتشير (أمين ، ا . . r: rاج) إلى أن الأطفال الذاتوين يظهرون عجزاً في مهارة التقليد نتيجة ما يعانونه دن اضطرابات في الانتباه والملاحظة. وبالتالي هذا يؤثر بدوره في قدرتهم على التقبليد

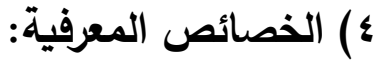

تشير الدراسات والأبحاث إلى أن اضطراب النواحي المعرفية يعد أكثر الملامح المميزة لاضطراب "الذاتوية" وذلك لما يترتب عليه من نقص في التواصل الاجتماعي، ونقص الاستجابة الانفعالية للمحيطين، ويعانى الأطفال الذاتويين من اضطرابات واضحة في التفكير والانتباه والإدراك والذاكرة واللغة. 


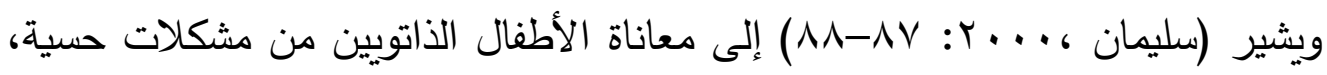
فاستجابتهم غير معتادة للمثيرات الحسية، ويمكن تفسير الاستجابات الثاذة للمثيرات الخارجية إلى وجود عجز أساسي في ترجمة الخبرات والتجارب الحسية، وخصوصا فيما يتعلق بالعجز

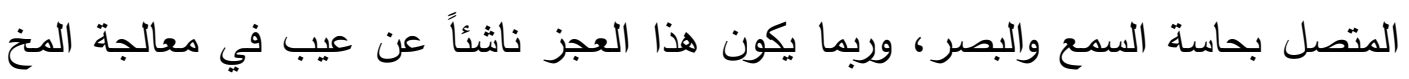

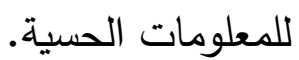

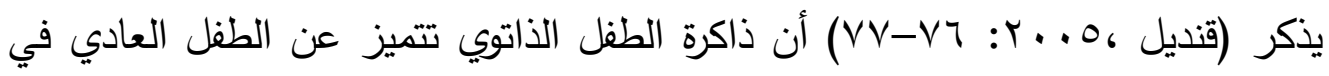
أنه يستحضر الأثياء إلى الذاكرة دون أي تغيير في ترتيبها، فالأثياء التي يسمعها والأثياء

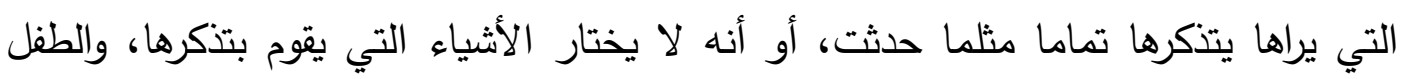

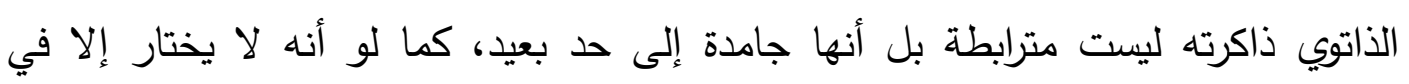
ظروف خاصة، ولذا وجد إن قدرته على اللعب التخيلي محدودة نتيجة لما سبق. يذكر (مليكة ،1991: YYY) أن الأطفال الذاتويين تتراوح مستوياتهم المعرفية فيما بين(ro \%) منهم توحد وتخلف عقلي شديد، (0 \% ) توحد وتخلف عقلي بسيط، (ro\%)

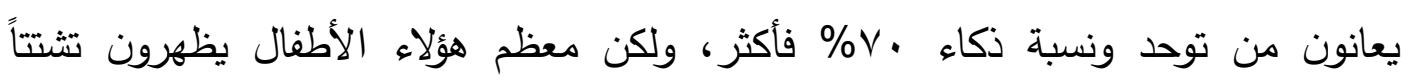
ملحوظا في وظائفهم المعرفية، وتكون درجة ارتقاء اللغة اللفظية أقل بكثير . تثير الدراسات والأبحاث السابقة أيضا إلى أن اضطراب النهاه النواحي المعرفية تعد أكثر لهربه الملامح الموضحة للاضطراب الذاتوي، كما يترتب عليه نقص في التواصل الاجتماعي والاستجابة الانفعالية للمحيطين به؛ ولذا أظهرت الدراسات أن حوالي ثلاثة أرباع الأطفال الذاتويين لديهم درجات من التخلف العقلي، وأظهرت دراسات أخرى أن بعض الأطفال

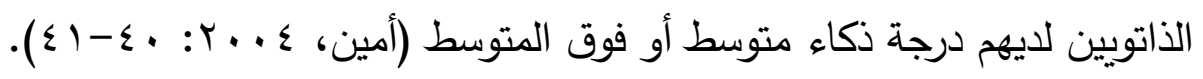




\section{(ط) (أعراض اضطراب الذاتوية}

عادة ما يتم تشخيص اضطراب الذاتوية بناءً علي سلوك الثخص، ولذلك فإنه من

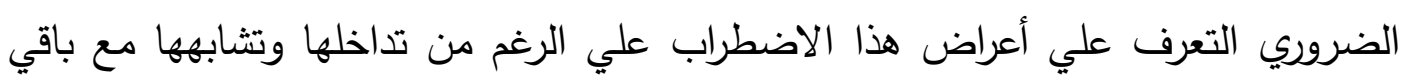

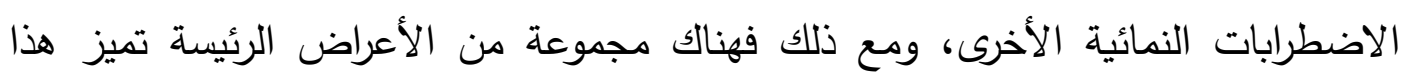
الاضطراب وهي: قصور واضح في التفاعل الاجتماعي، والنمطية ومحدودية الأنثطة

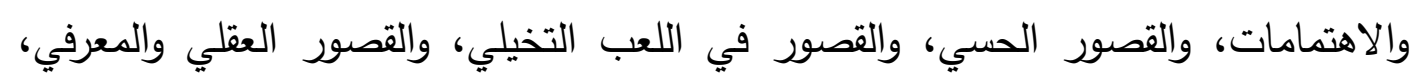
وضعف التواصل اللغوي (اللفظي وغير اللفظي). () قصور واضح في التفاعل الاجتماعي.

يلاحظ آباء الأطفال الذاتويين أن أطفالهم الرضع أو أثناء مرحلة المهد لا يستجيبون

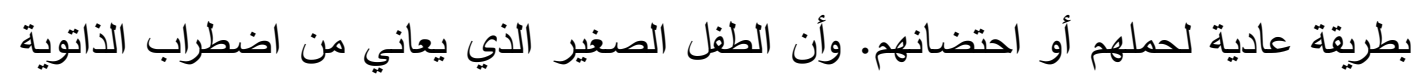

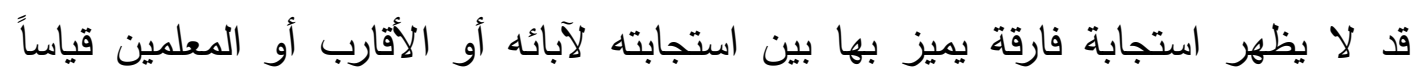

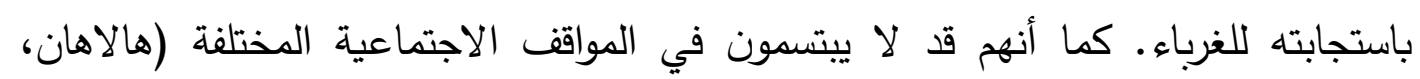

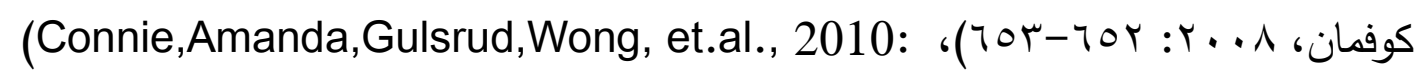

وقد يكون هناك اضطراب ملحوظ في استخدام أنماط من السلوك غير اللفظي المتعدد كالتواصل البصري، والتعبير الوجهي، والإيماءات والحركات الجسمية (الرابطة الأمريكية

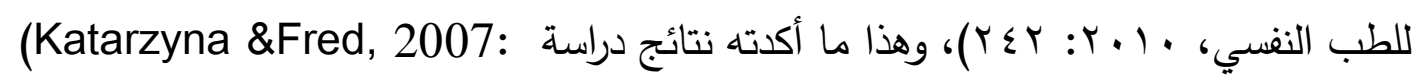
(266 حيث أشارت إلي أن مدى الثذوذ في القدرة على معالجة الوجوه المرتبطة بالذاتوية يؤدي إلى حدوث ما يُعرف باسم "عمى الوجوه" مما يؤثر على مجالات متعددة تثمل إدراك

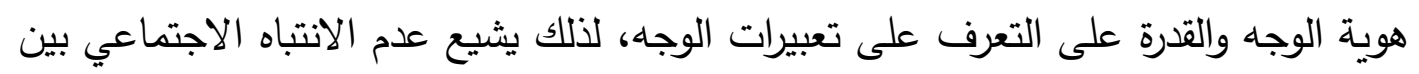

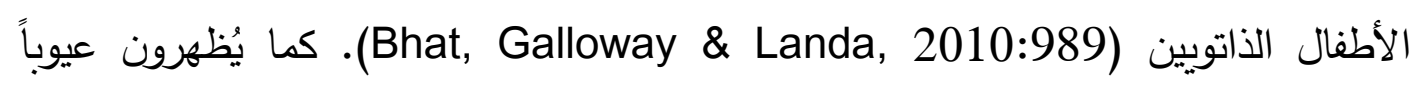

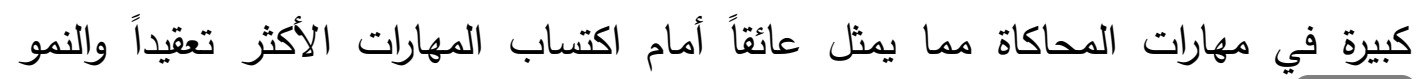


(Brooke, اجتماعي، وتبرز عيوب المحاكاة عندما يكون هدف المحاكاة اجتماعيا .2007:269)

ومما يميز هؤلاء الأطفال أن لايهم فثل في تكوين علاقات مع الأقران ولا يوجد عندهم اهتمام في تكوين الصداقات، كما يكون لديهم نقص في السعي التلقائي إلى مشاركة الآخرين

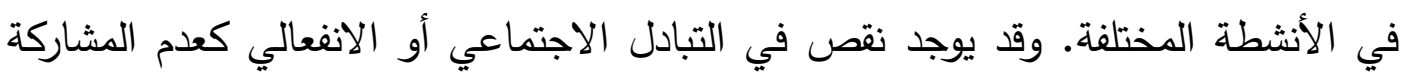
بفاعلية في اللعب الجماعي أو الألعاب أو المباريات الجماعية، وتفضيل الأنشطة الانفرادية، وغالبا ما يكون وعى الطفل بالآخرين مضطربا بثكل ملحوظ (الرابطة الأمريكية للطب النفسي، • (1)

\section{r) النمطية ومحدودية الأنثطة والاهتمامات:}

معظم سلوكيات الأطفال الذاتويين تبدو بسيطة من قبيل تكوير قطعة من اللبان بيديه،

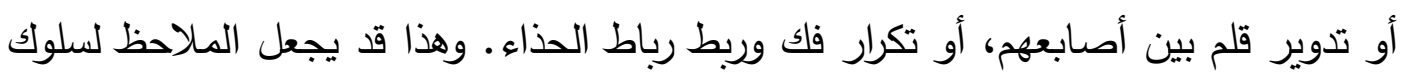

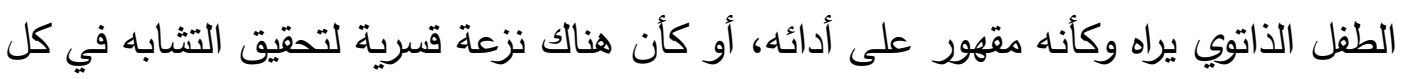

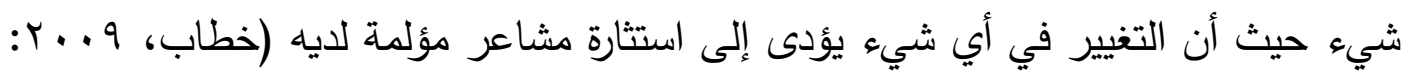
. (ro

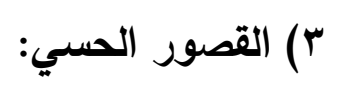

إن الخلل الحسي أهم ما يميز أعراض اضطرابات الذاتوية والتي يجب مراعاتها عند

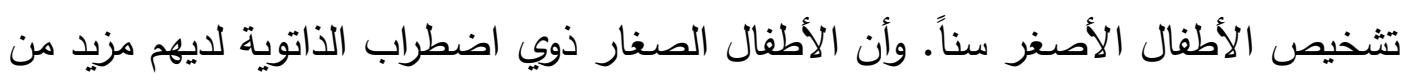
الحساسيات اللمسية والتذوقية والثمية والصعوبات في المعالجة السمعية (Lisa,Diana,Roger, etal.,2009:1089) 


\section{كلية التربية للطفولة المبكرة- جامعة بني سويف}

وتذكر (Susan,2013:896) أن ما يزيد على ،9\% من الأطفال الذاتويين يعانون من اضطرابات حسية ولديهم أعراض حسية في عديد من المجالات الحسية الخاصة بالثم

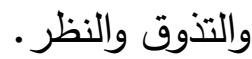

وقد تكون لدي الذاتويين استجابات غريبة للمنبهات الحسية مثل الإحساس الزائد بالألم،

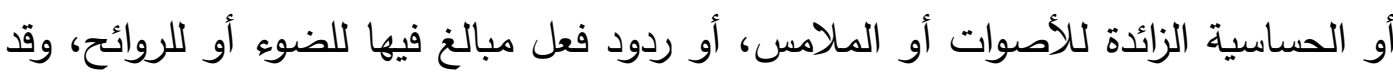
توجد اضطرابات في الأكل منها اضطراب بيكا وهو عبارة عن تتاول مواد غير قابلة للأكل وغير مفيدة لنمو الطفل، أو اضطرابات في النوم كالاستيقاظ المتقطع بالليل مع السقوط من على الفراش، وقد توجد اضطرابات في النواحي المزاجية أو الانفعالية مثل الضحك بصوت عال أو البكاء دون سبب واضح، وعدم وجود ردود فعل انفعالية، وربما لا يأتون باستجابة تدل على الخوف كرد فعل لأخطار حقيقية، في حين أنهم قد يظهرون خوفاً زائداً في بأي

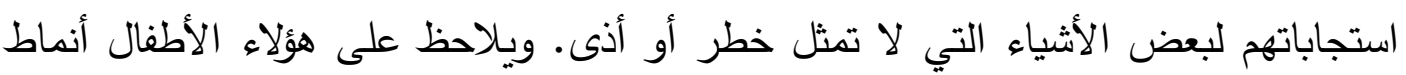

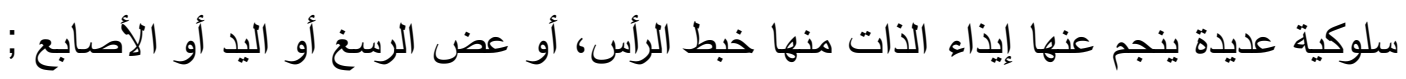
(Maarten,Herman,Chantal,etal.,2007:2014);(Alison,Robyne,Amy,Baker ,etal., 2010:112) ويغلب على الأطفال الذاتويين انتقائية الانتباه فيما يتعلق بأحداث البيئة التي يعيشون

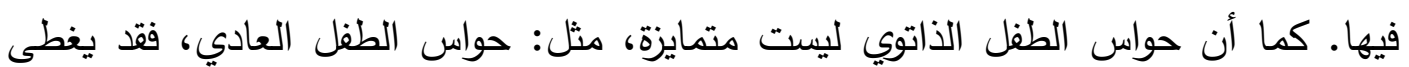

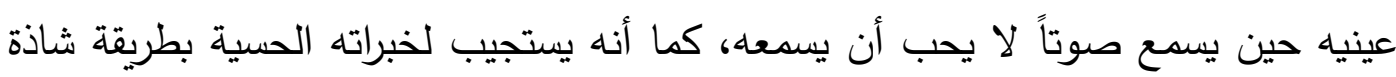

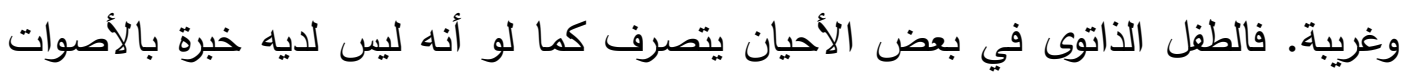

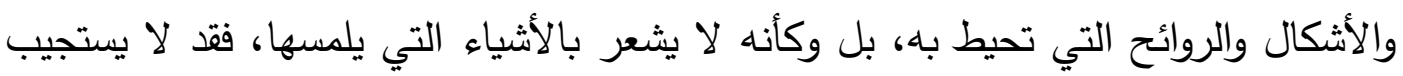

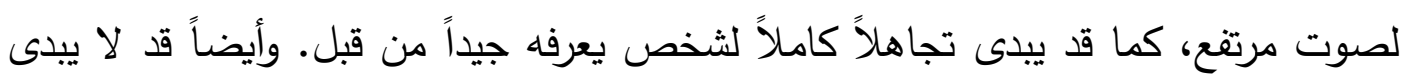
مبالاة للألم أو البرد، بينما في أوقات أخرى قد تبدو حواسه سليمة لارجة أنه يثعر بصوت

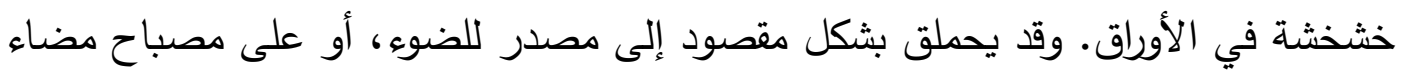


أو يقوم ببرم جزء من ورق مكراً ذلك عدة مرات، أو يخش سطح منضدة(خطاب، 9 . ب؟: $(r+r)$

ع) القصور في اللعب التخيلي:

يعاني الطفل الذاتوي من نقص في اللعب التلقائي أو الابتكاري، كما أنه لا يقلد حركات

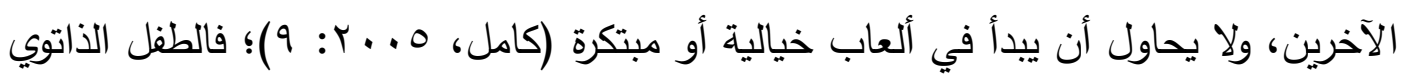

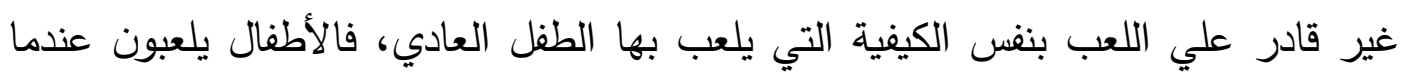

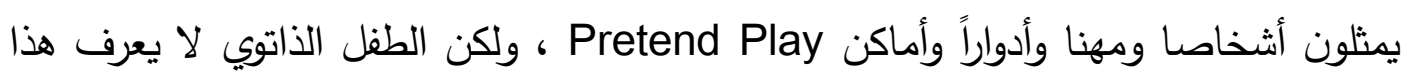

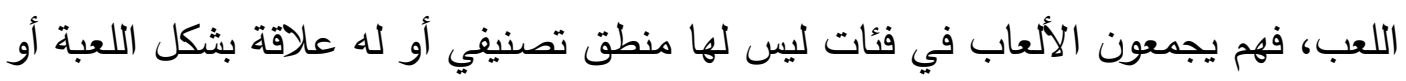

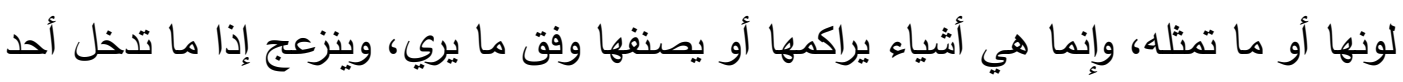

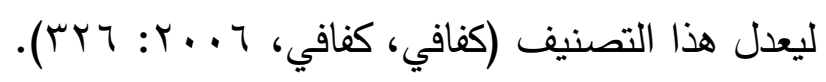
كما أن لعب الطفل الذاتوي بالسيارة يختلف عن لعب الطفل الطبيعي، فيقوم الطفل

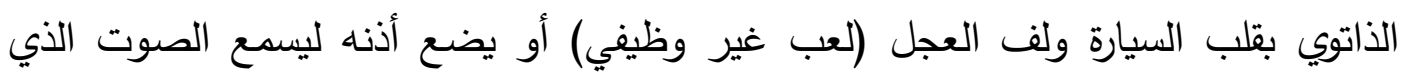

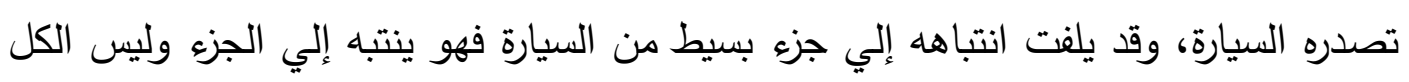

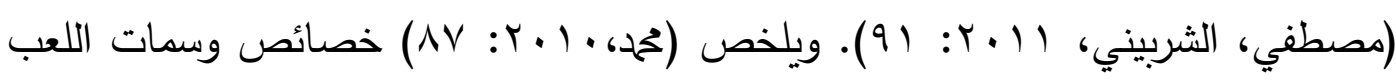
لاي الطفل الذاتوي فيما يلي: - الدين هفتقر إلي الكثير من أنواع اللعب الاستكثافي. تقل المظاهر الرمزية في ألعابه إلي حد كبير.

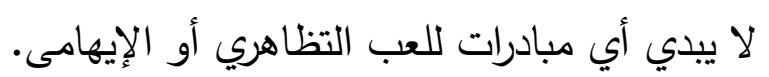

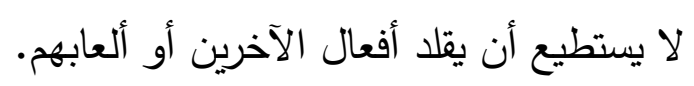

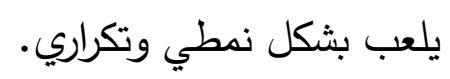
يتاول اللعب بطريقة غير مقصودة وبقليل من التتوع والابتكارية والتخيل. 


\section{كلية التربية للطفولة المبكرة- جامعة بني سويف}

لا يتناول اللعبة كي ترمز إلي شيء آخر بل ليرميها مثلا ويسع صوت ارتطامها، أو

$$
\text { ه) اليضعها مع اللعب الأخرى في صف. }
$$

تعتبر كتابات "تمبل جراندن"، و"دنا ويليامس"، وغيرها وسيلة لفهم كيف يفكر الأشخاص المصابون بالذاتوية، حيث يظهر من خلال الكتابات اعتماد الأشخاص المصابين بالذاتوية على طريقة من التفكير تتميز بالتالي (في معظم الأحيان): التفكير بالصور ، وليس الكلمات. عرض الأفكار على شكل شريط فيديو في مخيلته، الأمر الذى يحتاج إلى بعض الوقت

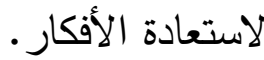

صعوبة في معالجة سلسلة طويلة من المعلومات الشفهية. صعوبة الاحتفاظ بمعلومة واحدة في تفكيرهم، أثناء محاولة معالجة معلومة أخرى. يتميزوا باستخدام قناة واحدة فقط من قنوات الإحساس في الوقت الواحد. لديهم صعوبة في تعميم الأشياء التي يدرسونها أو يعرفونها. لديهم صعوبات في عدم اتساق أو انتظام إدراكهم لبعض الأحاسيس(البطاينة، الجراح، $(0 \wedge \cdot: Y \cdot \cdot V$

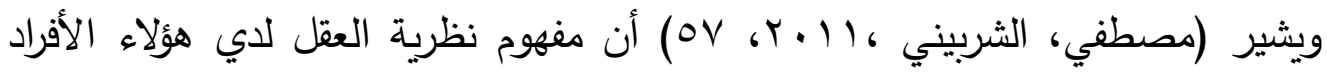
ظهر بواسطة "ولمان" Wellman (ب991) والتي تشير إلى أن الطفل الذاتوي غير قادر علي التنبؤ وشرح سلوكيات الآخرين من خلال حالاتهم العقلية، في حين نجد أن الأشخاص الأسوياء لديهم فهم خاص أو إحساس خاص يستطيعون من خلاله قراءة أفكار الآخرين. وبالتالي فالأطفال الذاتويين يعجزون عن التمييز بين ما هو موجود في عقولهم وما هو موجود في عقول الآخرين. ويشير (كحم، • ( •r: 109) إلي أن نظرية العقل أو المعرفة تختص في الأساس بتفسير ما يلي: 


\section{قصور أو تأخر مستوى النمو العقلي المعرفي. القصور في العمليات العقلية المعرفية.} القصور في الجانب الاجتماعي اعتماداً علي ما يحدث من قصور معرفي. القصور في أخذ دور أو منظور شخص آخر، وبالتالي القصور في إدراك النوايا والمشاعر والمعتقدات والرغبات سواء للشخص ذاته أو للغير القصور في قراءة الإشارات الاجتماعية المختلفة.

\section{ฯ) ضعف التواصل اللغوي (اللفظي وغير اللفظي):}

في كثير من حالات الذاتوية، يبدأ ظهور مؤشرات هذا القصور أو الاضطراب في النمو اللغوي مبكراً في حياة الطفل، وربما في الأشهر الثلاثة الأولى حيث يلاحظ الهدوء غير الطبيعي، وغياب المناغاة المعتادة عند الطفل السليم في هذه الفترة، وفى قلة أو توقف الأصوات التي يصدرها وفى مناسبتها للموقف ومعانيها بالنسبة إلى ما يطلبه أو يريده من أمه، فهي غالباً عشوائية عديمة المعنى لا تستهدف أي نوع من التواصل، بعكس الطفل

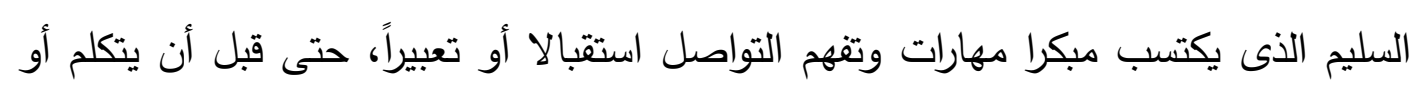

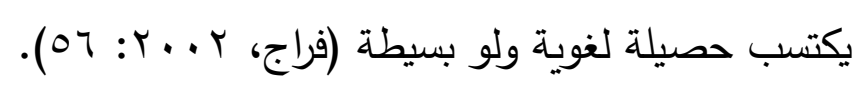

في حين يتضمن ضعف التواصل كلا من المهارات الثفهية واللاشفهية وقد لا توجد اللغة كلية، وعادة ما تتصف اللغة أثناء نموها بخصائص أهمها وجود تراكيب لغوية غير كاملة أو غير ناضجة، والمصاداة (ترديد الكلمة أو الجملة) فورية أو متأخرة، خلط الضمائر الشخصية، حديث شاذ وغير منتظم ولغة مضطربة بشكل متصل، وقد تقل مهارات التواصل غير اللفظي لديهح أو تغيب تماماً (مثل: الإيماءات، والتعبيرات الوجهية، والإشارات) أو تتدنى ولته إلى أقصى حد لها، أو تظهر في صورة اجتماعية غير لائقة ،وقد تكون طبقة الصوت أو نغدة الصوت أو معدل الكلام أو إيقاع الكلام أو الضغط على مخارج الألفاظ غير سوية 1227

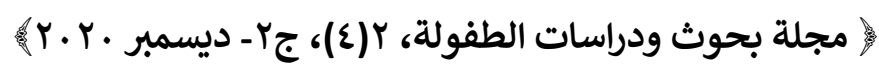




\section{كلية التربية للطفولة المبكرة- جامعة بني سويف}

فنغمة الصوت قد تكون رتيبة أو غير مناسبة للسياق، وتكون التراكيب النحوية غالبا غير ناضجة وتحتوى على استخدامات نمطية ومتكررة للغة كتكرار الكلمات أو العبارات دون الاعتبار للمعنى، وتكرار القوافي أو الإعلانات التجارية في التلفزيون، وغالبا ما يكون الفهر اللغوي متأخراً جداً وقد يظهر الطفل عجزاً ملحوظاً لفهم الأسئلة أو التوجيهات أو الدعابات البسيطة، والمعنى الساخر أو الضمني للجمل والعبارات (الرابطة الأمريكية للطب النفسي، $\cdot(r \leq r: r \cdot)$.

ويعتبر استخدام اللغة كأداة للتفاعل الاجتماعي أمراً صعباً بصفة خاصة بالنسبة لمعظم الأطفال الذاتويين، وإلي جانب ذلك فإننا نجد أنهح إذا ما اكتسبوا بعض المفردات اللغوية فإنهم قد يجدون صعوبة في استخدام مثل هذه المفردات في التفاعلات الاجتماعية المختلفة نظراً لأنهم لا يدركون ردود أفعال أولئك الأفراد الذي يستمعون إليهح (هالاهان، كوفمان، A . . r: ror). وفيما يتعلق باضطرابات اللغة فإن الأطفال الذاتويين يتسمون بعدد من السمات التي قد تميزهم دون سواهم من أهمها ما يلي: ضعف المحصول اللغوي لديهم بدرجة كبيرة. تدني مستوي التراكيب اللغوية من جانبهم. عدم القدرة علي استخدام تلك المفردات في إجراء محادثات مع غيرهم. عدم قدرتهم علي استخدام مفرداتهم اللغوية الاستخدام الأمثل. أن الطفل لا يستخدم معاني الكلمات كي تساعده علي استرجاع المعلومات. أن الطفل لا يستطيع أن يستخدم الكلمات التي لديه في سياقات مختلفة. الترديد المرضي للكلام المسموع Echolalia سواء كان ذلك ترديداً لمجرد كلمات فقط أو عبارات.

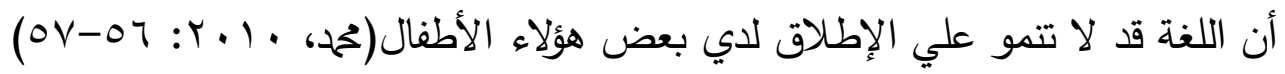
ثانياً: البروفيل النمائي لبرنامج التنمية الثاملة للطفولة المبكرة "بورتيج" 
نبذة عن برنامج التنمية الشاملة للطفولة المبكرة "بورتيج"

البرنامج المنزلي للتدخل المبكر لتثقيف أمهات الأطفال المعاقين من سن الولادة إلي

ست سنوات، يختص بالتخخل المبكر لتدريب الأطفال المعوقين داخل بيئتهم المحلية وخاصة بالمنزل وتدور فكرة البرنامج حول تزويد الأم خلال الزيارة المنزلية والتي تكون مرة بالأسبوع ومدتها ساعة بالأسس المتعلقة برعاية الطفولة والتعليم الخاص والمؤثرات الحسية التي تؤدي إلي تطوير المهارات العديدة للطفل المعاق. يتبع هذا البرنامج مشروع بورتيج المنزلي للتخخل المبكر الذي صمم في الولايات المتحدة عام 979 (، ويخدم البرنامج الأطفال ذوي الإعاقات المختلفة ومشاكل النطق والكلام وسوف يستخدم في هذا البحث كبرنامج للتخل المبكر

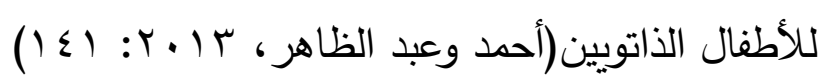

\section{تعريف برنامج "بورتيج"}

يعرف البرنامج بأنه مجموعة من الأنثطة، الألعاب والممارسات العلمية التي يقوم بها الطفل تحت إشراف وتوجيه من جانب المشرفة التي تعمل علي تزويده بالخبرات، المعلومات، المفاهيم، الاتجاهات وتدريبه علي أساليب التفكير السليم وحل المشكلات التي ترغبه في

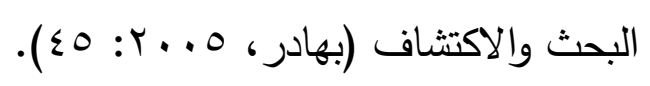

أهداف برنامج "بورتيج"

تقديم برنامج التأهيل المبكر داخل البيئة المألوفة للطفل وهي المنزل. الاكتثاف المبكر للإعاقة وذلك من خلال إجراء التقييم للأطفال ممن يعانون من مشاكل تتعلق بالنمو. الإشراك المباشر للأمهات والآباء في العملية التعليمية التدربية للطفل وتعد هذه وسيلة فعالة لتدريب الأطفال صغار السن. 


\section{كلية التربية للطفولة المبكرة- جامعة بني سويف}

تقديم مناهج تتلاءم والثقافة المحلية متضدنة موضوعات تغطي مرحلة الطفولة المبكرة والتعليم الخاص بالإضافة إلي التقييم المنتظم الذي يقيس النتائج ويزود المشرفين بالإطار المرجعي

$$
\text { للتعديلات المستقبلية. }
$$

تطبيق الخطوات العملية للبرنامج بدون أي موقف أو إرباك لترتيبات الحياة اليومية للأسرة. تحديد نقاط القوة والضعف لدي الطفل وذلك للمساعدة علي تصميم برنامج خاص لكل طفل مبنياً علي المعرفة الحالية للطفل وقدراته بالتعاون مع الأم.

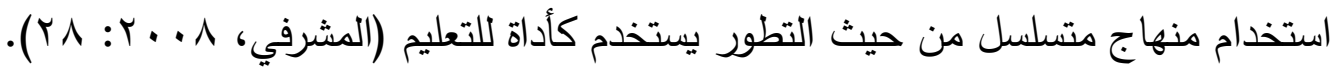
وصف برنامج "بورتيج: دليل بورتيج للتعليم المبكر هو أحد مكونات نموذج تقديم الخدمة، والتي يثير إليها نموذج بورتيج وقد صمم نموذج بورتيج للأطفال ذوي الإعاقات بمختلف أنواعها والذين تقع أعمارهم بين الميلاد وسن السادسة وكذلك لأسر هؤلاء الأطفال، وهذا النموذج فعال أيضا مع الأطفال متأخري النمو، أو منخفي المستوي الاقتصادي والاجتماعي، أو المعرضين للأخطار.

ويمكن تقديم الخدمة لهؤلاء الأطفال في أشكال متعددة تشمل برامج الطفولة المبكرة العامة والخاصة مثل برنامج لنبدأ سوياً "ايفن ستارت"EVEN START، برنامج البدء مبكراً "هيد ستارت" HEAD START وبرنامج ما قبل المدرسة، أو برنامج ما قبل رياض الأطفال، أو مراكز الرعاية النهارية DAY CARE وغيرها. ويسعي نموذج بورتيج لتحقيق التكامل بين مدخل النظم الأسرية وبين التتخل الخاص بعلاج طفل يوجد في بيئة معيقة لتطوره ويتشكل هذا النموذج من أربعة مبادئ رئيسة: • أن الأسرة هي التي توجه عملية التدخل. أن جوهر عملية التّخل هو التفاعل بين الوالدين والطفل. 
أن النظام اليومي، وعادات الأسرة، واللعب تشكل أنماط حياة الأسرة، وهي الوسيط الذي يتم

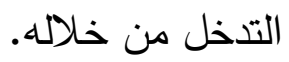

أن تسجيل الملاحظات والحوارات الدائرة بين الوالدين وفريق العمل، هو أساس القرارات التي تتخذ في عملية التخخل.

\section{العناصر الأساسية في برنامج "بورتيج"}

هناك ستة عناصر أساسية لنموذج بورتيج، سيتم عرض كل منها فيما يلي:

( ) مملية التشخيص

يشتمل نموذج بورتيج علي جهود مكثفة لتعريف مؤسسات المجتمع المحلي ببرنامج التخل وتقوم كل مؤسسة بوضع محكات نجاحها علي أساس طبيعة المجتمع الذي تخدمه والأنظمة السائدة، شروط مصادر التمويل وعدد الأسر التي يمكن تقديم الخدمة إليها.

\section{r التقييم البيئي الأيكولوجي}

التقييم هو جوهر عملية النشاط من بدايتها إلى نهايتها، فهو يهدف إلى اكتثاف نقاط القوة وأنواع الحاجات التي تنقص الطفل وأسرته، وبذلك فهو يهدف إلى إعادة برنامج للتدخل، خاص بكل أسرة على حدة، وقد تشمل استراتيجيات التدخل حوارات غير رسمية مع الأسرة، كملاحظة واستخدام أدوات التقييم المطبوعة أو القوائم الإنمائية، ويمكن استخدام نتائج تقييم الطفل والتي قامت على أساس التقييم الإنمائي - مثل دليل بورتيج للتعليم المبكر - في تخطيط الأنشطة اليومية التي تهدف إلى دعم نمو الطفل، وتتم جميع أنواع التقييم بالمشاركة التامة من الوالدين؛ وذلك بهدف الاستفادة من معلوماتهم عن طفلهم وأسرته ولضمان أن تتم هذه الأنشطة بتوجيه من الأسرة، ويشمل التقييم الأيكولوجي كذلك التوصل إلى معرفة بالمصادر المتاحة في المجتمع المحلي لمساعدة الأسرة. 
ب) التخطيط البيئي الأيكولوجي

يتم تتظيم المعلومات التي حصلنا عليها في عملية التقييم في شكل خطة لتقديم الخدمة، وقد تأخذ هذه الخطة شكل خطة لخدمة أسرة واحدة أي خطة للعمل في أسرة معينة، وقد تأخذ شكل أداة للتخطيط في برنامج معين، وتتضمن كل الخطط أهدافا بعيدة، وأهدافا قربية، وتتابعا للاستراتيجيات الهادفة لتحقيق هذه الأهداف، وبصرف النظر عن الثكل أو التظيم المستخدم، فالنقطة الأكثر أهمية هي أن تطوير الخطة يتم بتوجيه من الأسرة، ويقوم على أساس النقاط ذات الأهمية بالنسبة لهم.

؛ ( - (التدخل الأيكولوجي

يتضمن نموذج بورتيج مكونات عديدة لا يمكن تتفيذها في ظروف متتوعة، ومع ذلك فهو يستخدم غالبا كجزء من برنامج الزيارات المنزلية، وقد تختلف الزيارات المنزلية في مدتها وعددها من برنامج إلى أخر، لكن نموذج بورتيج يتضمن في العادة زيارة أسبوعية مدتها ساعة ونصف، وخلال هذه الزيارة تعمل الزائرة المنزلية مع الوالدة أو القائم على تقديم الخدمة معا على تخطيط وتتفيذ استراتيجية التعامل مع الحاجات الخاصة للطفل والأسرة كما تراها الأسرة، وكما سبق تحديدها في الخطة الفردية.

•) دعم الأنثطة القائمة

يعتبر الاتصال بين الزائرة والأسرة محدودا في أغلب البرامج، وذلك لأن الزائرة المنزلية تعمل مع كل أسرة لمعاونتها في تطوير استراتيجيتها الحالية وتحقيق أهدافها، وتقوم الأسرة بتنفيذ هذه الاستراتيجية التي في الفترة بين الزيارة والزيارة التالية، وقد يشمل ذلك اقتراحات بإدماج عمليات الإرشاد الهادفة إلى تتمية قدرات الطفل في الروتين اليومي للأسرة، وفي أنشطة اللعب، وفي جماعات اللعب التي تضم الوالدين والأطفال ذوي اضطراب الذاتوية، أو في أنشطة الأسرة الأخرى، وربط ذلك بشبكة المساعدات المقدمة للوالدين. 
ד) الإثراف وتقييم النتائج

تظهر أنشطة الطفل والأسرة ذات العلاقة ببرنامج المساعدة خلا برنامج التعليم الفردي، أو برنامج خدمة الأسرة الواحدة، أو من خلال برامج أخرى، ويتم توثيق الأنشطة من خلال الاتصال الأسبوعي وسجلات الملاحظة، ويتم تقييم الطفل من خلال الاستفادة بالكتيب الحالي دليل برنامج التتمية الثاملة للطفولة المبكرة "بورتيج" كمرجع، ويتم استكمال التقييم سنويا لمراجعة برامج التعليم الفردي، وخدمات الأسرة المتفردة ويتم قياس درجة رضا الوالدين والمجتمع المحلي عن خدمات البرنامج من خلال استبيانات في نهاية العام (وزارة التربية والتعليم، V +. r.ب: צ- • (1).

سادساً: طريقة استخدام قائمة المراجعة في برنامج "بورتيج"

تتكون قائمة المراجعة من خمسة مجالات إنمائية بالإضافة إلى قسم عن نمو الرضيع، ولا يعني تقسيم هذه المجالات إن كلا منها مستقل عن الأخر .بل إن التذاخل ضروري بين جميع هذه المجالات، والسلوكيات التي قد تتكرر في أكثر من مجال للنمو تقيد باعتبارها تبين الاستعداد، أو المتطلبات المهارية الضرورية لقيام الطفل بالسلوك في المجال الآخر للنمو. وقد تم تمييز جوانب النمو في القائمة بألوان مختلفة تتقق كل منها مع اللون المميز لبطاقة الأنشطة. وفيما يلي وصف لجوانب النمو الخمسة

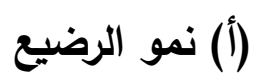

يقدم القسم الخاص بنمو الرضيع أنشطة مقترحة بهدف مساندة وتثجيع نمو الطفل خلال الثهور الأولى من حياته، فالرضيع يحتاج إلى مثيرات بيئية ذات معنى، قبل أن تتوقع استجابة لهذه البيئة، لذلك نجد أن الكثير من الفقرات المذكورة في القائمة هي أنشطة يقوم بها الوالدان، أو الزائرة المنزلية مع الطفل، ولا تحتاج بالضرورة إلى استجابة من الطفل، في نفس 


\section{كلية التربية للطفولة المبكرة- جامعة بني سويف}

الوقت فكلما زادت قوة التفاعل بين الوالدين والطفل، وكلما زادت الأنشطة التي يبدئ بها

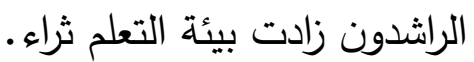

\section{(ب) (بنتئة الاجتماعية}

مهارات التتشئة الاجتماعية هي السلوكيات التي تثمل الحياة مع الآخرين والتفاعل معهم، وخلال سنوات ما قبل المدرسة تتعكس السلوكيات الاجتماعية في الطريقة التي يلعب بها الأطفال، ويعملون بها مع والديهم وإخوانهم وزملائهم في اللعب، وتساعد تتمية مهارات

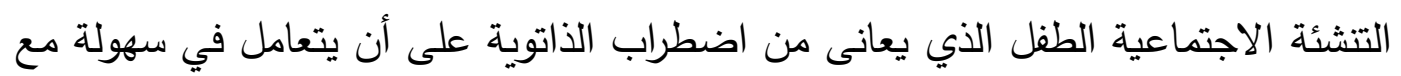

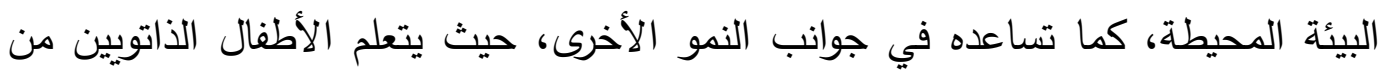
خلال التقليد والمشاركة والاتصال جميع المهارات الاجتماعية الأساسية، وكلما نمت مهارة التتشئة لاى الطفل فإنه يكتثف أنه يؤثر في بيئته، ويتم ذلك من خلال التفاعل الاجتماعي الملائم لظهور وتقوية السلوك في كافة الجوانب الأخرى للنمو.

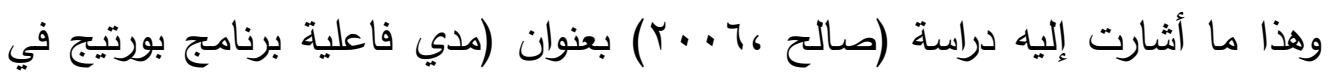
تتمية الجوانب الاجتماعية لطفل ما قبل المدرسة) حيث هدفت الدراسة إلي قياس دور برنامج البورتيج في النمو الاجتماعي لاي أطفال ما قبل الددرسة وقد تكونت عينة الدراسة من (VY) طفلاً وطفلة تتزاوح أعمارهم ما بين (ع-7) سنوات، وقد استخدمت الدراسة الأدوات التالية (برنامج التتمية الثاملة للطفولة المبكرة "بورتيج"- اختبار ذكاء الأطفال- بطارية اختبار بعض جوانب النمو لأطفال الروضة) وقد توصلت نتائج الدراسة إلي وجود فروق ذات دلالة إحصائية بين متوسطات درجات أطفال المجموعة التجريبية في النمو الاجتماعي قبل وبعد

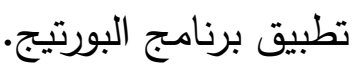


(ج) النمو اللغوي

نمو اللغة هو أحد أهم ما يحققه الطفل منذ ميلاده وحتى سن السادسة، حيث يتطور الطفل في هذه الفترة من الجهل التام باللغة إلى معرفة تقليد الكبار، ورغم تباين معدلات

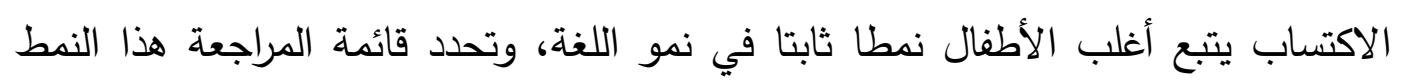
الإنمائي الثابت، هذا ولا تحدد قائمة المراجعة المفردات التي يكتسبها الطفل بقدر ما تركز

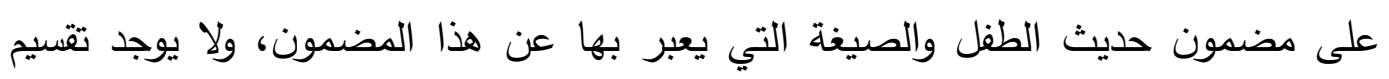
للمهارات اللغوية بين مهارات التعبير ومهارات التلقي رغم أن كليهما موجود في القائمة

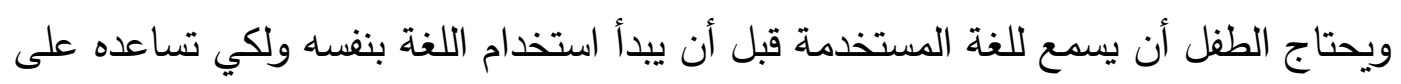

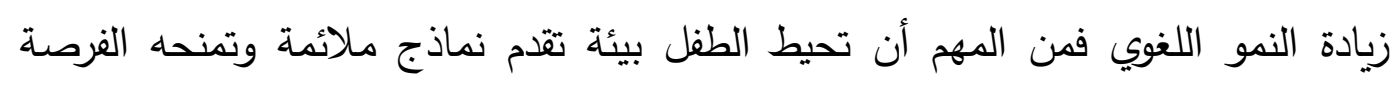
والدافعية لاستخدام اللغة. والطفل الذي يتوقع دائما المحيطون به حاجات ويقومون بتلبيتها

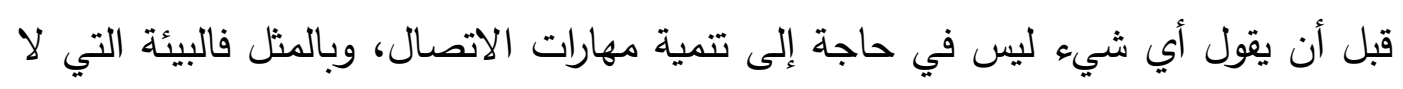

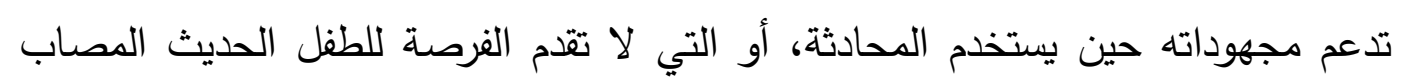

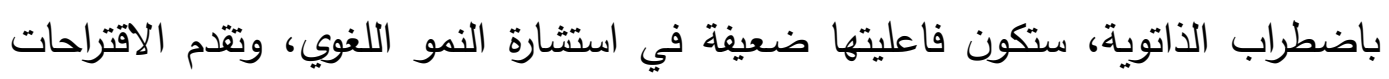
الواردة في قسم اللغة إرشادات لإنشاء بيئة تساند وتثجيع النمو اللغوي.

(د) مساعدة الذات

تركز فئة مساعدة الذات على السلوكيات التي تساعد الطفل الذاتوي على أن يصبح

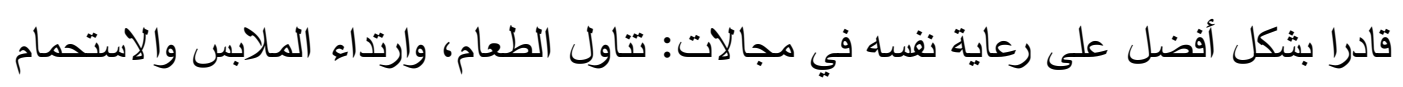
واستخدام دورات المياه، وقد تظهر هذه السلوكيات ضمن مجال التتشئة الاجتماعية لأن

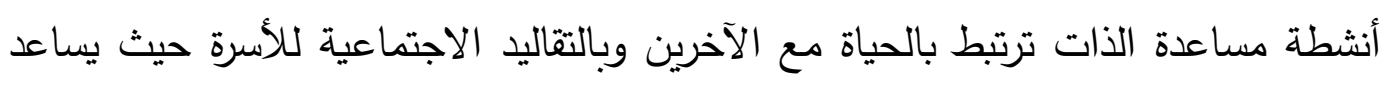
نمو سلوكيات مساعدة الذات الطفل في جهوده ليصبح عضوا سعيدا مستقلا في الأسرة والمجتمع وتتبع السلوكيات المذكورة في هذا الجانب بشان الجوانب الأخرى نمطا إنمائيا 


\section{كلية التربية للطفولة المبكرة- جامعة بني سويف}

متسلسلا وقد تم ترتيب هذه السلسلة على أساس الخطوات الملائمة في تنمية سلوك معين على ضوء المستوى الحالي للطفل في الفهم والقدرة.

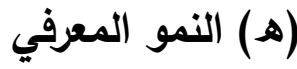

تشمل المعرفة أو التفكير على التذكر وعلى الرؤية أو الاستماع لأوجه التشابه والاختلاف وعلى تحديد العلاقات بين الأفكار والأشياء وعلى حل المشكلات، حيث تتم العمليات المعرفية داخل الطفل الذاتوي وعلى ذلك فان ما يمكن قياسه منها يبني على ما يقوله أو يعمله. وتقوم الذاكرة بتخزين المعلومات للتعرف عليها أو إعادتها، ويتذكر الطفل ويسهى الموضوعات والصور والأشكال والرموز (مثل إثارات المرور) قبل أن يتمكن من تحديد الحروف والكلمات وتشمل الناحية المعرفية في هذا الدليل أنشطة تتراوح فيما بين بداية الوعي بالذات والجو الملائم لتنمية الوعي بعدد من المفاهيم وتكرار القصص وإجراء المقارنات.

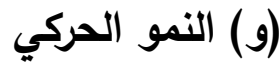

يهتم المجال الحركي بالحركات التآزرية للعضلات الكبيرة والصغيرة بالجسم والتي يشار إليها بالمهارات الحركية الكبرى ومن أمثلة الحركات الكبرى الجلوس والزحف والمشي والجري وإلقاء الكرة، أما المهارات الحركية الدقيقة فهي حركة العضلات الدقيقة والتي تعتبر أحيانا تحسينات على المهارات الحركية الكبرى وإصقالها مثال على ذلك تغير السلوك الذي يقوم به الطفل من الضرب العشوائي العنيف على الأشياء الصغيرة إلى توجيه اليد ككل للإمساك بها، وأخيرا استخدام الأصابع في الإمساك بهذه الأشياء، وهذه المهارة في استخدام الأصابع للإمساك بالأشياء هي مهارة حركية دقيقة هامة، وهي من المتطلبات الأساسية للعديد من المهام مثل استخدام القلم وتجميع أجزاء الصورة والمهارات السلوكية الحركية. (وزارة التربية

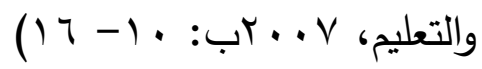


سابعاً: طريقة استخام بطاقات الأنثطة

بعد تحديد السلوك أو المهارة المطلوب التركيز عليها، نستخدم بطاقة الأنثطة التي

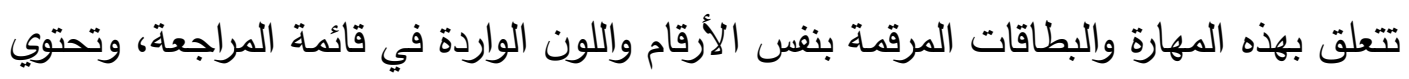

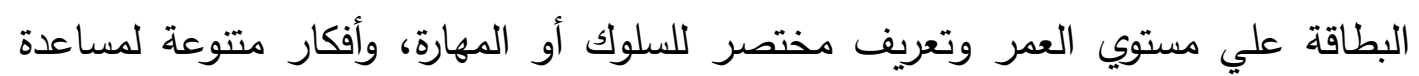
الطفل علي تنمية المهارة. وهذه الأفكار مجرد مقترحات ويمكن للأم أو للمعلمة أن يكون لديهما أفكار لاكتساب

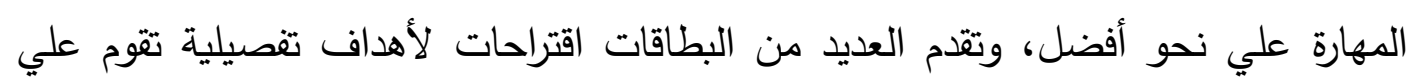

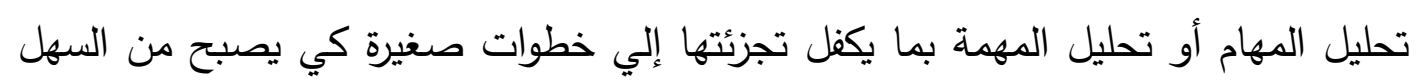

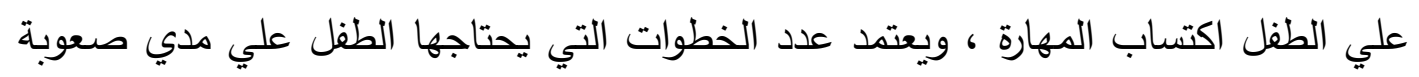

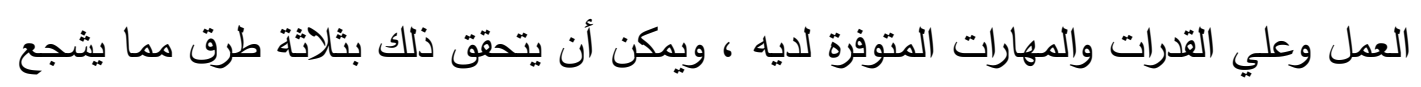

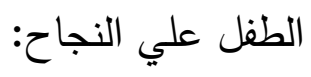

تغيير مستوي صعوبة المهمة. تعديل المواد المستخدمة في المهمة. تغيير نوع أو مقدار المساعدة التي يقدمها الكبار. قد تكون المساعدة محسوسة أو تكون مرئية أو لفظية. (وزارة التربية والتعليم، $(\wedge:$ r...v

ثامناً: دور الوالدين في تطبيق برامج التذخل المبكر للأطفال ذوي اضطراب الذاتوية إن والدي الطفل الذاتوي هما الطبيب الحقيقي الدعالج لطفلهم، فهم يلعبون دوراً هاماً

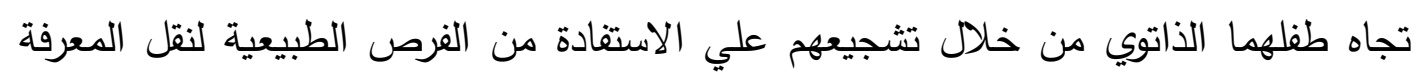

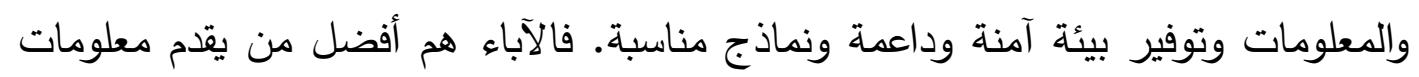

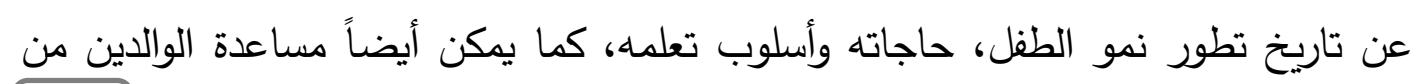
1237

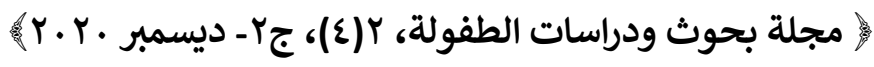




\section{كلية التربية للطفولة المبكرة- جامعة بني سويف}

خلال تعليمهم استخدام الأساليب التعليمية الفعالة مع طفلهما الذاتوي، كيفية ضبط مشكلاته السلوكية وتطوير مهاراته في المنزل، ولذلك فإن مشاركة الوالدان في برامج الطفل الذاتوي ووضع الأهداف التربوية والتدريبية له في الخطة التربوية والفردية؛ تعد ضرورة هامة في

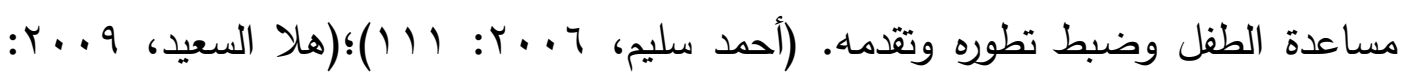

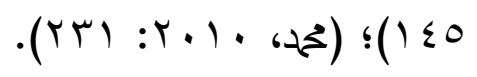

ومن بين الدراسات التي تتاولت استخدام البروفيل النمائي لبرنامج البورتيج في تقييم وتشخيص حالات اضطراب طيف الذاتوية نجد دراسة (2012, Reale) والتي هدفت إلى التحقق من كفاءة تطبيق البروفيل النمائي لبرنامج البورتيج في التشخيص الوظيفي لاضطرابات الذاتوية بين الأطفال الصغار • حيث طُبق البروفيل النمائي للبورتيج على عينة مكونة من با من الأطفال الذين يحملون أعراض الذاتوية في سن ما قبل المدرسة ممن تتراوح أعمارهم ما بين ب سنوات وعشر شهور إلى آسنوات وعشر شهور بأحد المراكز التأهيلية في جنوب أفريقيا. حيث أظهرت الدراسة نتائج إيجابية من خلال تطبيق البروفيل النمائي للبورتيج في التثخيص الوظيفي للذاتوية، وإمكانية الاستفادة منها والوصول بها إلى أقصى درجة متوقعة للنمو بالنسبة للأطفال الذاتويين في فترات الطفولة المبكرة. وفي دراسة (Mandy,Charman,Gilmur\&Skuse,2012) والتى هدفت إلى فحص كفاءة استخدام البروفيل النمائي لبرنامج البورتيج في تشخيص اضطرابات النمو الثامل غير المحدد للأطفال الصغار في سن ما قبل المدرسة، وتكونت عينة البحث من (7) مراكز لرعاية الأطفال ذوي الإعاقات النمائية التي تقوم بتأهيل (؟乏 ) ) طفل وطفلة من سن ما قبل المدرسة و كانت تلك المراكز تعتمد على تطبيق البروفيل النمائي لبرنامج بورتيج في تشخيص ودعم جوانب النمو للأطفال. وقد شارك في البحث مجموعة من آباء وأمهات الأطفال، حيث أشارت النتائج إلى فاعلية استخدام البروفيل النمائي لبرنامج البورتيج كأداة تشخيصية للاضطرابات النمائية غير المحددة بين الأطفال الصغار من خلال التحليل 


\section{كلية التربية للطفولة المبكرة- جامعة بني سويف}

والأوزان النسبية عبر المقاييس الفرعية لمقياس الكفاءة التشخيصية للبروفيل النمائي لبرنامج البورتيج.

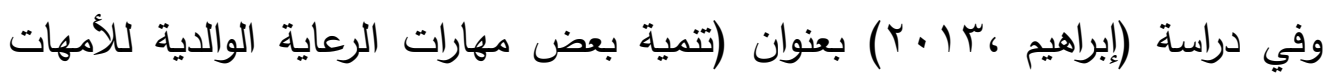
لخفض أعراض الذاتوية لدي أبنائهن) حيث هدفت الدراسة إلي معرفة ما مدي فاعلية برنامج لتتمية بعض مهارات الرعاية الوالدية للأمهات لخفض أعراض الذاتوية لاي أبنائهن، كذلك الكثف عن مستويات الرعاية الوالدية لدي أمهات الأطفال الذاتويين وكذلك محاولة رفع كفاءة العلاقة بين الأم والطفل بما يحقق جواً نفسياً ملائماً لنمو الطفل، وتكونت عينة الدراسة من (^) أمهات لأطفال ذاتوين، استخدمت الدراسة الأدوات التالية (مقياس الطفل التوحديمقياس جيليام لتشخيص التوحد- مقياس الرعاية الوالدية للطفل الذاتوي- مقياس السلوك التوافقي- برنامج لتنمية مهارات الرعاية الوالدية) وقد أظهرت نتائج الدراسة كفاءة البرنامج المستخدم فى تتمية بعض مهارات الرعاية الوالدية للأمهات في خفض بعض أعراض الذاتوية لدي أبنائهن.

وفي دراسة (2014, Layton\&Hao) التى هدفت إلى فحص فاعلية الخصائص التشخيصية لبرنامج البورتيج في التثييم المبكر للذاتوية بين الأطفال الصغار في أستراليا، وتكونت عينة البحث من (·r ) طفل تظهر عليهم مؤشرات الذاتوية في مركز لرعاية الطفل شرق أستراليا. حيث تم تقسيم الأطفال إلى مجموعتين متساويتين: مجموعة تجريبية (تمبية تشخيصها عبر المشاركة في برنامج البورتيج) وأخرى ضابطة (تم تشخيصها بأساليب تقليدية)، وقد أظهرت النتائج توافق السمات التشخيصية للبروفيل النمائي لبرنامج البورتيج مع تقييم اضطراب الذاتوية بين الأطفال الصغار . ودراسة (Attama,Uwakwe,Onyeama,\&lgwa,2015) حيث هدفت إلى بحث كفاءة استخدام البروفيل النمائي لبرنامج البورتيج مع كل من الأطفال الذاتويين وذوي الإعاقات النمائية الأخرى في جنوب شرق نيجيريا، وتكونت عينة البحث من (7ه) طفل 


\section{كلية التربية للطفولة المبكرة- جامعة بني سويف}

ذاتوي و(9 (1) من ذوي الإعاقات النمائية الأخرى، وأظهرت النتائج أن جوانب التشابه في نسبة( ^^\%) من حالات استخدام اختبارات البروفيل النفي للبورتيج مع كل من الأطفال الذاتويين وذوي الإعاقات النمائية الأخرى. من خلال عرض الإطار النظري للاراسة والدراسات السابقة ذات الصلة، يمكن للباحثة توضيح الآتي:

ا . أن البروفيل النمائي لبرنامج البورتيج يمكن أن يستخدم في التقييم والتشخيص لحالات اضطراب طيف التوحد، حيث يشمل البروفيل جميع جوانب النمو الخاصة بالطفل كالتنشئة الاجتماعية، النمو اللغوي، مساعدة الذات، النمو المعرفي والنمو الحركي، كما أنه يغطي جميع المستويات العمرية من سن الرضاعة وحتي ست سنوات ، وهذا ما يجعل البرنامج مستمر مع الطفل لفترة طويلة. r. أن البروفيل النمائي لبرنامج البورتيج قائم علي التكامل والتعاون بين الوالدين ومقدم البرنامج بداية من عملية التقييم ووضع الخطة، الأهداف وحتي تطبيق الأنشطة والمهام التي يحتاجها الطفل فبرنامج "بورتيج" من برامج التدخل المبكر التي تعتمد بشكل أساسي علي

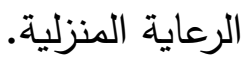

r. أن البرنامج يراعي الفروق الفردية بين الأطفال إذ أن الأفكار والأنشطة المتضمنة في برنامج "بورتيج" هي مجرد اقتراحات ونقطة بدء للمناقثة بين الوالدين والأخصائي لأفكار وأنشطة أخري تتاسب أولويات الأسرة، مصادرها، اهتماماتها وأسلوب حياتها.

\section{فروض الدراسة}

توجد فروق ذات دلالة إحصائية بين متوسطات رتب درجات حالات الأطفال

ذوي الاضطرابات النمائية (الأطفال الذاتويين منخفضي الأداء الوظيفي والأطفال الذاتويين مرتفعي الأداء الوظيفي) على مقياس البروفيل النمائي للبورتيج وذلك 
بالنسبة لتقييم المجالات النمائية المختلفة في اتجاه الأطفال الذاتويين مرتفعي الأداء الوظيفي.

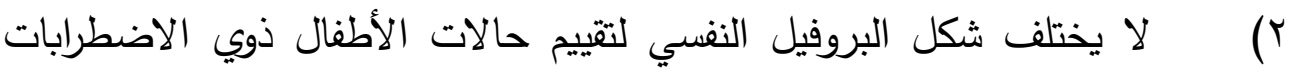
النمائية (الأطفال الذاتويين منخفي الأداء الوظيفي والأطفال الذاتويين مرتفعي لألئي

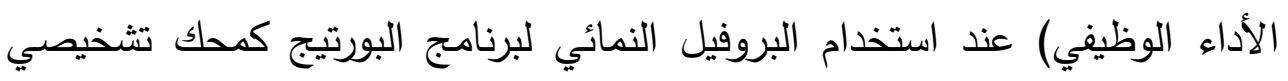
وتقييمي للمجالات النمائية المختلفة.

\section{منهج اللدراسة وإجراءاتها

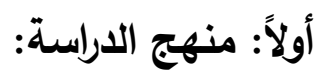

تهذف الدراسة الحالية إلي التثخيص الفارق باستخدام البروفيل النمائي لبرنامج البورتيج

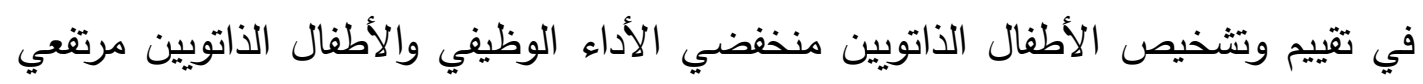

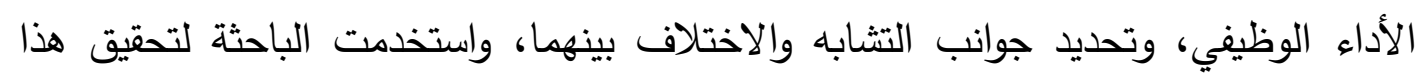
الهدف المنهج الوصفي.

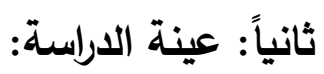

تكونت عينة الدراسة من (·r) طفل وطفلة من الأطفال ذوى اضطرابات الذاتوية مقسمين إلى:

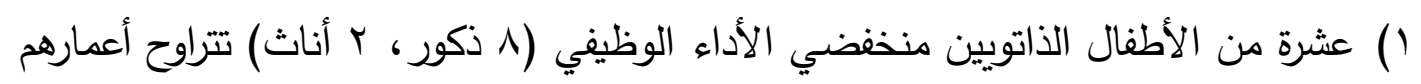
ما بين (Y V V Vنوات) من الأطفال المترددين على مركز المثالى للصحة النفسية .

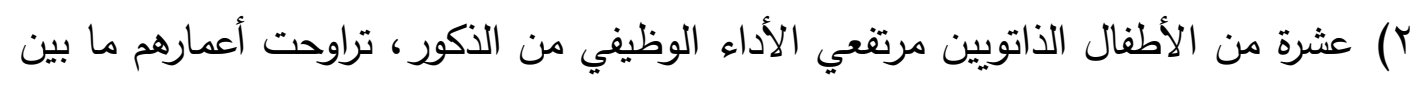

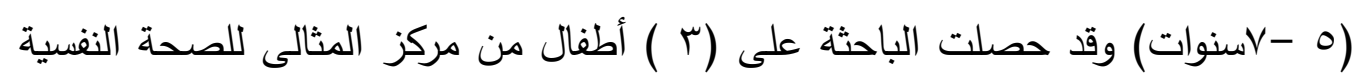
و(V) من مركز التأهيل المهنى التابع لجمعية الرعاية المتكاملة بحى وسط الإسكندرية. 


\section{كلية التربية للطفولة المبكرة- جامعة بني سويف}

وقامت الباحثة باختيار مركز المثالى للصحة النفسية ومركز التأهيل المهنى حيث يتوفر به عينات كافية من الأطفال ذوي الاحتياجات الخاصة والأطفال الذاتويين منخفضي الأداء الوظيفي والأطفال الذاتويين مرتفعي الأداء الوظيفي خاصة في نفس المرحلة العمرية، كما وجدت الباحثة تعاون ملموس من جميع العاملين وتوفير معظم الإمكانات التي ساعدت الباحثة علي سير إجراءات التطبيق وإتاحة مكان لتطبيق الأدوات.

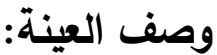

() من حيث السن: راعت الباحثة أن تمثل عينة الدراسة الفئة العمرية التي تقع ما بين (0-

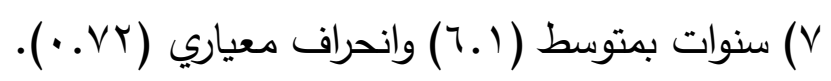

r) من حيث الجنس: ضمت العينة في الدراسة (• ( طفل ذاتوي منخفضي الأداء الوظيفي) مقسمين إلى (^) أطفال من الذكور و(r) من الإناث من الأطفال ذوى اضطراب الذاتوية. و( • أطفال ذكور من الذاتويين مرتفعي الأداء الوظيفي). r) تقدير درجة الذاتوية للأطفال الذاتويين منخفي الأداء الوظيفي والأطفال الذاتويين مرتغعي الأداء الوظيفي: حيث تضنمت عينة الدراسة الأطفال ذوى اضطراب الذاتوية منخفي الأداء الوظيفي بدرجة ذاتوية (•^-.9) بعد تطبيق مقياس جيليام للذاتوية،

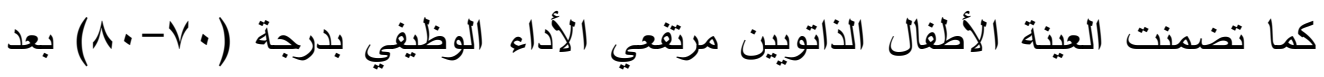

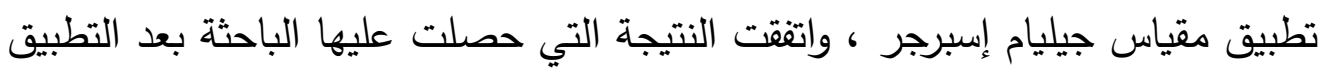
مع نتيجة الأخصائي النفسي بالمركز .

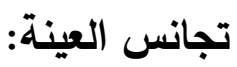
قامت الباحثة بإيجاد دلالة الفروق بين متوسطات درجات أطفال الذاتويين عينة الدراسة من حيث (العمر الزمني - درجة الذاتوية) كما يتضح في الجدول التالي: 


\section{كلية التربية للطفولة المبكرة- جامعة بني سويف}

جدول (飞)

دلالة الفروق بين أفراد العينة من حيث العمر الزمني ودرجة الذاتوية (ن= • ()

\begin{tabular}{|c|c|c|}
\hline الدلالة & كا' & لمتغيرات \\
\hline غير دالة & $\cdot . \wedge 1$ & لعمر الزمني \\
\hline غير دالة & $1 . .9$ & ربرجة الذاتوية \\
\hline
\end{tabular}

يتضح من جدول (ع) عدم وجود فروق دالة إحصائيا بين متوسطات رتب درجات

أطفال الذاتويين من حيث العمر الزمنى ودرجة الذاتوية مما يشير إلى تجانس أطفال هؤلاء المجموعة. كما قامت الباحثة بإيجاد التجانس بين عينة الأطفال الذاتويين مرتفعي الأداء

الوظيفي من حيث العمر الزمنى ودرجة الذاتوية كما يتضح من الجدول رقم (0)

$$
\text { جدول (0) }
$$

دلالة الفروق بين أفراد العينة من حيث العمر الزمني ودرجة الإسبرجر حيث (ن= • (1)

\begin{tabular}{|c|c|c|}
\hline الدلالة & كا' & المتغيرات \\
\hline غير دالة & 1.04 & العمر الزمني \\
\hline غير دالة & r.T & درجة الإسبرجر \\
\hline
\end{tabular}

يتضح من جدول (0) عدم وجود فروق دالة إحصائيا بين متوسطات رتب درجات الأطفال الذاتويين من حيث العمر الزمنى ودرجة الذاتوية مما يشير إلى تجانس أطفال هؤلاء

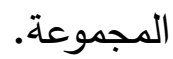

ثالثًا: أدوات الدراسةة: - م

تتمثل أدوات الدراسة في:

مقياس جيليام لتقدير الذاتوية (ترجمة وتعربب: عادل عبد الله، 7 ـ ب).

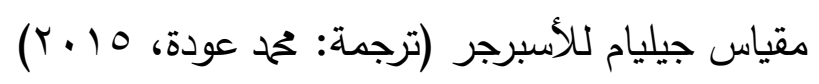

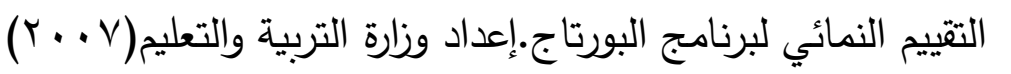




\section{كلية التربية للطفولة المبكرة- جامعة بني سويف}

(أ) مقياس جيليام لتقدير درجة الأتوية (تعريب: عادل عبدالله، 19 ـ ب)

صدم المقياس وقام بإعداده (James E. Gilliam,1995) كأداة عالية الثبات من أجل تشخيص الأشخاص الذاتويين، والذى يمثل الهدف الأساسي للمقياس، كما يوجد أهدافًا أخرى أشار إليها (Gilliam,1995) تتمثل في:

تقييم حالة الأفراد الذين تصدر عنهم مشكلات سلوكية خطيرة.

تحديد وتقييم مدى التطور أو التقدم الذى يمكن أن يطرأ على حالة الطفل الذاتوي أثر

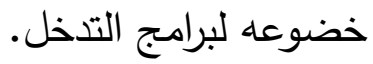

المساهمة الفاعلة في إعداد وتقديم خطة التعليم الفردية التي يتم تقديمها للطفل علي

أثر تشخيصه على أنه ذاتوي.

تقدير درجة ونسبة الذاتوية في البرامج والبحوث المختلفة.

ويتميز المقياس بعديد من الخصائص تتلخص في:

وجود (Y ( ) عبارة مقسمة إلى ثلاثة مقاييس فرعية تصف سلوكيات محددة من جانب

الطفل تعد في ذات الوقت سلوكيات ملاحظة توجد لديه ويتم قياسها على أثر ذلك.

وجود (ع () عبارة إضافية تخص الوالدين في سبيل جمع البيانات حول نمو الطفل

خلال السنوات الثلاث الأولى من عمره.

ترتكز العبارات في الأساس على التعريفات الحديثة للذاتوية ومعايير (DSM4).

تم استخراج معايير للمقياس على أثر تطبيقه على عينة (Y • ( ) ممن يعانون من

الذاتوية في (7 §) ولاية بالولايات المتحدة الأمريكية وكولومبيا وكندا.

يمكن أن يقوم المعلمون أو الوالدان بالاستجابة لبنود المقياس وإكمالها.

يتمتع المقياس بمعدلات صدق وثبات عالية يمكن الاعتداد بها.

يمكن تطبيق المقياس على الأفراد في المدى العدرى (r-Yr) عام وتستغرق الإجابة عليه ما بين (0- • ( ) دقائق تقربيًا. 
توافر دراجات معيارية ونسب أو رتب مئوية خاصة بهذا المقياس.

عن طريق المقياس يمكن تحديد احتمال تعرض الطفل لاضطراب التوحد والتعرف

$$
\text { على مدى حدة هذا الاضطراب لديه. }
$$

يعتبر كل مقياس فرعى من المقاييس الأربعة هو اختبار مستقلا في ذاته، يمكن أن يتم تطبيقه بمغرده أو دون سواه في البحوث المختلفة وذلك وفقًا لأهداف كل بحث. وصف المقياس:

يضم المقياس أربعة مقاييس فرعية يتألف كل منها من (ع ا ) عبارة ليصل بذلك إجمالي عدد عبارته (70) عبارة، وتصف العبارات التي يتضمنها كل مقياس فرعى الأعراض المرتبطة باضطراب الذاتوية: المقياس الفرعي الأول "السلوكيات النمطية": يضم العبارات الأبع عشر الأولى أي العبارات من (1-1) وجميعها تصف ما يصدر عن الطفل من سلوكيات نمطية، واضطرابات الحركة، وغيرها من الاضطرابات الأخرى الغريبة والفردية التي يمكن أن يتعرض مل الطفل لها.

المقياس الفرعي الثاني "التواصل": يضم العبارات الأربع عشر الثانية أي العبارات من (10-10) والتي تصف جميعها السلوكيات اللفظية وغير اللفظية التي تمثل أعراضا لاضطراب الذاتوية.

المقياس الفرعي الثالث "التفاعل الاجتماعي": ويضم العبارات من (qr-r ؛ ) والتي تعمل جميعًا على تقييم قدرة الطفل على أن يتفاعل بشكل ملائم مع الأفراد والأشياء والأحداث.

المقياس الفرعي الرابع " الاضطرابات النمائية": وتضم العبارات من (rع-1ه) ويتناول أسئلة هامة وأساسية عن نمو الطفل خلال طفولته المبكرة. 


\section{كلية التربية للطفولة المبكرة- جامعة بني سويف}

\section{تطبيق المقياس وتصحيحه:}

يتم تطبيق المقياس من خلال الآباء والمعلمين أو القائمين على رعاية الطفل وذلك في ضوء ملاحظتهم لما يصدر عنه من سلوكيات، علما بأنه لا توجد إجابه صحيحة وأخرى خاطئة لكن المهم أن تعبر كل عبارة بصدق ودقة عما يصدر عنه من سلوكيات، ومن ثم يجب أن تتم الإجابة عن جميع العبارات المتضمنة، وإذا كان هناك شك حول إحدى العبارات يتم تأجيلها للنهاية حتى تتم الملاحظة ، ويلاحظ الطفل لفترة زمنية مدتها ج ساعات لكى يستطيع تحديد الدرجة أو القيمة المناسبة للسلوك. وفيما يتعلق بالمقاييس الفرعية الثلاثة الأولى فإنه توجد أربعة اختيارات أمام كل عبارة (نعم، أحياناً، نادراً، لا) تحصل على الدرجات (ب- r- 1- صفر) على التوالي، أما عن كيفية تحديد الاستجابات فإنها تتم وفقاً لما يلى: يدل الاختيار (لا) علي عدم ملاحظته للطفل يأتي بمثل هذا السلوك. يدل الاختيار (نادرا) على أن الطفل يأتي بالسلوك نفسه ما بين مرة واحدة إلى اثثين في غضون ست ساعات. يدل الاختيار (أحيانا) على أن الطفل يأتي بذات السلوك ما بين (ب-§) مرات كل ست ساعات. يدل الاختيار ( نعم) على أن الطفل يأتي بذات السلوك لعدد من المرات يتراوح على الأقل بين (0- 7) مرات كل ست ساعات.

وعلي هذا يقوم الفاحص بوضع علامة صح أمام العبارة في الخانة التي يرى أنها تعبر بدقة عن سلوك الطفل، ووفقًا لذلك فإن درجة كل مقياس فرعى تتراوح ما بين (صفر - r ع) درجة، وتدل الدرجة المرتفعة على زيادة احتمال وجود اضطراب الذاتوية لدى الطفل، والعكس 
صحيح، وبذلك فإن درجات هذه المقاييس الفرعية الثلاثة تتراوح ما بين (صفر - بr () درجة.

أما بالنسبة للمقياس الفرعي الرابع والخاص بالاضطرابات النمائية فيوجد اختياران فقط أمام كل عبارة هما (نعم، لا) تحصل على الدرجتين (1- صفر ) على التوالي بحيث تحصل العبارة على درجة واحدة إذا ما تم تحديد الاختيار على أنه ذلك الاختيار الذى تمثله العلامة (+) ويحصل على صفر إذا ما كانت تمثل العلامة (-)، ويقوم أحد الوالدين أو أحد القائمين على رعاية الطفل ممن يكونوا على داريه تامة به بالاستجابة عليه وذلك بوضع علامة صح أمام العبارة التي تعبر بدقة وصدق عن حالة الطفل، ومن ثم فإن درجات المقياس الفرعي تتراوح ما بين (صفر - ؟ () درجة وهو الأمر الذي يجعل الدرجة الكلية لهذا المقياس بما يضمه من مقاييس فرعية أربعة (صفر - . ع ا ) درجة. ويتم جمع درجات البنود الخاصة بكل مقياس فرعى وضعها في القسم الثاني من كراسة تسجيل الإجابة، ثم يتم تحويل الدرجة الخام إلى رتبة مئينية أو درجة معيارية باستخدام الجدول (§) في صفحة (؟r)، ثم تجمع الدرجات المعيارية وتحول إلى محصلة الإصابة باضطراب الذاتوية والرتب المئينية المناظرة لها، وذلك من خلال جدول (0) في صفحة (^r)

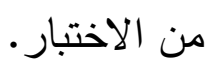

الخصائص السيكومتريـة للمقياس:

لحساب الخصائص السيكومترية للمقياس قام (James E. Gilliam,1995) بتطبيق المقياس على عينة ضمت (r9 • ()) مفحوصًا مدن يعانون من اضطرابا الذاتوية في (7؟) ولاية من الولايات المتحدة الأمريكية وفى كل من كولومبيا وكند، تتراوح أعمارهم ما بين (rع (r r 


\section{كلية التربية للطفولة المبكرة- جامعة بني سويف}

وتم حساب الصدق باستخدام صدق المحك لإيجاد معامل الارتباط بين المقياس وقائمة مراجعة السلوك الذاتوي، حيث تراوحت معاملات الارتباط ما بين (דب. •-؟؟9. •)، كما تم حساب العلاقة بين الأبعاد أو المقاييس الفرعية لهذا المقياس، وكانت قيمة (ر) دالة عند

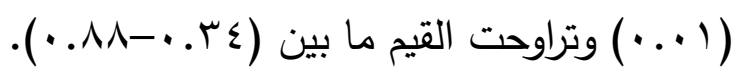

ولحساب الثبات تم استخدام إعادة التطبيق حيث بلغ معامل الثبات للسلوكيات النمطية

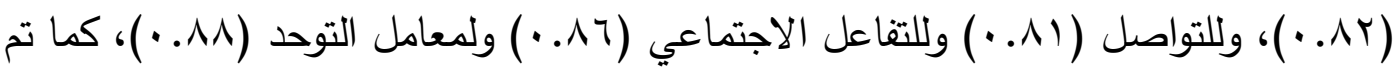
حساب الثبات باستخدام ألفا كرونباخ فكان معامل ألفا ( 9. • ) للسلوكيات النمطية و(9 . • )

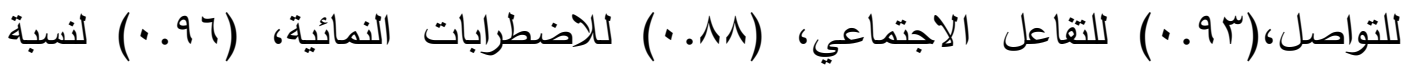
التوحد، كما تم اللجوء إلى ما يعرف بثبات المقدرين أي الذين يبلغون التقارير حول الأطفال وهو (0ب معلما) و(Vq والداً) وكانت قيم (ر) دالة عند (1 (..)، حيث تراوحت النسبة

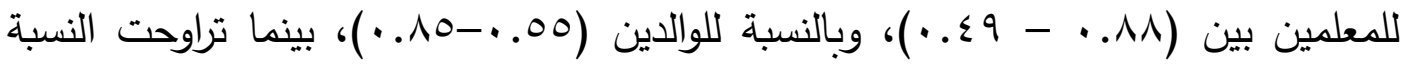
للوالدين والمعلمين ما بين (10. • - 91 . •)، وتعتبر هذه المعاملات جميعًا ذات قيم عالية تدل على أن العبارات التي تتضمنها المقاييس الفرعية ثابتة بدرجة كبيرة في قياس الذاتوية. وللتحقق من صدق وثبات المقياس في البيئة المصرية قام (عادل عبدالله، 17 ـ ب) بتطبيق المقياس على عينة بلغ عددها (r • ( طفل مقسمة إلى (10) من الأطفال الذاتويين، (ov) طفلا من المعاقين عقليا، و(7٪) من المتأخرين دراسيًا، و(9\&) من ذوى صعوبات التعلم، يتلقون الرعاية بعدد من المراكز والجمعيات والمدارس في محافظات القاهرة والإسكندرية والدقهلية والثرقية وبور سعيد تتراوح أعمارهم بين (0-7 ( ).

ولحساب الصدق تم استخدام صدق المحك حيث بلغت معاملات الارتباط (79..) للسلوكيات النمطية، (70. •) للتواصل، (YY. • ) للتفاعل الاجتماعي، (اT. . ) لاضطرابات النمائية، (VT. • ) لمعامل التوحد بالنسبة لاستجابة الآباء، أما للمعلمين فقد تراوحت معاملات 


\section{كلية التربية للطفولة المبكرة- جامعة بني سويف}

الارتباط (اV..) للسلوكيات النمطية، (rT..) للتواصل، (79. •) للتفاعل الاجتماعي،

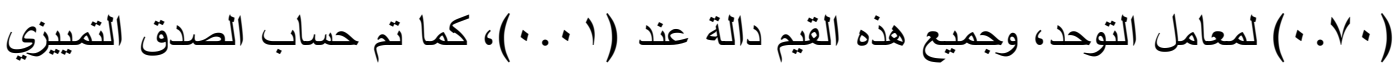
بين كل مجموعة من المجموعات الأخرى وكانت النتائج دالة عند ( (...) لصالح الأطفال الذاتويين وهو ما يعنى أن المقياس يميز بينهم وبين غيرهم من المجموعات. ولحساب الثبات تم استخدام إعادة التطبيق حيث بلغت نسبة الثبات (9 (1. •) للسلوكيات النمطية، (19. ( ) للتواصل، (^v.. ) للتفاعل الاجتماعي، (10. •) للاضطرابات النمائية و(§9. • ) لمعامل الذاتوية، كما تم حساب الثبات باستخدام ألفا كرونباخ حيث بلغت نسبة

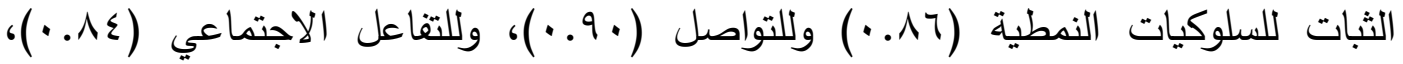
وللاضطرابات النمائية (1/.+)، ومعامل التوحد (r9..)، كما تم حساب الثبات بطريقة

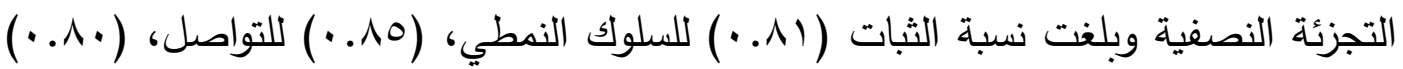

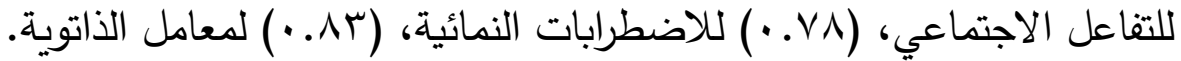
ولحساب الصدق والثبات في الاراسة الحالية قامت الباحثة بالتطبيق على عينة بلغ عددها (•r) طفل وطفلة من الأطفال الذاتويين تتراوح أعمارهم ما بين (ع-V) سنوات بمركز التأهيل المهنى وجمعية الرعاية المتكاملة ومركز جلوبال للتوحد بمحافظة الإسكندرية ، وتت استخدام صدق المحك الخارجي وذلك بإيجاد معامل الارتباط بين مقياس جيليام ، ومقياس

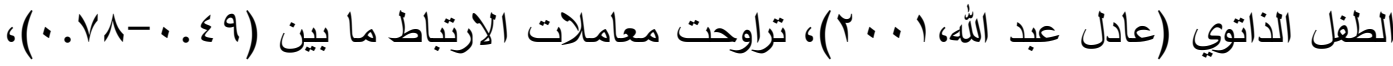

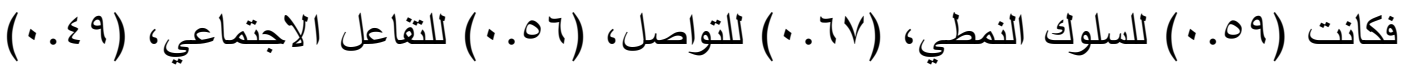

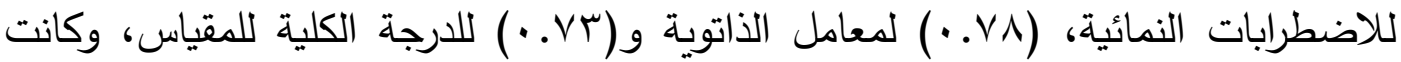

$$
\text { جميعها دالة عند مستوى (1 (. ). }
$$

ولحساب الثبات قامت الباحثة باستخدام معامل ألفا كرونباخ حيث تراوحت معاملات

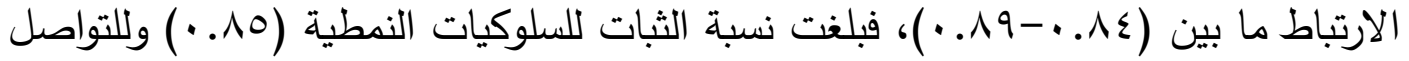

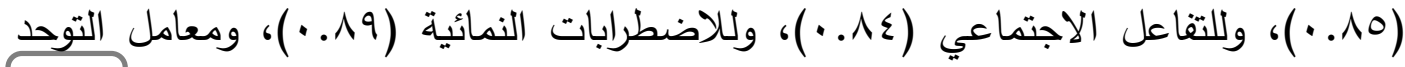




\section{كلية التربية للطفولة المبكرة- جامعة بني سويف}

( •^. •)، والدرجة الكلية للمقياس (^^. •)، مما يدل على أن المقياس يتمتع بدرجة عالية من

\section{(ب) مقياس جيليام لاضطراب أسبرجر (ترجمة: عحم عودة 10 • ب)}

صمم المقياس وقام بإعداده (James E. Gilliam, 2001) كأداة عالية الثبات من أجل تشخيص الأشخاص الأسبرجر (ذوى الأداء الوظيفى المرتفع) ، ويمكن تلخيص أهم استخدامات المقياس في النقاط التالية:

التعرف على الأشخاص المصابين باضطراب أسبرجر • لتقييم الأشخاص المحولين بسبب وجود مشاكل سلوكية. لتوثيق التقدم في مجالات المشاكل السلوكية كنتيجة لبرامج التدخل الخاصة. لتحديد أهداف للتغيير والتدخل في خطة تعليم الطالب الفردية. لتقييم وقياس اضطراب أسبرجر في المشاريع البحثية. ويتمتع المقياس بعدد من الخصائص هي:

يتكون من اثثان وثلاثون بندا واضحا مقسمة على أربع مقاييس فرعية تصف سلوكيات معينة قابلة للملاحظة والقياس. بنود المقياس قائمة على أكثر التعريفات حداثة لاضطراب الأسبرجر • استمارة مقابلة شخصية مع الآباء للتأكد من إنه لم يكن هناك تأخر من الناحية الطبية في النمو اللغوي والنمو المعرفي ومهارات الاعتماد على النفس المتماشية مع السن المناسب والسلوك التكيفي وفى اكتشاف البيئة المحيطة. تم تطبيق الأداة على (YVI) حالة من (T/) دولة وولاية مثل كندا وبربطانيا والمكسيك وأستراليا ودول أخرى. يمكن إكمال المقياس بسهولة بواسطة الآباء والمختصين في المدرسة، والأشخاص الذين على علم بسلوك الحالة أو لديهم فرصة كبيرة لملاحظة الحالة. 
كل من ثبات وصدق الأداة مدعمان بشكل واضح للأهداف المرجوة منها. يعتبر مقياس جيليام ملائم للأشخاص الذين تتراوح أعمارهم بين (r-Y r عاما. يمكن إكمال المقياس في مدة تتراوح ما بين (0- • () دقائق تقرببا. توافر الدرجات المعيارية والمئينية. توافر جدول لتحديد احتمالية إصابة الثخص باضطراب أسبرجر • وصف المقياس:

يضم المقياس أربعة مقاييس فرعية واستمارة مقابلة شخصية مع الآباء يجب ملأها بواسطة الآباء، ويتألف كل مقياس من مجموعة من البنود التي تصف السلوكيات الخاصة بالأسبرجر هم: مقياس التفاعل الاجتماعي: يشمل البنود من (1-. (1) وتصف السلوكيات التفاعلية مع المجتمع والتعبير عن التواصل والسلوكيات المعرفية والانفعالية. r) مقياس أنماط السلوك المحدد: يثمل البنود من (•-1 (1) وتصف أنماط السلوك المحدودة والنمطية المميزة لاضطراب أسبرجر • r) مقياس المهارات المعرفية: يشمل البنود من (9-19) والتي تقيم الكلام واللغة والمهارات المعرفية. ع) المهارات (البرجماتية) العملية: وتشمل البنود (جr-Yr) والتي تهتم بقدرة الفرد على استخدام اللغة ضمن السياق الاجتماعي. 0) استمارة المقابلة مع الوالدين وتشمل (rV) سؤال يتم تقيمهم في القسم السادس من كراسة الإجابة خاصة بالنمو الطفولي المبكر ونتائج هذا الجزء يمكن أن تستخدم لاستبعاد أي اضطرابات نمائية أخرى. 


\section{كلية التربية للطفولة المبكرة- جامعة بني سويف}

تطبيق المقياس وتصحيحه:

يتم تطبيق المقياس من خلال الآباء والمعلمين أو القائمين على رعاية الطفل، ويتميز مقياس جيليام بسهولة تطبيقه والبساطة في تسجيل الدرجات، كما يتميز بعدم تقيده بوقت محدد، إذ يمكن أن يحدد المقيمون خطوات تقدمه نحو إتمام الإجابة على البنود، فهم يستطيعون إنهاء كل المقاييس الفرعية في جلسة واحدة تتراوح مدتها من (0- • ( ) دقائق، لأن المعلومات المطلوبة في استمارة لمقابلة الثخصية للآباء في القسم السادس عادة ما يوفرها آباء الأشخاص الأسبرجر ، ويجب على القائم بعملية التقييم أن يكون متأكد من كيفية حدوث السلوك، وإذا لم يكن على دراية بأحد البنود فيجب على الفاحص أن يؤخر الإجابة عليه ويلاحظ الطفل لفترة زمنية مدتها ست ساعات لكى يستطيع تحديد الدرجة أو القيمة المناسبة للسلوك. ويتم تقييم كل بند طبقا لتكرار الحدوث، من خلال التقييم التالي: لم يلاحظ: لم ترى الشخص يتصرف بهذه الطريقة يلاحظ نادرا: يتصرف الشخص بهذه الطريقة مرة أو مرتين في فترة ملاحظة تصل إلى ست ساعات.

يلاحظ أحيانا: يتصرف الثخص بهذه الطريقة (r-؟) مرات في فترة ملاحظة تصل إلى ست ساعات. يلاحظ بشكل متكرر: يتصرف الشخص بهذه الطريقة على الأقل ه مرات في فترة ملاحظة تصل إلى 7 ساعات.

ويأخذ كل أداء درجة بحسب الترتيب (صفر - 1-r-r) وتسجل في كراسة تسجيل الإجابة ثم تجمع درجات كل اختبار فرعى وتسجل في كتيب ملخص الدرجات، أما فيما يتعلق باستمارة المقابلة الثخصية فيتم الإجابة عنها بواسطة الآباء أو مقدمي الرعاية الذين كانوا على اتصال مباشر ودائم بالطفل خلال (דr) شهرا الأولى من حياته، ويتم تجيل 
إجاباتهم على الأسئلة لمطروحة بنعم أو لا، ويساعد هذا القسم الفاحص في تقرير احتمالية إصابة الطفل باضطراب أسبرجر •

ويتم جمع درجات البنود الخاصة بكل مقياس فرعى ووضعها في القسم الثاني من كراسة تسجيل الإجابة، ثم يتم تحويل الدرجة الخام إلى رتبة مئينية أو درجة معيارية باستخدام الجدول (أ.) في الملحق (أ)، ثم تحول نتائج الدرجات المعيارية إلى محصلة الإصابة باضطراب أسبرجر والرتب المئينية المناظرة لها، وذلك من خلال جدول (ب. () في ملحق لهق له (ب) (بالمقياس.

\section{الخصائص السيكومترية للمقياس:}

قام جميس جيليام بحساب معايير الصدق والثبات للمقياس وذلك من خلال التطبيق

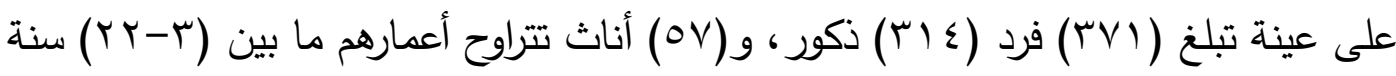
بمتوسط (· ( ) وانحراف معياري (ع)، وتم تثخيصهم مسبقا بأن لايهم اضطراب أسبرجر ،

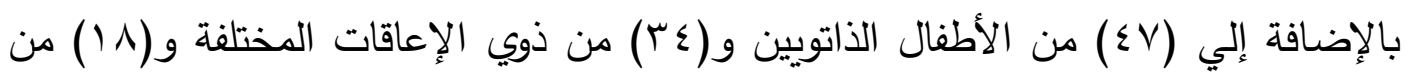
الأطفال العاديين، وتم اختيارهم بعدة طرق مختلفة بواسطة المعلمين والأخصائيين النفسيين والأخصائيين التربويين داخل المدارس أو في المراكز العلاجية، وطلب منهم تقييم المقياس، ويغطى أفراد عينة التقنين مجموعة جغرافية واسعة تتكون من (T؟) دولة وولاية مثل كولومبيا وكندا وبريطانيا والمكسيك وأستراليا وغيرها.

وقد تمتع المقياس بدلالات صدق وثبات عالية حيث تم حساب الصدق باستخدام صدق المحتوى حيث كانت معاملات الوسيط لكل المقاييس الجانبية كما يلى، (· آ. ) لدقياس

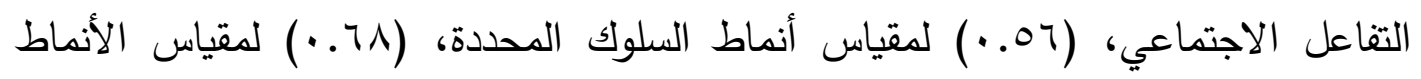
المعرفية، (ا7..) للمهارات البرجماتية، وكل هذه المعاملات دالة عند (1 ...)، كما تم 


\section{كلية التربية للطفولة المبكرة- جامعة بني سويف}

حساب صدق المحك وذلك بإيجاد معاملات الارتباط بين جيليام أسبرجر وجيليام للذاتوية حيث تراوحت معاملات الارتباط بين (ror. - •.V.•)، كما تم حساب صدق البناء وكانت

$$
\text { النتائج دالة عند (1 ( . (•). }
$$

ولحساب الثبات تم استخدام معامل ألفا وطريقة إعادة الاختبار وثبات المقيمين،

وتراوحت قيم معامل ألفا ما بين (NV . . . . .)، كما تراوحت معاملات الارتباط بطريقة

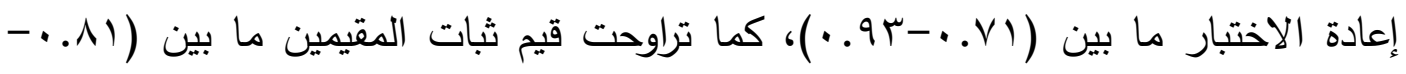
$\cdot(\cdot .19$

ولحساب الصدق والثبات علي عينة الدراسة قامت الباحثة بالتطبيق علي عينة (•r) طفل وطفلة (ع 1) طفل أسبرجر و(7 1) من الذاتويين ذوي القدرات المرتفعة تتراوح أعمارهم (1-0) وتم استخدام صدق المحك الخارجي بإيجاد معامل الارتباط بين مقياس جيليام ومقياس زملة أسبرجر للأطفال (آمال باظة، 9 9..ب) وتراوحت معاملات الصدق بين

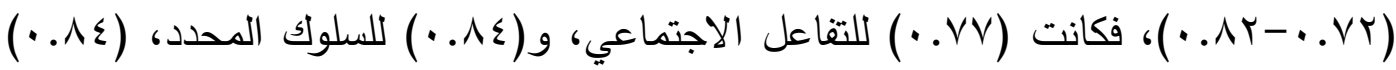
للمهارات المعرفية، (VY.VY · للمهارات البراجماتية، (r.A. • ) لمعامل الأسبرجر وكانت جميعها دالة عند ( ( ...) مما يدل على صدق المقياس. ولحساب الثبات قامت الباحثة باستخدام معامل ألفا كرونباخ وتراوحت قيم الثبات ما بين

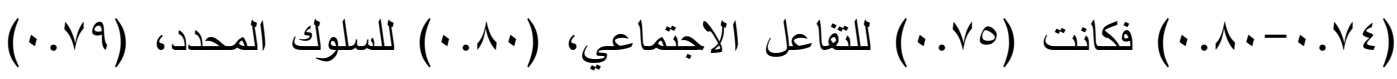
للمهارات المعرفية، (ع V..) للمهارات البراجماتية (العملية)، وتدل هذه القيم على ثبات

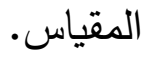

\section{التقييم النمائي لبرنامج البورتيج:}

يعرف البرنامج بأنه مجموعة من الأنثطة، الألعاب والممارسات العلمية التي يقوم بها الطفل تحت إشراف وتوجيه من جانب المشرفة التي تعمل علي تزويده بالخبرات، المعلومات، 
الهفاهيم، الاتجاهات وتدريبه علي أساليب التفكير وحل المشكلات التي ترغبه في البحث

$$
\text { والاكتثاف (بهادر، 0. . T، 0 ؛). }
$$

ويعتبر برنامج بورتيج أحد أهم أدوات التدخل المبكر حيث يتم تطبيقه على المرحلة

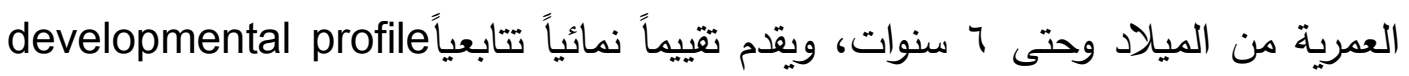
يتكون من: قائمة ملاحظة السلوك checklist: وهو كراسة اختبارات السلوك ويطبق على كل طفل ولكل طفل checklist قائمة خاصة به ويكتب عليه (اسم الطفل، اسم المؤسسة، تاريخ ميلاده) ويشتمل على خمس مجالات تقييمية five core areas هي: ا ب. المجال الاجتماعي (التفاعل والتواصل) socialization. r. المجال الإدراكي(المعرفى) cognitive.

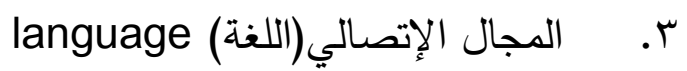

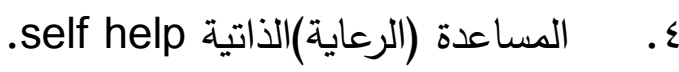

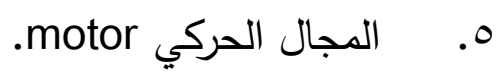

وقد صمم برنامج البورتيج في الولايات المتحدة عام (979 1979) وترجم إلى العديد من اللغات وتم تطبيقه وتقنينه في العديد من دول العالم ومن بينها بعض الدول العربية. حيث الديث يخدم البرنامج الأطفال ذوي الإعاقات المختلفة مثل الإعاقات العقلية، الإعاقات الجسمية لئل متعددي الإعاقات واضطرابات النطق والكلام.

\section{وصف برنامج "بورتيج"}

دليل بورتيج للتعليم المبكر هو أحد مكونات نموذج تقديم الخدمة، والتي يشير إليها

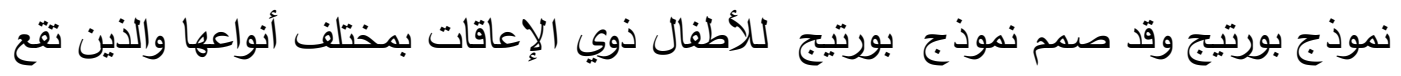

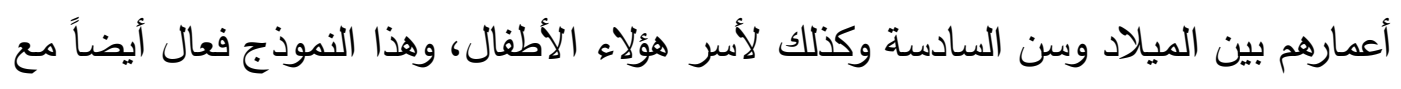
الأطفال متأخري النمو،أو منخفضي المستوي الاقتصادي والاجتماعي،أو المعرضين للأخطار 1255

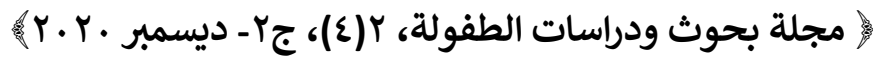


ويمكن تقديم الخدمة لهؤلاء الأطفال في أشكال متعددة تشمل برامج الطفولة المبكرة

العامة والخاصة مثل برنامج لنبدأ سوياً "ايفن ستارت"EVEN START، برنامج البدء مبكراً "هيد ستارت" HEAD START وبرنامج ما قبل المدرسة، أو برنامج ما قبل رياض الأطفال، أو مراكز الرعاية النهارية DAY CARE وغيرها. ويسعي نموذج بورتيج لتحقيق التكامل بين مدخل النظم الأسرية وبين التدخل الخاص بعلاج طفل يوجد في بيئة معيقة لتطوره ويتشكل هذا النموذج من أربعة مبادئ رئيسية: أن الأسرة هي التي توجه عملية التدخل.

أن جوهر عملية التذخل هو التفاعل بين الوالدين والطفل.

أن النظام اليومي، وعادات الأسرة، واللعب تثكل أنماط حياة الأسرة، وهي الوسيط الذي يتم التدخل من خلاله. - اله. أن تسجيل الملاحظات والحوارات الدائرة بين الوالدين وفريق العمل، هو أساس القرارات التي تتخذ في عملية التدخل. هنالك ستة عناصر أساسية لنموذج بورتيج، سيتم عرض كل منها فيما يلي: ( ) (1) (لتشخيص

يشتمل نموذج بروتيج علي جهود مكثفة لتعريف مؤسسات المجتمع المحلي ببرنامج التخل وتقوم كل مؤسسة بوضع محكات نجاحها علي أساس طبيعة المجتمع الذي تخدمه والأنظمة السائدة، شروط مصادر التمويل وعدد الأسر التي يمكن تقديم الخدمة إليها. r) التقييم البيئي الأيكولوجي

التقييم هو جوهر عملية النشاط من بدايتها إلى نهايتها، فهو يهدف إلى اكتشاف نقاط القوة وأنواع الحاجات التي تتقص الطفل وأسرته، وبذلك فهو يهدف إلى إعادة برنامج للتدخل، 
خاص بكل أسرة على حدة، وقد تثمل استراتيجيات التدخل حوارات غير رسمية مع الأسرة، كملاحظة واستخدام أدوات التقييم المطبوعة أو القوائم الإنمائية، ويمكن استخدام نتائج تتييم الطفل والتي قامت على أساس التقييم الإنمائي - مثل دليل بورتيج للتعليم المبكر - في تخطيط الأنثطة اليومية التي تهدف إلى دعم نمو الطفل، وتتم جميع أنواع التقييم بالمشاركة التامة من الوالدين؛ وذلك بهدف الاستفادة من معلوماتهم عن طفلهم وأسرته ولضمان أن تتم هذه الأنشطة بتوجيه من الأسرة، ويشمل التقييم الأيكولوجي كنلك التوصل إلى إلى معرفة بالمصادر المتاحة في المجتمع المحلي لمساعدة الأسرة.

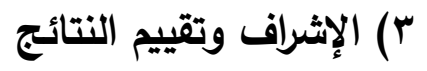

تظهر أنثطة الطفل والأسرة ذات العلاقة ببرنامج المساعدة خلال برنامج التعليم الفردي، أو برنامج خدمة الأسرة الواحدة، أو من خلال برامج أخرى، ويتم توثيق الأنشطة من خلال

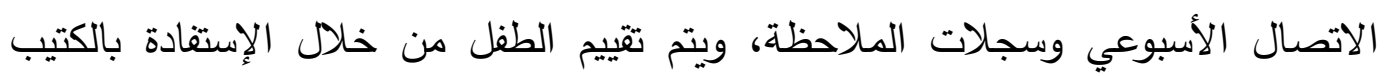
الحالي دليل برنامج التنمية الثاملة للطفولة المبكرة "بورتيج" كمرجع، ويتم استكمال التقييم سنويا لمراجعة برامج التعليم الفردي، وخدمات الأسرة المتفردة ويتم قياس درجة رضا الوالدين والهجتمع المحلي عن خدمات البرنامج من خلال استبيانات في نهاية العام (وزارة التربية

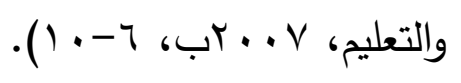

\section{؛) الأسس التي يقوم عليها التقييم النمائي لبرنامج "بورتيج"}

يعتمد هذا الأساس على مجموعة من المفاهيم الأساسية والتوجيهات بعضها يرتبط بالإطار المعرفي الذي يعمل فيه البرنامج والبعض الآخر يتعلق بما يكفل حسن التخطيط وحرية التنفيذ والتقويم. 


\section{كلية التربية للطفولة المبكرة- جامعة بني سويف}

ا. ـ المفهوم الأول: إن عملية الرعاية والتتمية والعلاج للأطفال الذاتويين تطبق في رحاب الأسرة، بحيث تقوم الأم أو الأب بمتابعة تعليم أطفالهما، ورصد أداءهم، والعمل على تتميتها للوصول بها إلى المستويات المناسبة للنمو. r. المفهوم الثاني: هو الاتجاه السلوكي في تثخيص المشكلة السلوكية للطفل الذاتوي، وفي إعداد تدريبات عملية في التقويم وهذا الاتجاه يحدد أهداف عملية التعليم تحديدا ويمكن من اختبار أساليب التدريب التي تكفي لمعالجة القصور في جوانب النمو المختلفة. r. المفهوم الثالث: ويرتبط المفهوم الثالث بالمفهوم السابق وهو أن البرنامج يحتوي من بين أدواته على قائمة للمراجعة تضم المجالات الستة الآتية: مجال استثارة الرضيع، المجال المعرفي، المجال الحركي، مجال مساعدة الذات، المجال الاجتماعي، المجال اللغوي. ويلاحظ من هذه القائمة أن ثمة مفهوما أساسيا يستند إليه البرنامج في تصور طبيعة الطفل الذي يعانى من اضطراب الذاتوية وجوانب شخصيته ونموه يقوم على تكامل جميع مجالات النمو، كما انه يعتمد- في نفس الوقت -على تحليل ورصد شامل لجميع مظاهر ومهارات النمو في ظل كل مجال من هذه المجالات تحديدا أدائيا سلوكيا، إذن فهو مفهوم سلوكي أدائي معرفي شامل للطبيعة الإنسانية للطفل. ع. المفهوم الرابع: ويستند على أن هذا البرنامج يأخذ في اعتباره ما حدث من تقدم في مجال تصميم التعليم وتطويره فهو يقتفي تدريب القائمين على رعاية الأطفال ذوي الاحتياجات الخاصة عامة وأطفال الذاتوية خاصة ووضع استراتيجيات تكفل ترتيب منهج تعليمي قائم على هذا التحليل، بما يحقق الأهداف ووضع استراتيجيات تكفل ترتيب خطوات التعلم بشكل متسلسل ييسرها ويؤدي إلى تحقيق الأهداف، أي أن هذا البرنامج يستند إلى مفهوم التنسيق أو النظام وضرورة وجود اتساق أو تتاغم بين تحليل المهمة، وبين الهدف السلوكي، وبين خبرات التعلم والتعليم، وبين بلوغ مستوى النجاح الذي ينص عليه الهدف المنصوص عليه في 
ه. المفهوم الخامس: من المفاهيم الأساسية لهذا البرنامج المرونة، فعلى الرغم من وجود قائمة مراجعة تضم وترصد جميع الأداءات التي يقوم بها الطفل السوي أو العادي في المجالات الستة، وعلى الرغم من أنه يوجد لكل أداء من هذه الأداءات بطاقة نشاط تحدد خطوات العمل والتعليم والرعاية التي تكفل اكتساب وتتمية هذا العنصر السلوكي أو الأداءعلى الرغم من ذلك كله فان المجال متسع للأم والأب أو المعلمة المشرفة قبل أن يبتكر أنشطة بديلة، وطرائق تعليمية مختلفة ومواد متباينة مما تيسره الظروف ومما يكفل تحقيق الهدف التتموي (وزارة التربية والتعليم، V . . rأ، r- 0)

\section{الخصائص السيكومترية لمقياس البروفيل النمائي للبورتيج}

قامت الباحثة بإيجاد معاملات الصدق والثبات لمقياس البروفيل النمائي للبورتيج على

$$
\text { عينة قوامها (·r) طفلا على النحو التالي: }
$$

صدق المحك الخارجي: قامت الباحثة بإيجاد معاملات الارتباط بين مقياس البروفيل النمائي للبورتيج ومقياس فاينلاند للسلوك التكيفى المطور من مقياس فاينلاند للنضج الاجتماعى ، تعريب وتقنين( بندر العتيبى، ؛ . . r) كمحك خارجي، كما يتضح في جدول (T)

جدول (T)

معاملات الصدق لمقياس البروفيل النمائي للبورتيج

\begin{tabular}{|c|c|}
\hline معاملات الصدق & الأبعاد \\
\hline$\because \vee \wedge$ & الحركي \\
\hline$\cdot \wedge \varepsilon$ & الاجتماعي \\
\hline..$\wedge 9$ & الرعاية الذاتية \\
\hline$\cdot v 1$ & المجال المعرفي \\
\hline.$V \varepsilon$ & المجال اللغوي \\
\hline$\cdot . \wedge r$ & الدرجة الكلية للمقياس \\
\hline
\end{tabular}




\section{كلية التربية للطفولة المبكرة- جامعة بني سويف}

معاملات الثبات

قامت الباحثة بإيجاد معاملات الثبات لمقياس البروفيل النمائي للبورتيج باستخدام معامل

(ألفا بطريقة كرونباخ كما يتضح في جدول (v)

جدول (v)

معاملات الثبات لـقياس البروفيل النمائي للبورتيج باستخدام معادلة كرونباخ

\begin{tabular}{|c|c|}
\hline معاملات الثبات & الأبعاد \\
\hline ד. & الحركي \\
\hline.$\wedge \varepsilon$ & الاجتماعي \\
\hline.$\wedge \Lambda$ & الرعاية الذاتية \\
\hline. .19 & المجال المعرفي \\
\hline.$\wedge \varepsilon$ & المجال اللغوي \\
\hline.$\wedge \wedge$ & الدرجة الكلية للمقياس \\
\hline
\end{tabular}

يتضح من جدول (V) أن قيم معاملات الثبات مرتفعة مما يدل على ثبات الاختبار

الخطوات الإجرائية للدراسة.

1. الاطلاع على التراث النظرى لكتابة الجزء النظري للدراسة.

r. تحديد عينة الدراسة لعمل بروفيل نفسى (الأطفال الذاتويين منخفضي الأداء الوظيفي والأطفال الذاتويين مرتفعي الأداء الوظيفي) وحساب التجانس بين أفراد العينة من حيث درجة الذاتوية والعمر الزمنى، وتحديد أدوات الدراسة. r. إجراء الدراسة الميدانية من خلال تطبيق اختباري جيليام للذاتوية والأسبرجر والتتييم النمائي لبرنامج البورتيج وذلك في فترة زمنية وصلت إلى ه أشهر خلال العام 19 • / .$Y \cdot Y$. 
؛. تصحيح الاختبارات وتغريخ البيانات واستخدام الأساليب الإحصائية المناسبة لاختبار صحة الفروض.

ه. الوصول إلى النتائج وتفسيرها بعد المعالجة الإحصائية، ومناقثتها في ضوء الإطار النظري والدراسات السابقة.

الأساليب الإحصائية المستخدمة في الاراسة.

قامت الباحثة باستخدام برنامج الحزمة الإحصائية للعلوم الاجتماعية (SPSS)

Statistical Package for Social Sciences

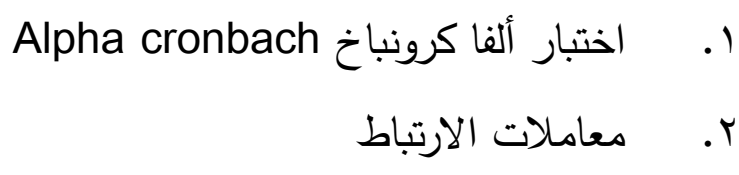

Mann- Whitney U مان ويتني

أولاً : عرض نتائج الدراسة ومناقشتها

(أ) عرض نتائج الفرض الأول ومناقشتها:

ينص الفرض الأول على أنه: توجد فروق ذات دلالة إحصائية بين متوسطات رتب

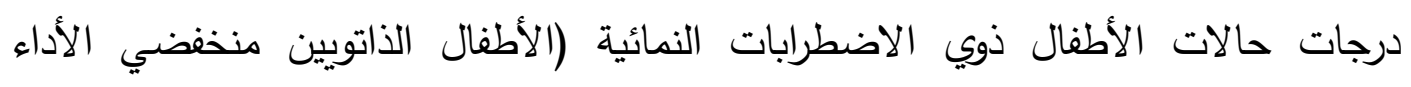
الوظيفي والأطفال الذاتويين مرتفعي الأداء الوظيفي) على مقياس البروفيل النمائي للبورتيج

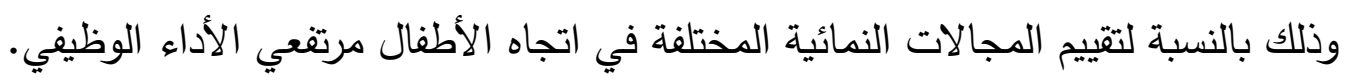

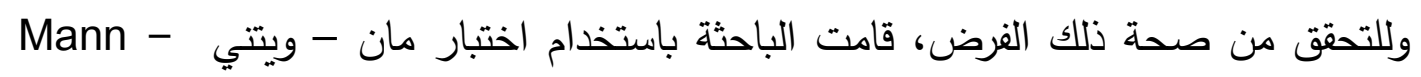
Whitney (الأطفال الذاتويين منخفضي الأداء الوظيفي والأطفال الذاتويين مرتفعي الأداء الوظيفي) 


\section{كلية التربية للطفولة المبكرة- جامعة بني سويف}

على مقياس البروفيل النمائي للبورتيج وذلك بالنسبة لتقييم المجالات النمائية المختلفة كما

$$
\text { يتضح من جدول (^). }
$$

جدول (^) الفروق بين متوسطات رتب درجات الأطفال ذوي الاضطرابات النمائية(الأطفال الذاتويين منخفضي الأداء الوظيفي والأطفال الذاتويين مرتغعي الأداء الوظيفي) على مقياس البروفيل النمائي للبورتيج

\begin{tabular}{|c|c|c|c|c|c|c|c|}
\hline اتجاه الدلالة & الدلالة & $z$ & مجموع الرتب & متوسط الرتب & العدد & المجموعات & المتغيرات \\
\hline- & غير دالة &. .901 & $\begin{array}{l}118.0 \\
94.0\end{array}$ & $\begin{array}{l}11.00 \\
9.10\end{array}$ & $\begin{array}{l}1 . \\
1 . \\
r .\end{array}$ & مرتخفضي الألأداء & الحركي \\
\hline لصالح & دالة عند & & $\begin{array}{l}100 \\
00\end{array}$ & $\begin{array}{l}10.0 \\
0.0\end{array}$ & $\begin{array}{l}1 . \\
1 . \\
r .\end{array}$ & مرنفضي الأداء & الاجتماعي \\
\hline- & غير & $1 . \vee \wedge$. & $\begin{array}{l}\text { MrN.0 } \\
\wedge 1.0\end{array}$ & $\begin{array}{l}1 \% .10 \\
1.10\end{array}$ & $\begin{array}{l}1 . \\
1 . \\
r .\end{array}$ & مرنفضي الأداء & الذاتية \\
\hline لصالح لمرتعي & دالة عند & 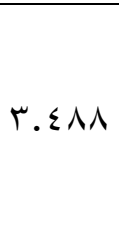 & $\begin{array}{l}101 \\
09\end{array}$ & $\begin{array}{r}10.1 \\
0.9\end{array}$ & $\begin{array}{l}1 . \\
1 . \\
r .\end{array}$ & مرنفضي الأداء & المجرفي \\
\hline لصالح لأنعي & دالة عند & $r . \leqslant \wedge q$ & $\begin{array}{l}101 \\
09\end{array}$ & $\begin{array}{r}10.1 \\
0.9\end{array}$ & $\begin{array}{l}1 . \\
1 . \\
r .\end{array}$ & منففضي الأداء & اللغوي \\
\hline لصالص لمرتعي & مستوى & r.vAr & $\begin{array}{l}100 \\
00\end{array}$ & $\begin{array}{l}10.0 \\
0.0\end{array}$ & $\begin{array}{l}1 . \\
1 . \\
r .\end{array}$ & مرنخفي الأجماء & اللكلية الدرجة \\
\hline
\end{tabular}

.. . $1.97=Z$

... I. Y عند مستوى = Z 
يتضح من جدول(^) وجود فروق ذات دلالة إحصائية بين متوسطات رتب درجات الأطفال الذاتويين منخفضى ومرتفعى الأداء الوظيفى فى المجالات الاجتماعية والمعرفية والدرجة الكلية لصالح الأطفال ذوى الأداء الوظيفي المرتفع ، بينما لم تظهر دلالة للفروق بين متوسطات رتب درجات الأطفال منخفضى ومرتفعى الأداء الوظيفى من الذاتويين على أبعاد المجال الحركى والرعاية الذاتية.

ويوضح شكل (1) الفروق بين متوسطات رتب درجات الأطفال ذوي الاضطرابات النمائية (الأطفال الذاتويين منخفضي الأداء الوظيفي- الأطفال الذاتويين مرتفعي الأداء الوظيفي) على مقياس البروفيل النمائي للبورتيج

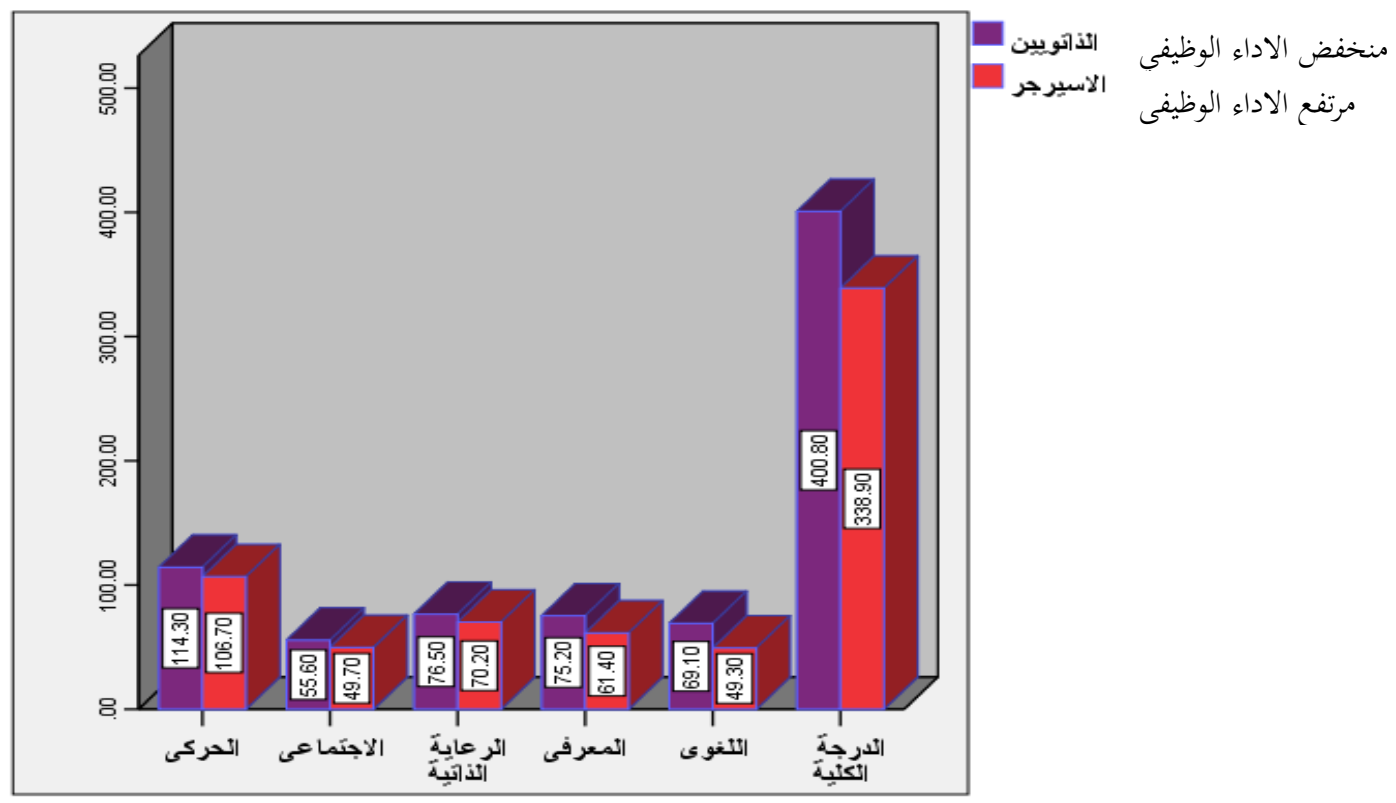

شكل (1)

الفروق بين متوسطات رتب درجات الأطفال ذوي الاضطرابات النمائية (الأطفال الذاتويين منخفي الأداء الوظيفي- الأطفال الذاتويين مرتفعي الأداء الوظيفي ) على مقياس البروفيل النمائي للبورتيج 


\section{كلية التربية للطفولة المبكرة- جامعة بني سويف}

\section{عرض نتائج الفرض الثاني:}

ينص الفرض الثاني على أنه: لا يختلف شكل البروفيل النفسي لتثييم حالات الأطفال ذوي الاضطرابات النمائية (الأطفال الذاتويين منخفضي الأداء الوظيفي- الأطفال الذاتويين مرتفعي الأداء الوظيفي) عند استخدام البروفيل النمائي برنامج البورتيج كمحك تثخيصي

وتقييمي للمجالات النمائية المختلفة. قامت الباحثة بإيجاد البروفيل النفسي لتتييم حالات الأطفال ذوي الاضطرابات النمائية (الأطفال الذاتويين منخفضي الأداء الوظيفي- الأطفال الذاتويين مرتفعي الأداء الوظيفي ) عند استخدام البروفيل النمائي للبورتاج كما يتضح في شكل (r)
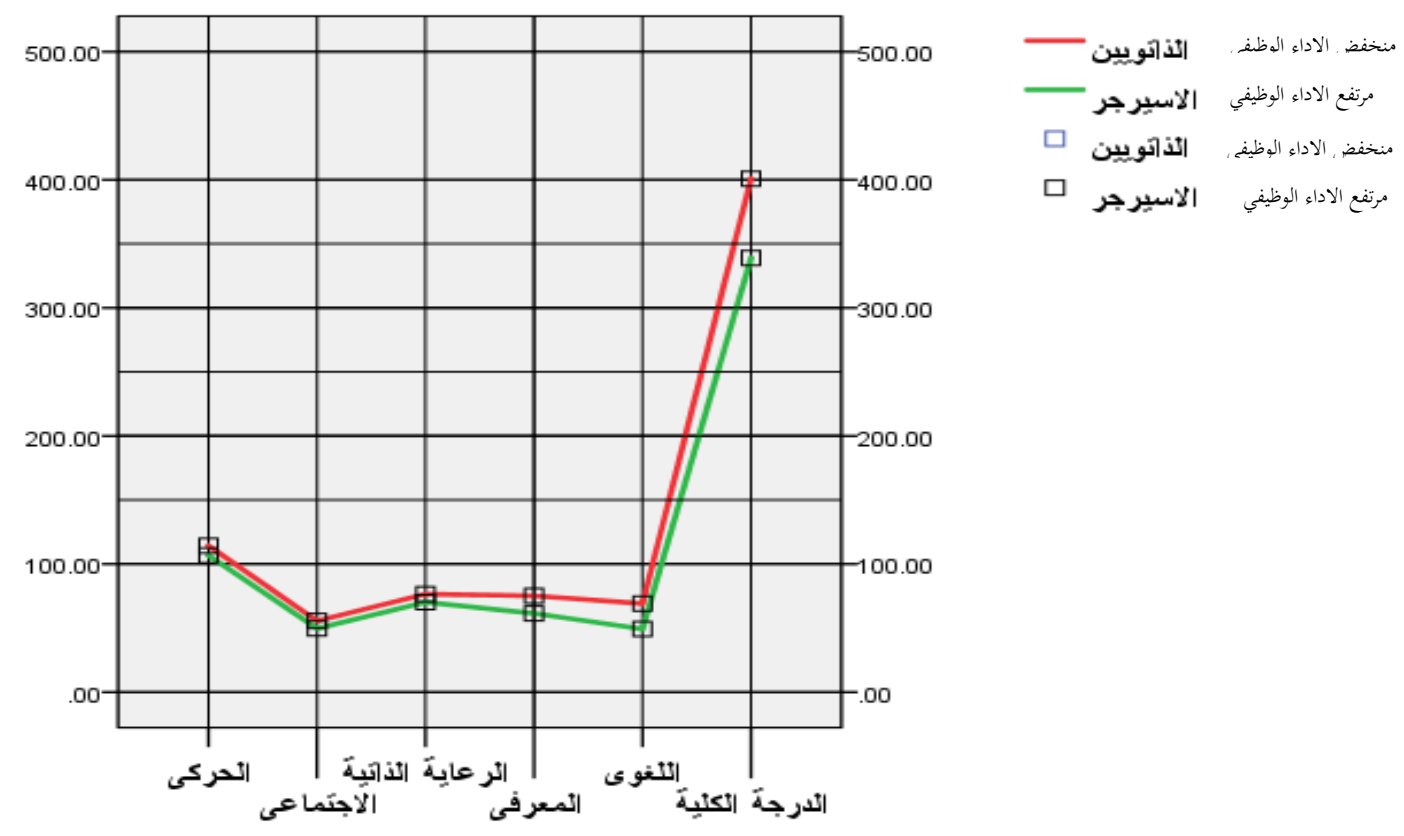

شكل (r)

البروفيل النفسي لتقييم حالات الأطفال ذوي الاضطرابات النمائية (الأطفال الذاتويين منخفي الأداء الوظيفي- الأطفال الذاتويين مرتفعي الأداء الوظيفي) عند استخدام البروفيل النمائي للبورتيج تثير نتائج البروفيل النمائي لبرنامج بورتيج إلى فاعلية استخدام البروفيل النمائي لبرنامج البورتيج في التقييم والتشخيص الفارق لحالات الأطفال الذاتويين منخفي الأداء 
الوظيفي - الأطفال الذاتويين مرتقعي الأداء الوظيفي، مما يدعم فرض الدراسة والتوقع بفاعلية استخدام البروفيل النمائي لبرنامج البورتيج في عمليات التقييم النمائي والتشخيص الفارق. ومن ثم يتضح فاعلية استخدام البروفيل النمائي لبرنامج البورتيج في تثخيص وتقييم الأطفال الذاتويين منخفضي الأداء الوظيفي- الأطفال الذاتويين مرتفعي الأداء الوظيفي. بالإضافة إلى تحديد مكامن القوة التعليمية الخاصة والمهارات القابلة للتعلم عند الطفل. ويتقق هذا مع ما أشار إليه كل من (Villa, Micheli, Pastore\&Molteni, 2010) والتي هدفت إلى التحقق من صلاحية البروفيل النمائي لبرنامج البورتيج، وأظهرت النتائج ثبات وصدق المقياس في تقييم وتتخيص ذوى الاضطرابات النمائية (حالات الذاتوية (Waligórska,Pisula,Waligórski\&Letachowicz, وحالات الأسبرجر)، ودراسة (2012 والتي هدفت إلى التأكد من فعالية برامج التدخل المبكر للأطفال الذاتويين باستخدام مقياس البروفيل النفسي التربوي (PEP)، وأظهرت النتائج تقدم للأطفال على اختبار (PEP) (Fulton \& D'entremont, الاختبارات الفرعية والدرجة الكلية للمقياس، كما اشارت دراسة (2013 إلى أهمية مقياس (PEP3) حيث هدفت إلى فائدة البروفيل النفسي التربوي في تقييم المهارات المعرفية واللغوية للأطفال الذاتويين. وترى الباحثة أن نتيجة الدراسة الحالية جاءت متفقة تماما مع عديد من نتائج الدراسات السابقة والتي تؤكد على فاعلية استخدام البروفيل النمائي لبرنامج البورتيج للقيام بعمليات التثييم النمائية الكاملة والمدققة وكذلك عمليات التشخيص الفارق لحالات الاضطرابات النمائية متمثلة في حالات اضطراب الذاتوية منخفضى ومرتفعى الأداء الوظيفى وذلك بنفس الكفاءة والفاعلية لاستخدام البروفيل النفسي التربوي PEP3، وجاء ذلك متفقاً مع نتائج دراسة (Reale, 2012) (Mandy, البورتيج في التثخيص الوظيفي لاضطرابات الذاتوية، وكذلك مع دراسة Charman, Gilmour\&Skuse, 2012) 


\section{كلية التربية للطفولة المبكرة- جامعة بني سويف}

Layton النمائي لبرنامج البورتيج في تثخيص اضطرابات النمو الثامل، ومع نتائج دراسة ( \& Hao, 2014) التى هدفت إلى فحص فاعلية الخصائص التثخيصية لبرنامج البورتيج

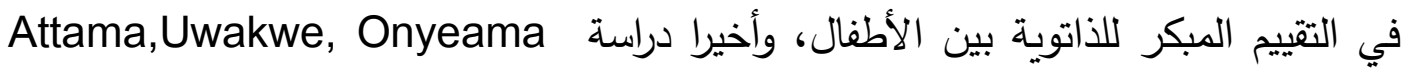
(\&lgwe, 2015) مع كل من الأطفال الذاتويين وذوي الإعاقات النمائية.

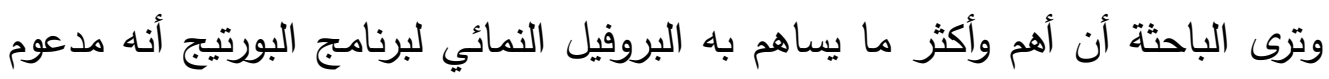
ببرامج تدريبية ، ولا يكتفي فقط بتقييم وتشخيص حالات الأطفال الذاتويين منخفي الأداء الوظيفي- الأطفال الذاتويين مرتفعي الأداء الوظيفي ، ولذا يمكننا القول بأنه يمكن الحصول على صورة متكاملة عن الطفل من خلال عمليات التقييم والتثخيص ؛ بل ونستطيع معها تقديم الخدمات التربوية والتعليمية بشكل أفضل من خلال البرامج التي تدعم البروفيل المستخدم (البرنامج النمائي للبورتيج). كما قامت الباحثة برسم الصفحة النفسية لكل من الأطفال الذاتويين منفضضي الأداء الوظيفي- الأطفال الذاتويين مرتفعي الأداء الوظيفي باستخدام التقييم النمائي لبرنامج البورتيج، وجاءت الصفحة النفسية تعكس مساحة التشابه بين العينيتين علي جميع أبعاد التقييم النمائي لبرنامج البورتيج، وفيما يلي رسم شكل الصفحة النفسية لكل من العينتين وأوجه

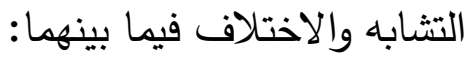




\section{كلية التربية للطفولة المبكرة- جامعة بني سويف}
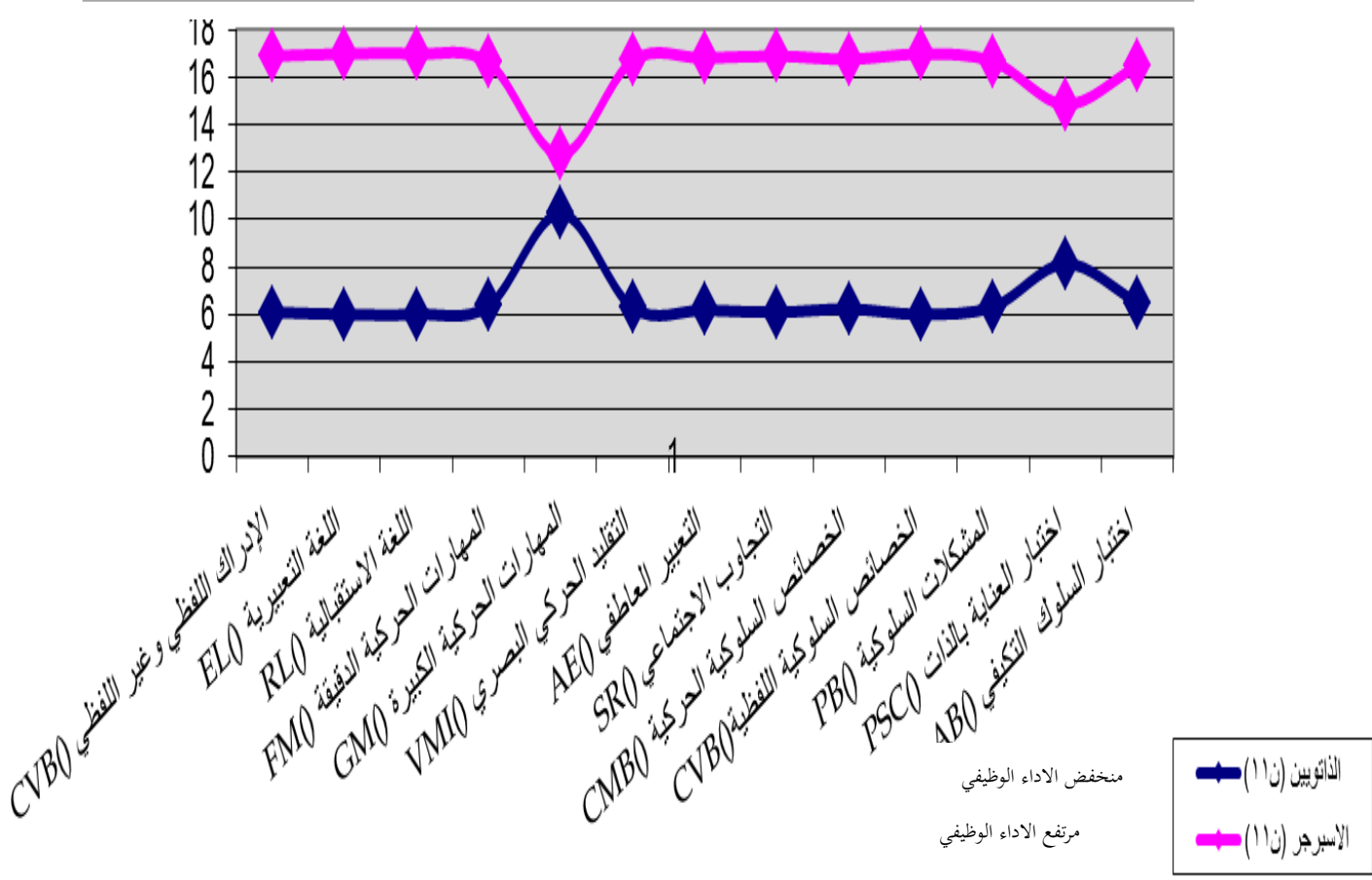

شكل (r)

الصفحة النفسية لكل من الأطفال الذاتويين منخفضي الأداء الوظيفي- الأطفال الذاتويين مرتفعي الأداء الوظيفي وأوجه التثابه والاختلاف فيما بينهم

من خلا الصفحة النفسية يتضح لنا وجود أوجه التشابه لدي الأطفال الذاتويين منخفضي الأداء الوظيفي- الأطفال الذاتويين مرتفعي الأداء الوظيفي علي التقييم النمائي لبرنامج البورتيج تتضح فيما يلي: في بعد التواصل فقد ظهر من خلال النتائج وجود قصور في مهارات التواصل (اللغة التعبيرية واللغة الاستقبالية والإدراك اللفظي وغير اللفظي) لدى الأطفال الذاتويين منخفضى الأداء الوظيفى مقارنة بالأطفال الذاتوين مرتفعي الأداء الوظيفي، تراوح التأخر في اللغة ما بين المتوسط والثديد، وكذلك توقف تأخر في القدرة على التخاطب والاتصال، كما أن بعض الأطفال الذاتويين الذين استطاعوا التحدث كانت اللغة لديهم غريبة حيث كانوا 


\section{كلية التربية للطفولة المبكرة- جامعة بني سويف}

يقومون بترديد بعض الكلمات أو الجمل بشكل مستمر حتى وإن كانت من حديث سابق ليس لله علاقة بالموضوع الحالي، وهو الأمر الذى لم يظهر عند الأطفال الذاتويين مرتفعي الأداء الوظيفي، فبالرغم من تفوقهم في مهارات التواصل علي الأطفال الذاتويين منخفضى الأداء الوظيفى إلا أن مشكلة التواصل اللفظي لديهم تكمن في أنهم يفترون إلى قواعد المحادثة مع لهع الآخرين، فهم يريدون الاستئثار بالحديث لفترات طويلة و يتحدثون عن بعض الاهتمامات

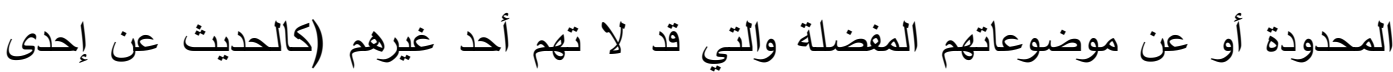
الثخصيات ، وغيرها) وغير مهتمين بالآخرين ومشاعرهم وإذا كانوا مهتمين أم لا.

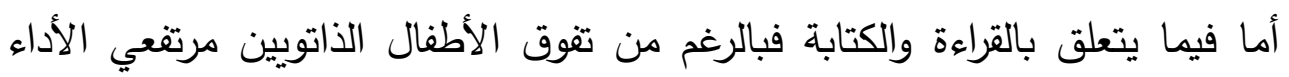
الوظيفي على الذاتويين منخفى الأداء الوظيفى في هذا البعد إلا أن الفرق بينهم ليس كبير

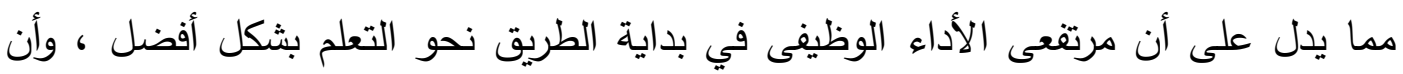

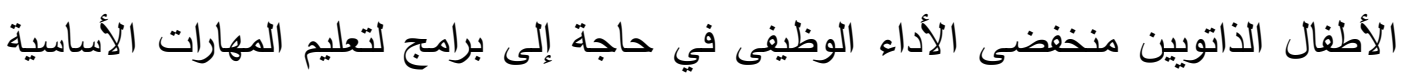
للتعلم (الكتابة القراءة الحساب). أما من الناحية الاجتماعية فقد أبدي الأطفال الذاتويين مرتفعي الأداء الوظيفي تفوقاً

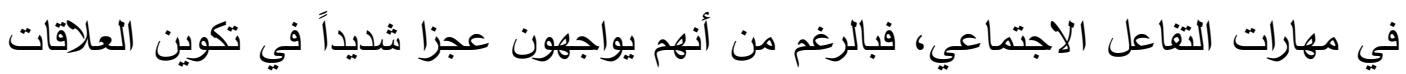

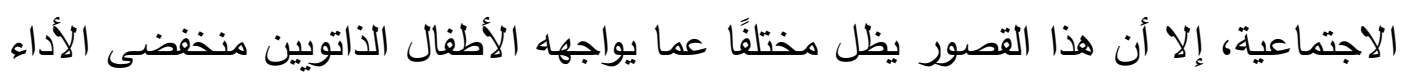
الوظيفى ، فبالرغم من وجود مشكلات اجتماعية تتراوح ما بين الانعزال والرغبة في الانفصال

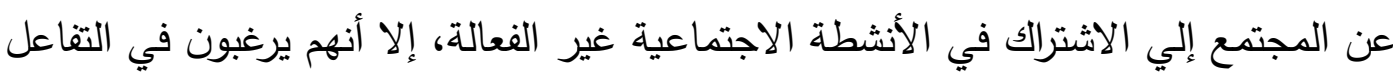
الاجتماعي وإقامة الصداقات حتى ولو لم تكن بشكل مكتمل، ويرجع ذلك إلي نمو المهارات اللغوية من حيث حصيلة المفردات وقواعد اللغة والنطق، كما أنهم قادرون على تكوين جمل ولتحل طويلة ومعقدة في قواعدها لاستخدامها في التواصل والتفاعل الاجتماعى ، أما الأطفال الذاتويين منخفىى الأداء الوظيفى فهم يعانون من قصور شديد في مهارات التفاعل 
الاجتماعي، وفى القدرة على إقامة اتصال اجتماعي متبادل، وعدم الرغبة في تكوين علاقات أو صداقات، كما اتضح من نتائج المقياس ونتائج ولى الأمر . وفيما يتعلق بالمهارات الحركية: بالرغم من أن الاطفال الذاتويين مرتفعي الأداء

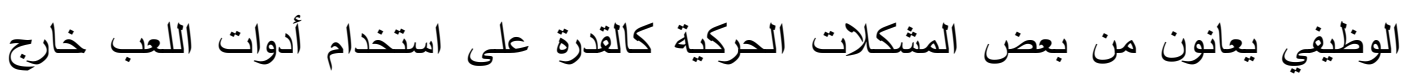

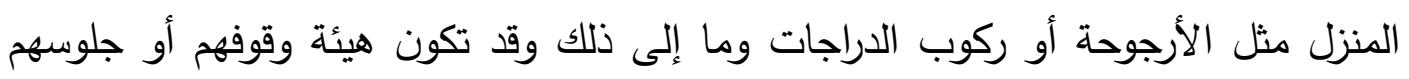
غريبة ، كما أنهم قد يظهرون صعوبات في تناسق المهارات البصرية الحركية إلا أنهم أظهروا تفوقًا على الأطفال الذاتويين منخفى الأداء الوظيفى في هذا الهجال (المهارات الدقيقة والإدراك الحركي البصرى) فالقدرات الحركية لدي الذاتويين مرتفعى الأداء الوظيفى تتباين

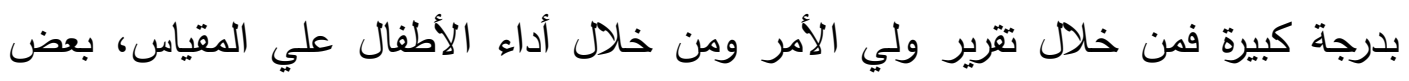

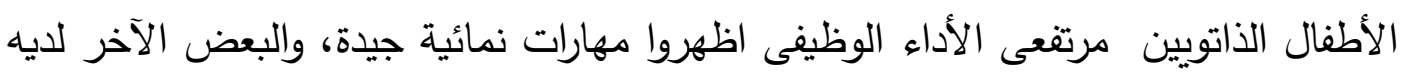
قصور في قدراتهم الحركية الدقيقة منها بطء في تعلم مهارات ارتداء الملابس، ومهارات

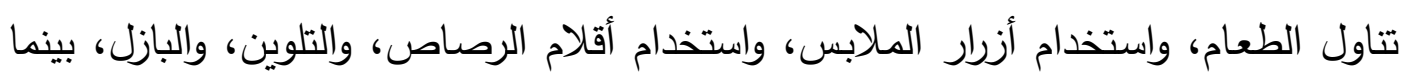
لم توجد فروق بين الفئتين في المهارات الكبيرة. السلوكيات النمطية: أظهر الأطفال الذاتويين منخفضى الأداء الوظيفى استجابة سلبية

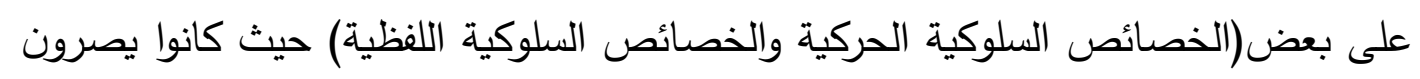

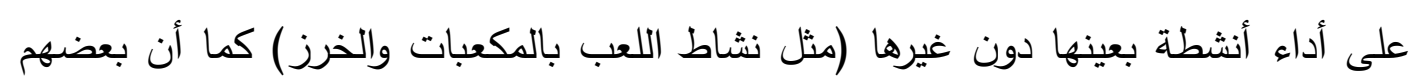

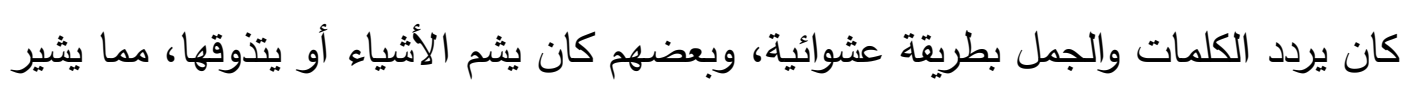
إلى تفوق الأطفال الذاتويين منخفضى الأداء الوظيفى عن مرتفعي الأداء الوظيفي في شدة ونداء السلوكيات النمطية وهو ما يتقق مع خصائصهم. لهعن. 


\section{توصيات اللدراسة}

في ضوء نتائج الدراسة الحالية توصي الباحثة بما يلي:

ا. ضرورة الاهتمام بتجديد طرق التشخيص والتقييم التي تستخدم مع الأطفال ذوى الاحتياجات الخاصة عموما والأطفال ذوى اضطرابات الذاتوية خاصة. r. الاستفادة من البروفيل النمائي لبرنامج البورتيج في عمليات التقييم والتشخيص ووضع الخطة التربوية الملائمة للتذخل. r. تصميم أدوات لرصد التغير فى نمو الطفل ومدي التقدم نحو تحقيق الأهداف والنتائج التي تصبو المعلمة لتحقيقها. ع. توفير الاختبارات والمقاييس النفسية والتربوية داخل مؤسسات التربية الخاصة وتدريب الأخصائيين علي استخدامها.

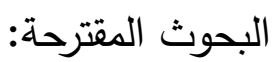

1- استخدام البورتيج في التشخيص الفارق ورسم البروفيل النفسى لحالات الاصابة الدماغية . r- قدرة برنامجى تيتش والبورتيج في التشخيص الفارق بين حالات الذاتوية مرتفعى ومنخفضى الأداء الوظيفى.

r- استخدام برنامج التخخل المبكر البورتيج فى التشخيص الفارق بين حالات الضعف

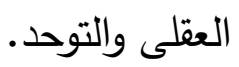
ع - قدرة البورتيج في التشخيص الفارق لحالات التوحد وصعوبات التعلم • 


\section{المراجع}

\section{أولاً: المراجع العربية}

إبراهيم، أكرم(r ( ץ). تتمية بعض مهارات الرعاية الوالدية لخفض أعراض الذاتوية لدي أبنائهن. رسالة دكتوراه. كلية البنات للآداب والعلوم التربوية، جامعة عين شمس. أبو يوسف، حسام(T + . ץ). الطفل التوحدي (خصائصه السلوكية والتربوية) اختبارات تقيس قدراته دمجه في المجتمع. القاهرة: إيتراك للنشر والتوزيع. أحمد، علي، عبد الظاهر، عبد الله(ب ب). التدخل المبكر واستراتيجيات الدمج. الرياض: دار الزهراء.

أديب، نادية(ب99 (19) الأطفال المتوحدون. ورشة عمل عن الأوتيزم. مركز سيتي، ديسمبر • آرونز ، مورين وجيتتس، تيسا(^ . . ץ). الأوتيزم المشكلة والحل العلاج الأمثل لمرض التوحد. ترجمة دار الفاروق. القاهرة: دار الفاروق للنشر والتوزيع.

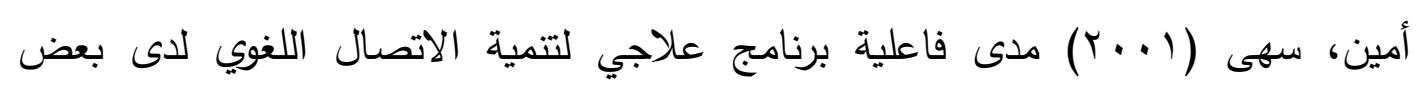
الأطفال الذاتويين. رسالة دكتوراه. معهد الدراسات العليا للطفولة، جامعة عين شمس. أمين، هدي(؟ . . ץ). الصورة الإكلينيكية لحالات الأوتيزم ذات المستوي الوظيفي المرتفع والمنخفض. رسالة دكتوراه. كلية الدراسات الإنسانية. جامعة الأزهر . البطاينة، أسامة، والجراح، عبد الناصر(V. . . Y). علم نفس الطفل غير العادي. عمان: دار المسيرة للنشر والتوزيع والطباعة.

بهادر ، سعدية(0 . ץ). نموذج بورتاج للتدخل المبكر . الكويت: دار البحوث العلمية. 


\section{كلية التربية للطفولة المبكرة- جامعة بني سويف}

الجارحي، سيد (ع . . ب). فاعلية برنامج تدربي في تتمية بعض مهارات السلوك التكيفي لاى الأطفال التوحديين وخفض سلوكياتهم المضطربة. رسالة ماجستير • كلية التربية النوعية، جامعة عين شمس.

خطاب، حمد (؟ . . (). فعالية برنامج علاجي باللعب لخفض درجة بعض الاضطرابات السلوكية لدى عينة من الذاتوين. رسالة دكتوراه. معهد الدراسات العليا للطفولة، جامعة عين شمس.

الرابطة الأمريكية للطب النفسي ( ( • ب): الدليل التشخيصي والإحصائي الرابع للاضطرابات النفسية تعديل النص الصورة العربية، الجزء الأول، (ترجمة: مدينة الشارقة للخدمات

$$
\text { الإنسانية)، أبو ظبى: الثارقة للخدمات الإنسانية. }
$$

رياض، سعد(1 . . r). الطفل التوحدي أسرار الطفل التوحدي وكيف نتعامل معد. القاهرة: دار النشر للجامعات.

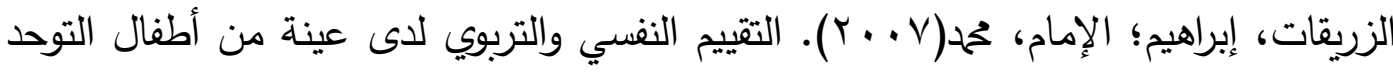
بالأردن المؤتمر السنوي الرابع عشر ، مركز الإرشاد النفسي، جامعة عين شمس. الزغبي، محمود(0 1 • r). برامج أنشطة حسية لتنمية مهارات التواصل لدي عينة من الأطفال الذاتوين. رسالة ماجستير • كلية رياض الأطفال. جامعة القاهرة. سبارو، سارا ،وبالا، ديفيد ،وشيكشتي، دومينيك . (2004 ) مقياس فاينلاند للسلوك التكيفى صورة معدلة ومنقحة لمقياس فاينلاند للنضتج الاجتماعي، تأليف إدجار دول ، تعريب وتقنين:بندر بن ناصر العتيبي، كلية التربية: جامعة الملك سعود . السعيد، هلا(9 . . r). الطفل الذاتوي بين المعلوم والمجهول. القاهرة: مكتبة الأنجلو. سليم، أحمد( ( . . r). التوحد واضطراب السلوك. عمان: دار المشرق الثقافي. 
سليمان، عبد الرحمن( . . †) محاولة فهم الذاتوية " إعاقة الذاتوية عند الأطفال"، القاهرة: مكتبة زهراء الثرق.

سليمان، عبدالرحمن(Y (Y). معجم مصطلحات اضطراب التوحد. القاهرة: الأنجلو المصريـة.

سليمان، عبد الرحمن(10 • ب). متلازمة إسبرجر الطيف الثاني من اضطرابات التوحد دليل المعلمين. القاهرة: عالم الكتب.

الثامي، وفاء(ع . . ץ). خفايا التوحد (أشكاله - أسبابه - تشخيصه). الرياض: الجمعية الفيصلية.

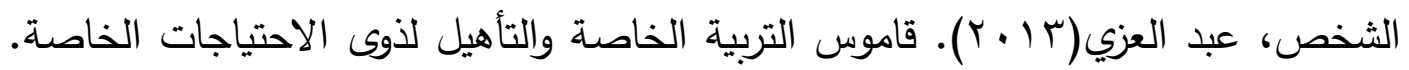
القاهرة: الأنجلو المصرية.

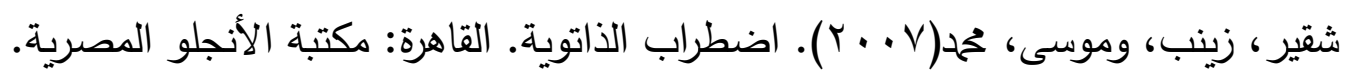
صالح، صفاء (T + . ץ). مدي فاعلية برنامج بورتاج في تتمية الجوانب الاجتماعية لطفل ما قبل المدرسة. رسالة ماجستير • معهة الدراسات العليا للطفولة، جامعة عين شمس. صقر ، مروة. (10 • ب). فعالية العلاج المعرفي السلوكي في تتمية مهارات الأمهات للتعامل مع الطفل التوحدي. رسالة دكتوراه. كلية الخدمة الاجتماعية، جامعة حلوان. عبد الله، عادل. (ع ( • ب). مدخل إلى اضطراب التوحد النظرية والتشخيص وأساليب الرعاية. القاهرة: الدار المصرية اللبنانية. عبد الله، ححم. (1 . . ץ). مقياس جيليام التقديري لتشخيص اضطراب التوحد. القاهرة: دار الرشاد. 


\section{كلية التربية للطفولة المبكرة- جامعة بني سويف}

عوده، حمد (0 1 • (1). مقياس جيليام لاضطراب إسبرجر • القاهرة: مكتبة الأنجلو المصرية. عوض، رأفت. (0 . . ب). فاعلية برنامج تدريبي سلوكي لتمية الانتباه لدى الأطفال التوحديين. رسالة دكتوراه. كلية التربية، جامعة عين شمس.

فراج، عثمان. (Y . . r). الإعاقات الذهنية في مرحلة الطفولة " تعريفها - تصنيفها أعراضها - تشخيصها - أسبابها - التتخل العلاجي ". القاهرة: المجلس العربي للطفولة و التنمية.

فرج، إبراهيم(؟ . . r). التوحد الخصائص والعلاج. عمان: دار وائل للنشر والتوزيع فؤاد، فيوليت ( • ( • ). مدخل إلى التربية الخاصـة. القاهرة: الأنجلو المصرية. الفوزان، حمد ( . . . ץ): التوحد / المفهوم - التعليم - التدريب، مرشد إلى الوالدين والمهنيين. الرياض: دار عالم الكتب للطباعة والنشر •

فيري جبر (T ( ب). إعادة تعريف الأمراض النفسية، (ترجمة) مصطفي شقيب، .www.arabpsyynet.com

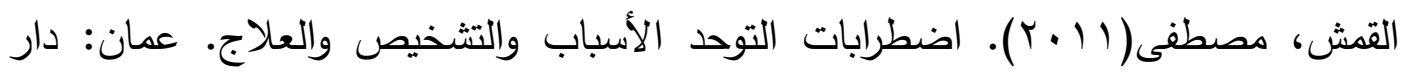
الميسرة للنشر

قنديل، شاكر (0 . . ب). إعاقة الذاتوية طبيعتها وخصائصها. جامعة المنصورة: المؤتمر

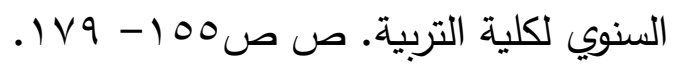

كامل، سهير (r I • r). اضطرابات الطفولة المبكرة (تأخر النمو والإعاقات). الرياض: خبراء التربية / مركز الطفولة

كامل، ححد(0 . . ب). التدخل المبكر ومواجهة اضطرابات التوحد. القاهرة: مكتبة ابن سينا. 
كفافي، علاء الدين؛ كفافي جهاد (T . . Y): موسوعة علم النفس التأهيلي المجلد الثاني الإعاقات. القاهرة: دار الفكر العربي.

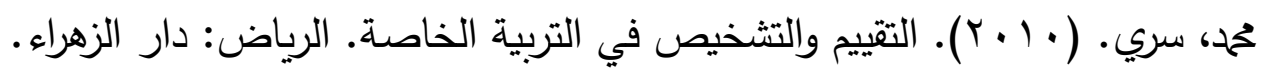
محح، عادل(T ( • ب). مقياس جيليام التثخيصى لتقدير اضطراب التوحد، كراسة التعليمات.

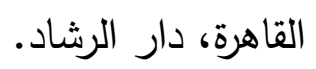

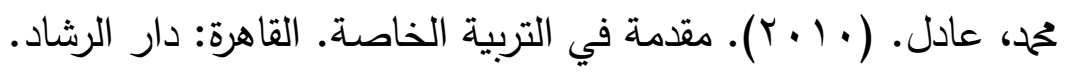
المشرفي، انشراح. (1).ب). الاكتثاف المبكر لإعاقات الطفولة. الإسكندرية: مؤسسة

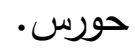

مصطفي، أسامة؛ الثربيني، السيد. (1) • ب): التوحد الأسباب -التشخيص -العلاج. عمان:

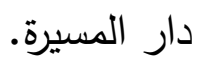

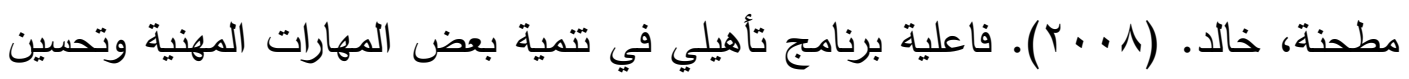

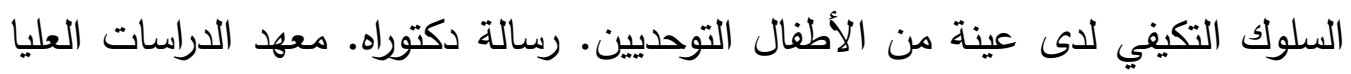
للطفولة، جامعة عين شمس لكس

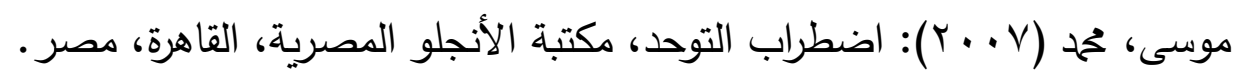

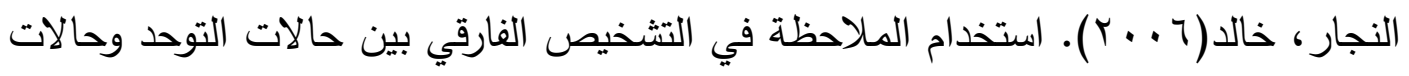

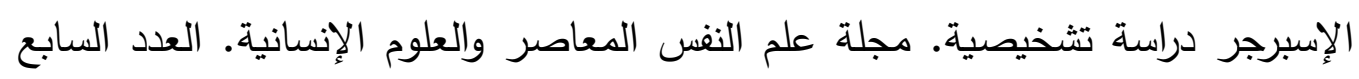

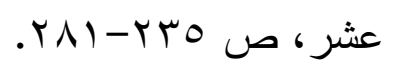

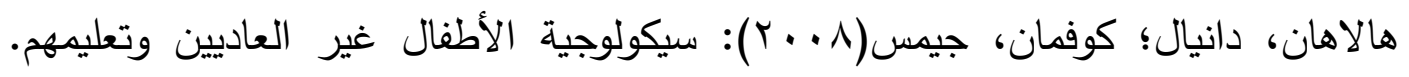
(ترجمة: عادل عبد الله محح)، عمان: دار الفكر للنشر والتوزيع. 
وزارة التربية والتعليم(V ...rأ). برنامج التنمية الثاملة للطفولة المبكرة (بورتاج) "التقرير الشامل". القاهرة: قطاع الكتب.

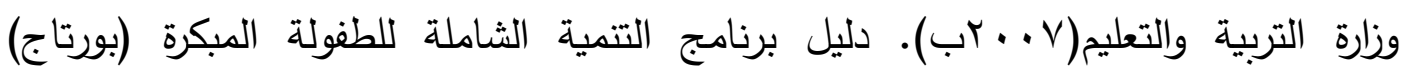
"إرشادات الاستخدام". القاهرة: قطاع الكتب.

\section{ثانيًا: المراجع الأجنبية}

Alison, E.L.Robyn, L.Y.Amy, E.Z.Baker, L.etal. (2010): Sensory Processing Subtypes in Autism: Association with Adaptive Behavior, J. of Autism Dev. Disorder. 40,112-122.

American psychiatric Association (2013).Diagnostic and Statistical manual of mental disorders (DSM-5).American Psychiatric PUB.

Attama, C. M. Uwakwe, R. Onyeama, G.M. \& Igwe, M.N. (2015).

Comparison of Using Psychological Profile of Portage among Childhood Autistic Subjects and those with Other Developmental Disorders in South East Nigeria: A Comparative Study. Annuals of Medical and Health Sciences Research. 5 (3).33-54.

Bhat, A. N. Galloway, J. C.\&, Landa R. J.(2010): Social and nonsocial visual attention patterns and associative learning in infants at risk for autism, Journal of Child Psychology and Psychiatry, 51( 9), 989-997.

Brooke, I.(2007): Teaching Imitation to Children with Autism: A Focus on Social Reciprocity, SLP- ABA, 2( 3), 269-277.

Carpenter, J. M.Charles L. A.Jenner, W\& Nicholas,J. S. (2008). Recent advances in autism spectrum disorders, International Journal of psychiatry in medicine, 38 (2), 133 - 140.

Carpenter, L.A.(2013).Screening and diagnosis of autism spectrum disorders(ASD). J S C Med Assoc.102 (8)3-23.Review. PubMed PMID: 17319241. 
Cheryl, Y.Trepagnier, M.M.Sebrechts, A.Finkelmeyer, L.etal. (2006):

Simulating Social Interaction to Address Deficits of Autistic Spectrum Disorder in Children, Cyber psychology \& Behavior, 9(2), 213-217.

Cindy, L. (2005): Autism and the Environment? Environmental Health Perspectives, 113(6), 405-416.

Connie,K.Amanda,C.Gulsrud,C.Wong,L.etal.,(2010): Randomized

Controlled Caregiver Mediated Joint Engagement Intervention for Toddlers with Autism, J.of Autism Dev. Disorder,40, 1045-1056.

Fulton, M.L. \&D'Entremont, B. (2013). Utility of the Psychoeducational Profile-3 for Assessing Cognitive and Language Skills of Children with Autism Spectrum Disorders. Journal of Autism and Developmental Disorders. 43. (10): P 2460-71. DOI 10. 1007/s10803-013-1794-y.

Heinricks, R. (2013).Perfect targets: Asperger syndrome and bullying practical solution for surviving the social world. Shawnee mission, Kansas: Autism Asperger publishing.

Helen,V. R.(2011): Theoretical aspects of autism: biomarkers a review, Journal of Immuno. Toxicology, 8(1), 68-94.

James B.A.Jane,R.V. M. Sadagopa, R., etal.,(2007): Mercury, Lead, and Zinc in Baby Teeth of Children with Autism Versus Controls, Journal of Toxicology and Environmental Health, Part A, 70, 1046-1051.

Katarzyna, C. \&Fred, V. (2007): Face recognition in ASD Impairments in monkey and human face recognition in2-year-old toddlers with Autism Spectrum Disorder and Developmental Delay, Developmental Science, 10(2), 266-279.

Klin, 1. (1993): concept formation: children with autism, down syndrome, and normal development d. a. i, 55(2), 44-61. 
Layton, T. \&Hao, G. (2014).Early Assessment in Autism Spectrum Disorders Using Portage. Journal of Psychological Abnormal Child, 3 (4), 33-46.

Lisa,D.W.Diana,L.R.Roger B.etal., (2009) Sensory Abnormalities as Distinguishing Symptoms of Autism Spectrum Disorders in Young Children, J.of Autism Dev. Disorder, 39,1087-1091.

Maarten, J.Van, d.S.Herman, V.E. \&Chantal, K. (2007) Can You See what is Not There? Low-level Auditory-visual Integration in Autism Spectrum Disorder, J.of Autism Dev.Disorder, 37, 20142019.

Mandy, W.Charman, T.Gilmour, J. \&Skuse, D. (2012). Toward Specifying Pervasive Developmental Disorder-Not Otherwise Specified. Autism Research; doi: 10. 1002/aur. 178. [E pub ahead of print] PMID: 21298812.

Shek, D.T. L.Tsang, S. K. M.Lam, L. L.Tang, F. L.Y.\& Cheung, P. M. P. (2005). Psychometric properties of the Chinese version of the psycho-educational profile-revised (CPEP-R). Journal of Autism and Developmental Disorders, 35(1), 37-44.

Stephen, G.V. \&Dominick, M.M. (2009): BrainAnatomy, Electrophysiology and Visual Function/Perception in Children within the Autism Spectrum Disorder, Optima. Vis. Dev., 40(3), 157-163.

Susan, R. (2013): Describing the Sensory Abnormalities of Children and Adults with Autism, J.of Autism Dev.Disorder,37, 894-910.

Valkanova,V.Rhodes,F.Allan,C.L.etal.,(2013):Diagnosis and management of autism in Adults, The Practitioner,257( 1761),1316

Villa, S.Micheli, E.Villa, L.Pastore, V. Crippa, A. \&Molteni, M. (2010). Further Empirical Data on the Psych educational Profile- 
Revised (PEP-R): Reliability and Validation with the Vineland Adaptive Behavior Scales Journal of Autism and Developmental Disorders, 40, 334-341. DOI 10. 1007/s10803-009-0877-2.

Waligórska, A. Pisula, E.Waligórski, M. \&Letachowicz, M. (2012). Autism Pro system in supporting treatment of children with autism in Poland. Pediatrics International. 54(5), 693-700. 


\section{Use of the Potage Developmental Profile in the} Differential Diagnosis for some Developmental Disorders

\section{Prepare: \\ Eman Ahmed Khamis}

Assistant Professor of Child Psychology

Faculty of Education for Early Childhood - Menoufia University 